Florida International University

FIU Digital Commons

FIU Electronic Theses and Dissertations

University Graduate School

$12-6-2012$

\title{
A Comparison of the Effects of Classroom and Multi-User Virtual Environments on the Perceived Speaking Anxiety of Adult Post-Secondary English Language Learners
}

Abdulaziz Abal

Florida International University, aabal@fiu.edu

DOI: $10.25148 /$ etd.FI13040102

Follow this and additional works at: https://digitalcommons.fiu.edu/etd

\section{Recommended Citation}

Abal, Abdulaziz, "A Comparison of the Effects of Classroom and Multi-User Virtual Environments on the Perceived Speaking Anxiety of Adult Post-Secondary English Language Learners" (2012). FIU Electronic Theses and Dissertations. 806.

https://digitalcommons.fiu.edu/etd/806 


\title{
FLORIDA INTERNATIONAL UNIVERSITY \\ Miami, Florida
}

\section{A COMPARISON OF THE EFFECTS OF CLASSROOM AND MULTI-USER VIRTUAL ENVIRONMENTS ON THE PERCEIVED SPEAKING ANXIETY OF ADULT POST-SECONDARY ENGLISH LANGUAGE LEARNERS}

\author{
A dissertation submitted in partial fulfillment of the \\ requirements for the degree of \\ DOCTOR OF EDUCATION \\ in \\ CURRICULUM AND INSTRUCTION
}

by

Abdulaziz Abal

2013 
To: Dean Delia C. Garcia

College of Education

This dissertation, written by Abdulaziz Abal, and entitled, A Comparison of the Effects of Classroom and Multi-User Virtual Environments on the Perceived Speaking Anxiety of Adult Post-Secondary English Language Learners, having been approved in respect to style and intellectual content, is referred to you for judgment.

We have read this dissertation and recommend that it be approved.

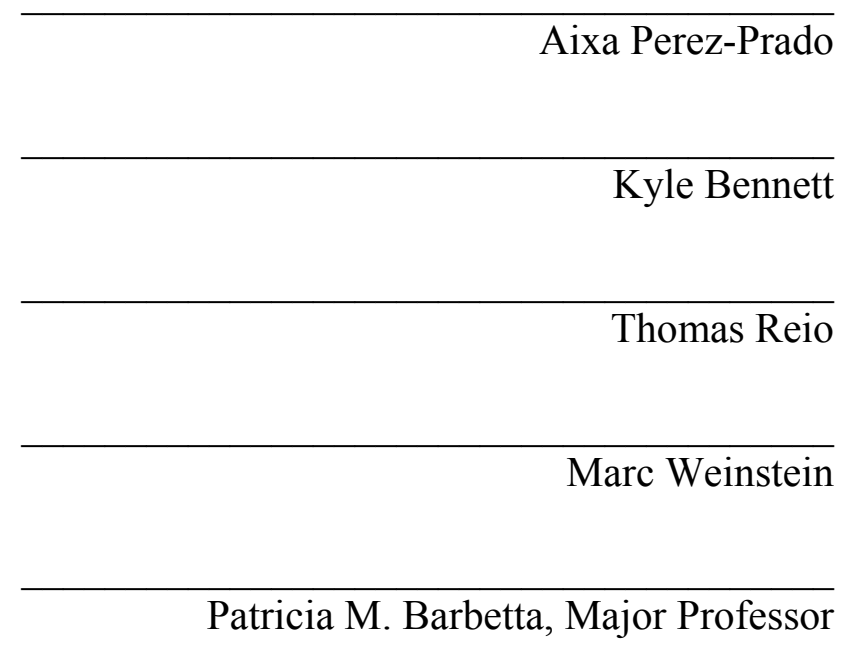

Date of Defense: December 6, 2012

The dissertation of Abdulaziz Abal is approved.

Dean Delia C. Garcia

College of Education

Dean Lakshmi N. Reddi

University Graduate School

Florida International University, 2013 
(C) Copyright 2013 by Abdulaziz Abal

All rights reserved. 


\section{DEDICATION}

To Faris, Yara, Lamya, and my parents. You gave me unconditional love, ambition, strength and inspiration to follow my dream and make it a reality. 


\section{ACKNOWLEDGMENTS}

I would like to thank my committee members, led by Dr. Barbetta, for their constant support and for providing an extraordinary academic model. Thank you for always being available and for providing the finest advice. I would also like to thank the faculty members, staff, and administration at the College of Education for their support and effort throughout my Ph.D. Also, I want to express many thanks to Mr. Luis Sanchez, from the English Language Institute at Florida International University, for his facilitating this research study by cooperating fully and providing the participants. Mostly, I would like to thank my family for their unconditional love and support during my academic journey. This experience has intensely improved my academic disposition, and equipped me with exceptional knowledge to pursue my goals. 


\begin{abstract}
OF THE DISSERTATION
A COMPARISON OF THE EFFECTS OF CLASSROOM AND MULTI-USER VIRTUAL ENVIRONMENTS ON THE PERCEIVED SOEAKING ANXIETY OF

ADULT POST-SECONDARY ENGLISH LANGUAGE LEARNERS

by
\end{abstract}

Abdulaziz Abal

Florida International University, 2012

Miami, Florida

Professor Patricia M. Barbetta, Major Professor

The population of English Language Learners (ELLs) globally has been increasing substantially every year. In the United States alone, adult ELLs are the fastest growing portion of learners in adult education programs (Yang, 2005). There is a significant need to improve the teaching of English to ELLs in the United States and other English-speaking dominant countries. However, for many ELLs, speaking, especially to Native English Speakers (NESs), causes considerable language anxiety, which in turn plays a vital role in hindering their language development and academic progress (Pichette, 2009; Woodrow, 2006).

Task-based Language Teaching (TBLT), such as simulation activities, has long been viewed as an effective approach for second-language development. The current advances in technology and rapid emergence of Multi-User Virtual Environments (MUVEs) have provided an opportunity for educators to consider conducting simulations online for ELLs to practice speaking English to NESs. Yet to date, empirical research on 
the effects of MUVEs on ELLs' language development and speaking is limited (GarciaRuiz, Edwards, \& Aquino-Santos, 2007).

This study used a true experimental treatment control group repeated measures design to compare the perceived speaking anxiety levels (as measured by an anxiety scale administered per simulation activity) of 11 ELLs ( 5 in the control group, 6 in the experimental group) when speaking to Native English Speakers (NESs) during 10 simulation activities. Simulations in the control group were done face-to-face, while those in the experimental group were done in the MUVE of Second Life.

The results of the repeated measures ANOVA revealed after the Huynh-Feldt epsilon correction, demonstrated for both groups a significant decrease in anxiety levels over time from the first simulation to the tenth and final simulation. When comparing the two groups, the results revealed a statistically significant difference, with the experimental group demonstrating a greater anxiety reduction. These results suggests that language instructors should consider including face-to-face and MUVE simulations with ELLs paired with NESs as part of their language instruction. Future investigations should investigate the use of other multi-user virtual environments and/or measure other dimensions of the ELL/NES interactions. 


\section{TABLE OF CONTENTS}

CHAPTER

PAGE

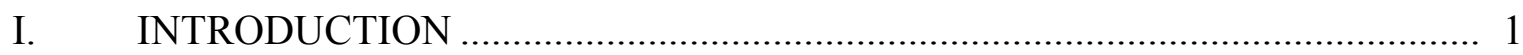

Language Teaching Approches: CLT and TBLT ...................................... 3

Computer-Assisted Language Learning ......................................................... 6

Theoretical Perspective ................................................................................... 12

Purpose of the Study .................................................................................... 14

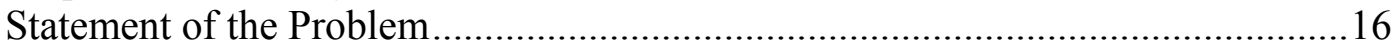

Research Questions ................................................................................. 17

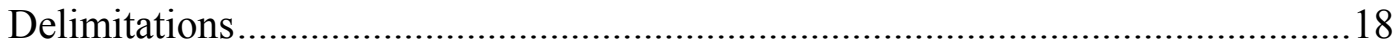

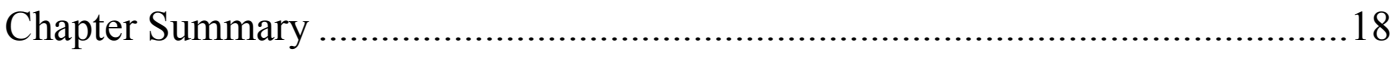

II. LITERATURE REVIEW .................................................................... 21

English Language Learners from Childhood to Adulthood................................24

Anxiety: Speaking and Language Development..............................................26

Approaches: Anxiety and Language development ........................................28

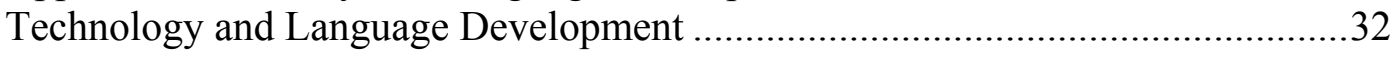

Virtual Environments and Language Development......................................... 37

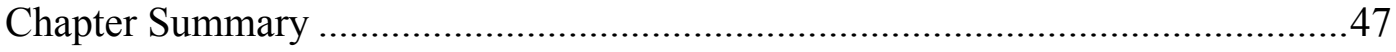

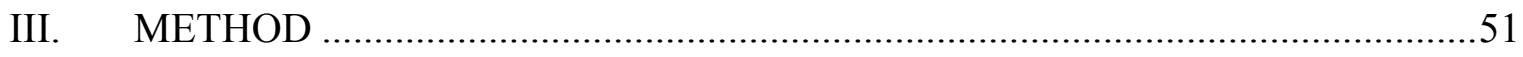

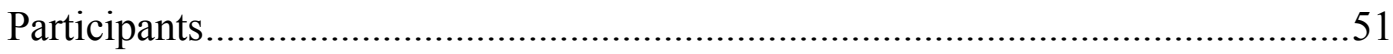

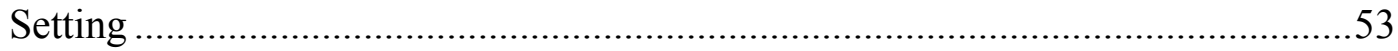

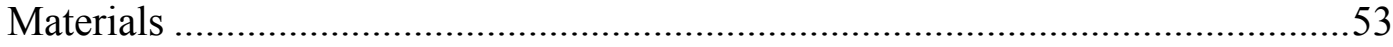

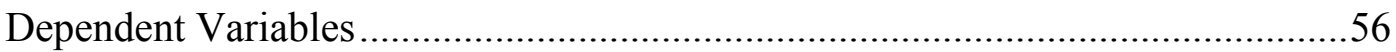

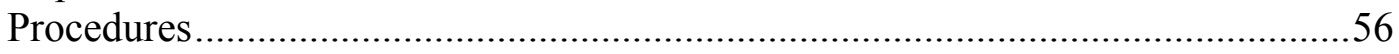

Research Design, Instrumentation, and Data Analysis ..................................63

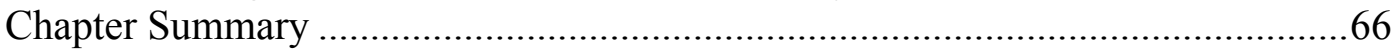

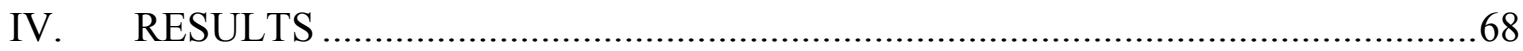

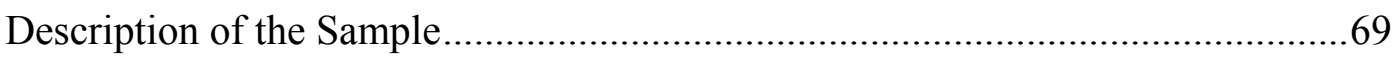

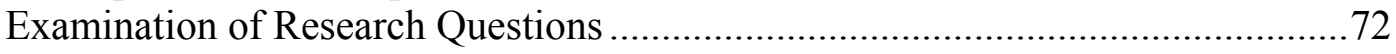

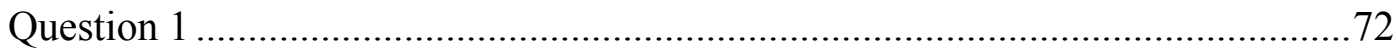

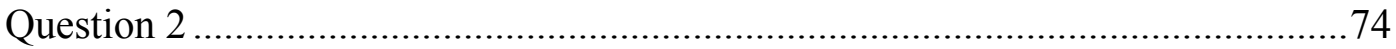

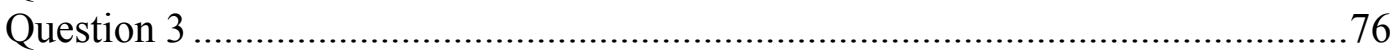

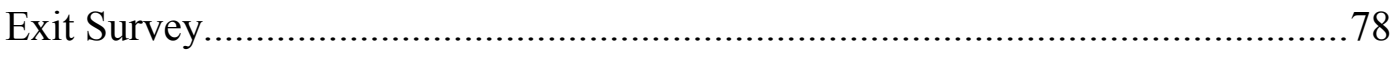

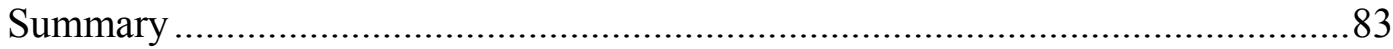




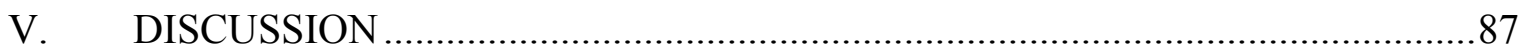

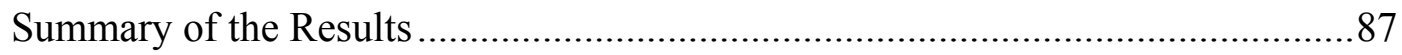

Discussion of Findings from Theoretical Perspectives..........................................93

Implications for Practice ............................................................................ 94

Limitations of the Study.........................................................................95

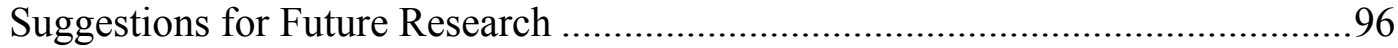

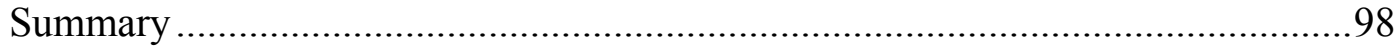

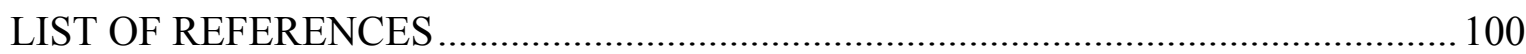

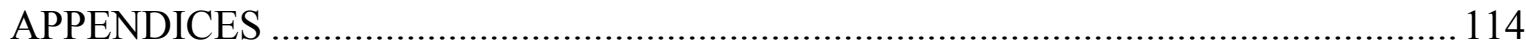

VITA 


\section{LIST OF TABLES}

TABLE

PAGE

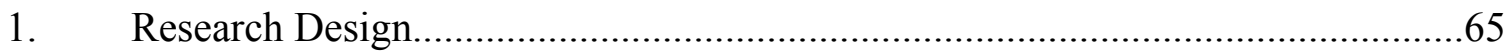

2. Frequency Table of Demographic Variables …...............................................

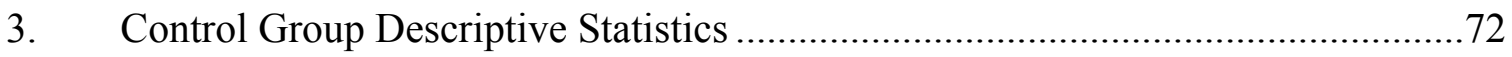

4. Experimental Group Descriptive Statistics .....................................................74

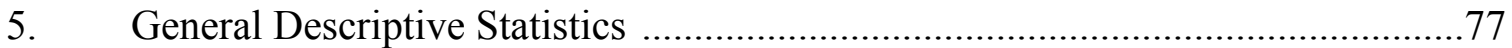

6. Mean and Range Results of Quantitative Component of Exit Survey...................80 


\section{ABBREVIATIONS AND ACRONYMS}

$\begin{array}{ll}\text { CALL } & \text { Computer-Assisted Language Learning } \\ \text { CLT } & \text { Communicative Language Teaching } \\ \text { CMC } & \text { Computer Mediated Communication } \\ \text { COE } & \text { College Of Education } \\ \text { CVI } & \text { Core Values Index } \\ \text { ELI } & \text { English Language Institute } \\ \text { ELL } & \text { English Language Learner } \\ \text { ELLSAS } & \text { English Language Learner Speaking Anxiety Scale } \\ \text { ESL } & \text { English as a Second Language } \\ \text { FF\# } & \text { Face-to-Face participant Number } \\ \text { FIU } & \text { Florida International University } \\ \text { MUVE } & \text { Multi-User Virtual Environment } \\ \text { NCLRC } & \text { National Capital Language Resource Center } \\ \text { NES } & \text { Native English Speaker } \\ \text { VE\# } & \text { Task-Based Language Teaching } \\ \text { TBtual Environment Participant Number }\end{array}$




\section{CHAPTER I \\ INTRODUCTION}

Today, English is a global language (Crystal, 2003). As such, learning to speak English for non-native English speakers is an important requirement for achieving social, cultural, and economic success in the United States and other English-speaking dominant countries (Chaney \& Burke, 1998; Wrigley et al., 2003) As the need to speak English well rises, so does the population of English Language Learners (ELLs). ELLs are learners whose first language is not English; the proficiency level of the students may vary from beginner to advanced (NEA, 2010). The U.S. Census Bureau (2007) reported that $44.1 \%$ of the US population who spoke a language other than English at home considered themselves to speak English less than very well. In 2008, in kindergarten through $12^{\text {th }}$ grade levels, as many as 5.3 million $10.7 \%$ of the 49.9 million student population were ELLs (Batalova, Jeanne, \& Margie McHugh, 2010). With respect to college-age learners in the United States, between 2007/08 and 2008/09, the number of international students enrolled in intensive English language courses increased over 10\% (IIE, 2009). According to Yang (2005), adult ELLs are the fastest growing portion of learners in adult education programs.

Learning a second language is not without its challenges. There are many factors that influence learning to speak a second language such as, but not limited to, motivation, age, English use outside the classroom, teaching strategies, and access to native speakers (Aoyama \& Guion, 2007; Beckman, 1986; Chesterfield \& Chesterfield, 1985; Genesee, Lindholm-Leary, Saunders, \& Christian, 2006; Munoz, 2006; Noels, Pelletier, Clement, \& Vallerand, 2003). 
Learning a second language also has been known to cause anxiety in language learners, which in turn can negatively affect the language learning process (Horwitz, 2001; Pichette, 2009; Woodrow, 2006; Young, 1991). Language anxiety is defined as the apprehension experienced when a situation requires the use of a second language with which the individual is not fully proficient (Gardner \& MacIntyre, 1993). Dulay and Burt (1977) and Krashen (1985) theorize that motivation, self-esteem, and anxiety are affective variables that play an important role in language learning. It has been suggested that language learners will experience more successful language learning if motivation and self-confidence are high and anxiety is low (Dulay \& Burt, 1977; Krashen, 1985). For ELLs, speaking English as a second or foreign language is one of the most anxiety generating activities (Horwitz, 2001; Pichette, 2009; Young, 1991), and this likely plays an important part in hindering their language development (Woodrow, 2006). Relatedly, Woodrow has argued that for ELLs, speaking to a Native English Speaker (NES) is a situation that frequently increases an ELL's anxiety level. The results of a phenomenological study with adult ELL international students conducted by Halic, Greenberg, and Paulus (2009) supported this view. Their findings showed a recurring theme of expressed higher anxiety feelings by adult ELLs when speaking with NESs. The participants also reported lower levels of anxiety and more confidence when speaking with other ELLs.

Numerous other research studies of foreign and second language classrooms have found a significant negative correlation between anxiety and language performance generally, and more specifically, with speaking (Aida, 1994; Cheng, 1999; Horwitz, 1986; Kim, 2009; Phillips, 1992; Woodrow, 2006). The research of these instigators 
further suggests that the higher the anxiety levels, the less language learning takes place. For example, Woodrow conducted a study in Austria with 275 adult advanced ELLs, where he explored the relationship between second-language anxiety and speaking performance. The participants' speaking anxiety was measured using the Second Language Speaking Anxiety Scale and through oral assessments. The findings reconfirmed prior research (e.g., Aida, 1994; Cheng, 1999; Horwitz, 1986; Kim, 2009; Phillips, 1992), indicating that there was a significant negative relationship between second language speaking anxiety and oral performance. Woodrow's findings indicated that second language anxiety levels were significant predictors of oral achievement.

Given the negative effect of anxiety on language instruction for ELLs, it is imperative that instructors provide effective second language instruction that limits anxiety levels. Two approaches that have shown to be effective with the language development of second language learners are Communicative Language Teaching (CLT; Ellis, 2003; Hellermann, 2007; Long, 1996), and Task-Based Language Teaching (TBLT; Brown, 2007; Ellis, 2003; Izadpanah, 2010).

\section{Language Teaching Approaches: CLT and TBLT}

As a reaction to the audiolingual method of teaching a language in the 1960s, CLT emerged in the 1970s. CLT was based on the theory that the purpose of language is communication (Celce-Murcia, 1991), and that language should be taught by means of communication. CLT has since been widely applied in language classes, and is argued by some to be the most influential approach in the history of second language instruction for its flexibility and adaptability to different areas of second language education (Spada, 2007). 
In recent years, TBLT has gained popularity as a refined method and strong version of CLT (Ellis, 2003). TBLT is defined as language teaching that is based entirely on tasks that are performed by students (Ellis, 2003). TBLT's functional approach to learning has led advocates to see it as a successor to CLT (Thomas \& Reinders, 2010). In TBLT, a "task" is defined as an activity carried out by means of the target language that results in a product with measurable results that indicate to the student whether he/she has adequately completed the assignment (Leaver \& Kaplan 2004). Willis (1996) defined task-based activities as those in which learners are given specific tasks to accomplish using the target language. For example, a specific task might be to order from a restaurant or book an airline ticket.

TBLT approaches provide opportunities for ELLs to practice speaking and for them to receive immediate input and feedback from their interaction partners (Ellis, 2003; Hellermann, 2007; Long, 1996), thereby encouraging them to make a conscious effort to communicate with clarity and understanding, and to be understood (Lantolf, 2000). With the TBLT approach, language fluency development occurs in the ELL's classroom with learning activities that focus on speaking and listening skills (Brown, 2007), thereby allowing the ELLs multiple opportunities to speak in their second language through authentic activities and meaningful tasks. The learning activities designed often involve a group of ELLs communicating together to accomplish a goal or complete a task.

Two commonly used TBLT approaches in teaching oral skills are role-playing and simulations. Role-playing involves assigning one or more members of a group a role and an objective that must be accomplished (Brown, 2007). Simulations are similar to role-playing; however, with simulations the learners assume their own identity, whereas 
with role-playing the learners represent a role known in everyday life different from their own typical roles. The use of simulations corresponds with TBLT and the need to use and utilize authentic and purposeful language in the classroom (Crookall, 2002; Higgins \& Johns, 1984; Jones, 1986). Educational simulations are regarded as important and powerful pedagogical and motivational tools for integrated courses (Hertel \& Millis, 2002). Simulations and role-play activities are generally used interchangeably, but for consistency purposes both activities henceforth will be referred to as simulations. Often, simulations and other language development activities for ELLs have been conducted in a classroom setting under the direct supervision of the language teacher.

More recently, there have become opportunities for simulation activities to be conducted by ELLs using computer technologies. In fact, the use of technologies to support language development has existed for many decades. For example, historically the phonograph was used for the teaching of intonation (Stocker, 1921), and the radio was considered a technological resource for remote classrooms around the world (Garfunkel, 1972). In the 1980s, technologies such as film, television, language labs, computers and interactive videos were also used in language instruction (Cunningham, 1998).

Today, the characteristics of TBLT can be further supported by the use of computers (Ehsani, \& Knodt 1998; Davis \& Thiede, 2000). Computers are one of the most widely used devices and can be harnessed for language learning (Garrett, 2009) and their use in education has been positively correlated with student performance (Furstenberg, 1997; Kelm 1998; Warschauer, 1997). Additionally, the numbers of students using computers is also on the rise (Lasagabaster \& Sierra, 2003). Further, with 
the expansion of technology, students are using computers at increasingly younger ages (Goldschmidt, MacDonald, \& O’Rourke, 2011), which may suggest an increased consideration of the use of computer technologies in the area of TBLT.

\section{Computer-Assisted Language Learning (CALL)}

CALL is used to describe an approach that uses computers for teaching English to second language learners (Chaka, 2009). Computers can be useful in second language development as they allow for the integration of sound, voice interaction, text, video, and animation in a self-paced interactive learning environments that could be used to enhance the classroom model of language learning significantly (Ehsani \& Knodt 1998; Davis \& Thiede, 2000). Lasagabaster and Sierra (2003) point out that numbers of students using CALL technologies are constantly increasing, and CALL has been reported to have positive correlations with students' performances (Furstenberg, 1997; Kelm 1998; Warschauer, 1997).

One rationale behind the increased use of technologies to facilitate the acquisition of language is that the use of technology may lead to more enjoyable learning activities and may facilitate the acquisition of language, especially when compared to memorization of words (Marriott \& Torres, 2008). Along with enjoyment, these computer-based language activities have the capability of actively connecting words they are using to real-world scenarios (Hertel \& Millis, 2002).

\section{Computer Mediated Communication (CMC)}

In recent years, more serious consideration has been given to the use of computers for language instruction using social software over the Internet. Social software is software that enables individuals to create and join online communities in which the users 
collaborate (Guth \& Petrucco, 2009), and it allows the user to interact with other users via computers, instead of interacting with a computer. Interaction using social software is referred to as Computer Mediated Communication (CMC), which is any communicative transaction that occurs through the use of two or more networked computers (McQuail, 2005). Types of CMCs include email, instant messaging, and chat rooms (Merchant, 2001). Websites such as myspace and facebook are used to socialize with friends. Youtube and flickr are used to express creativity. Blogs and wikis are used to share knowledge (Huffaker, 2005). Lastly, interaction through Internet based videoconferencing, allows two or more users to interact via two-way video and audio transmissions simultaneously (Plonczak, 2010).

Recently, the impact of various forms of social software on language and/or communication skills of ELLs has been examined (e.g., Black, 2005; Bloch, 2007; Fellner \& Apple, 2006; Guth \& Petrucco 2009; Kovacic, Bubas, \& Zlatovic, 2007; Mak \& Coniam, 2008; Molenda \& Pershing, 2008; Satar \& Ozdener, 2008; Sykes, Oskoz, \& Thorne, 2008). In a study by Satar and Ozdener, 90 ELL participants were examined on the effects of synchronous CMC on speaking proficiency and anxiety. The participants were divided into three groups, voice chat and text chat (experimental groups), and a control group. The experimental group engaged in 40-45 minute-long chat sessions in dyads for a period of 4 weeks with a total of eight tasks. Findings from the study suggest that the speaking proficiency of both experimental groups increased in comparison with the control group, providing that social software may support language development.

Another study investigated the effects of blogs on the English writing proficiency of an ELL population at a Japanese university. The study's participants, identified as low 
in English speaking proficiency and low in motivation, attended a 7-day (38-hour) intensive English program designed to aid them in passing a college English proficiency exam (Fellner \& Apple, 2006) The researchers used students' blogs to measure writing fluency. The findings confirmed that the use of blogs improved English writing proficiency by $350 \%$ compared from the beginning of the course.

Overall, research in CMC suggests that using social software for teaching English may aid in language development (Satar \& Ozdener, 2008). Bakar, Latif, and Ya'acob (2010) found that the use of social software such as blogs was perceived by the participants to have enhanced their reading and writing skills, improved their communication skills, and reduced their anxiety. According to Hsu, Wang and Comac (2008), the use of audioblogs may also enhance the students' language learning capabilities. The research emerging appears to indicate that social software may have a positive influence on learning the English language as a foreign language, and on the English language learners.

The impact of social software has not only affected language development, but also language pedagogy in general. Bonaiuti (as cited in Guth \& Petrucco, 2009) reasoned that the existence of social software can impact pedagogy in at least two ways. First, social software learning can be more informal than formal, and one can easily shift from content-based to collaborative learning, therefore allowing for a more relaxed setting in which to converse and possibly acquire the language more effectively. Second, Mejias (2006) noted that when social software tools are used together, students learn how to learn by managing software tools, working cooperatively, and developing online research skills, thus allowing the learner to engage in a cooperative relaxed environment. 


\section{Virtual Reality Environments and Learning}

With more recent advancements of software and Internet technologies, virtual environments have emerged and educators are using them in education (Dalgarno, 2002; Dickey, 2005; Schwienhorst, 2002; Zhang \& Zigurs, 2009). The term virtual reality refers to a class of computer-controlled, multisensory communication technologies that allow more intuitive interaction with data and involve human senses in new ways (McLellan, 2004). In Multi-User Virtual Environment (MUVE) sites, users can find digital, threedimensional graphical representation of physical environments in which they can move and interact with other users at the site (Jamison, 2008). Within a three-dimensional MUVE, avatars, which are three-dimensional characters on the screen, are used to represent the users and can be controlled by the user to walk, talk, fly and so forth. Even though the MUVE's avatars' mouths do not move, when the user engages, in speak or text chat, user's voices can be heard and text messages seen. Subsequently, users via their avatars can interact within the online environment with other users through movement, text chat, and voice chat in real time (Dickey, 2005; Henderson, Huang, Grant, \& Henderson, 2009). This means that users can interact synchronously with each other, making it a potentially useful learning environment (Henderson et al., 2009).

There are numerous reasons to consider using MUVEs in education (Clarke \& Dede, 2005; Jarmon, Traphagan, Marrath \& Trivedi, 2009; Kalyuga, 2007; Prensky, 2006). For example, recent research has suggested that virtual worlds/environments are correlated with positive motivation (Tuzun, Soylu, Turkan, Yavuz, \& Gonca, 2009), learner autonomy, and creativity (Henderson et al., 2009). Research in educational virtual reality reveals that $3 \mathrm{D}$ interactive environments provide support for constructivist-based 
learning activities by allowing learners to interact directly with information from a firstperson perspective (Bricken \& Byrne, 1993; Dede, 1995). More recently, Ranalli (2008) considered the use of the MUVE SIMS as a virtual learning tool to increase language use and comprehension. Ranalli reports that virtual environments that provide language simulations are rich in natural associations that facilitate cohesive meaningful use of language.

Outside of education, MUVEs have been used in varied ways from delivering exposure therapy to posttraumatic stress disorder among veterans (Rizzo, Parsons, Belinda et al., 2011) to training instructions that allow trainees to learn assembly operations (Brough et al., 2007). Similarly, in education, MUVEs have been used for a variety of disciplines such as pre-service teacher training (Bull, Bull, \& Kajder, 2004; Bronack, Riedl, \& Tashner, 2005; Schlager, Fusco, \& Schank, 2002), science-based activities (Kafai, 2006), biology instruction (Mikropoulos, Katsikis, Nikolou, \& Tsakalis, 2003), and engaging in scientific inquiry (Clarke, Dede, Ketelhut, \& Nelson, 2006).

With respect to foreign language learning specifically, there is an emerging body of literature discussing the potential benefits of MUVEs. For example, Von Der Emde, Schneider, and Kotter (2001) argued that virtual learning environments for English language instruction provide learners with the ability to contextualize language use as part of culture and social interaction. Research suggests that through interactive activities in virtual communities, ELLs can construct their identities while engaging in multiple learning practices (Black, 2005; Lam, 2000; Yi, 2008). Further, these benefits can be achieved in the convenience of the individual's Internet connected device without the 
need to physically travel anywhere. The end result for ELLs can be an individualized, authentic, and autonomous language learning experience (Von Der Emde et al., 2001). However, empirical research on the benefits or effects of MUVEs on ELLs' language development and speaking is limited (Garcia-Ruiz, Edwards, \& Aquino-Santos, 2007; Ranalli, 2008; Zheng, Young, Brewer, \& Wagner, 2009). Of the few studies available, it has been found that virtual environments have provided an enhanced learning environment (e.g., Barkand \& Kush, 2009; Peterson, 2006; Zheng et al., 2009). Overall, the results of these studies have demonstrated that virtual environments may be useful as a tool for language development, are effective for distance education, and are satisfactory for post-secondary ELLs. However, the research lacks an in-depth examination of the effects virtual environments may have on ELLs' oral proficiency and speaking anxiety.

For the present study, the MUVE used was Second Life. Second Life is software of a virtual world that is accessible via the Internet in which users (residents) create an identity and may perform social, educational, and financial activities. Communication through Second Life is available by means of text chat, instant messaging, and live voice chat. Second Life is not the only MUVE readily available, but it is considered to be the most established and recognized environment, and it has been researched and welcomed by educational institutes (Au, 2009; Rymaszewski, Au, Wallace, Winters, Ondrejka, \& Batstone-Cunningham, 2007). The opportunity for residents to meet together combined with the ability to build virtual property, means that an educational environment could be built for students to practice online virtual learning and for research on its effects. The versatility of Second Life could be why educational institutions have taken the initiative of building virtual campuses and offering a variety of courses in Second Life. Second 
Life has also been shown to be highly effective for distance education in a post-secondary environment (Barkand \& Kush, 2009). For example, Petrakou (2010) conducted an ethnographic study to explore how Second Life facilitates online education. The oral production data gathered from the participants found that synchronous communication through Second Life enhanced interactivity (Petrakou, 2010).

According to Henderson et al. (2009), Second Life can support competency-based training such as skill, vocabulary, and grammar. In addition, they found that it can also support synchronous interaction with teachers, students and others, including native speakers in rich creative ways. They conducted a study to measure the self-efficacy of students' capacity to use Chinese in a variety of authentic contexts in the MUVE of Second Life. The results of their study found significant improvements between the participants' pre- and post self-efficacy ratings, which in turn may have constructive associations with language development. Although the research is limited, MUVEs such as Second Life thus far have been associated with positive learning outcomes, which is why it was used in this study.

\section{Theoretical Perspective}

This study was grounded in Vygotsky's "Zone of Proximal Development" in which learning occurs through collaboration with more capable peers (Vygotsky, 1978). This social constructivist view stresses the importance of social interaction in the process of learning (Satar \& Ozdener, 2008). Learning among and/or between students and teachers is essential for students' development. The synchronous nature of MUVEs provides the ideal setting for collaborative learning (Pullen \& Nah, 1999), and provides a powerful "zone of proximal development" for organizing knowledge in multiple and 
flexible contexts (Spiro et al., 1991). Mainly due to its synchronous nature, MUVEs also allow interaction with multiple users without restricting time or distance. MUVEs are synchronous because users can interact with the online environment and other users through movement, text chat, and voice chat in real time (Dickey, 2005; Henderson et al., 2009).

This study is also based on the theoretical frameworks of the socio-affective filter (Dulay \& Burt, 1977), and the Affective Filter Hypothesis (Krashen, 1985). Socioaffective and affective filters are defined as different levels of affective variables such as motivation, self-confidence, and anxiety that may facilitate or hinder second language acquisition (Krashen, 1985). Krashen asserts that high motivation and self-confidence, and low anxiety lower the affective filter producing a better-equipped language learner. Whereas low motivation and self-confidence, and high anxiety levels raise the affective filter causing a mental block for language learners and obstructing the language acquisition process. It has been suggested that virtual environments represent a more relaxed and stress-free atmosphere than a traditional classroom environment which could subsequently reduce anxiety, and be advantageous for second language learners (Roed, 2003; Zheng et al., 2009; Henderson, et al., 2009). In this study, the affective filter hypothesis was tested by means of collecting questionnaire data after each simulation activity throughout the study.

Another theoretical perspective guiding this study was the Interaction Theory Hypothesis (Long, 1985). This hypothesis theorizes that interaction and communication between ELLs and native speakers of the target language assist the ELLs in their 
language development. The present study therefore is designed to give the opportunity for ELLs and NESs to communicate in both face-to-face and MUVE settings.

\section{Purpose of the Study}

Adult ELLs are the fastest growing portion of learners in adult education programs (Yang, 2005) with the population of legal and illegal immigrants in the United States reaching a record of 38.5 million in 2009 . Over $50 \%$ of the immigrant population was foreign-born with Limited English proficiency (U.S. Census Bureau, 2009).

Adults with limited English proficiency face poor labor market prospects (Wrigley et al., 2003) hence they would benefit greatly from language development. It has been reported that adults with limited English proficiency face a $46 \%$ wage difference between English speaking immigrants and non-English speaking immigrants regardless of education and work experience (Wrigley, Chen, White, \& Soroui, 2009). Wrigley et al. (2003) stated that the need for language job training is greater than the current resources available, hence placing greater challenges on the limited English proficient speaker.

A portion of the adult ELL population in the United States consists of international students who come to the United States to pursue postsecondary education. In 2008, the number of international students enrolled in intensive English programs in the United States reached more than 57,500 (IIE, 2009). Many of these students come to the United States and need to reach a level of English proficiency that would allow them to enter the nation's universities, colleges, and community colleges. Chaney and Burke (1998) state that in order to obtain social, cultural, or economic success, a certain level of fluency in speaking English is required. 
The National Capital Language Resource Center (NCLRC) reports that language learners widely regard speaking as the most important language skill they can acquire (NCLRC; 2004). However, many language learners' progress is often inhibited due in part to speaking anxiety (Horwitz, Horwitz, \& Cope, 1986). Research has shown that anxiety affects language performance and development, especially speaking skills (Aida, 1994; Cheng, 1999; Horwitz, 2001; Phillips, 1992; Pichette, 2009; Young, 1991). In addition, it has been demonstrated that speaking anxiety is increased when ELLs speak to NESs (Woodrow, 2006; Halic, Greenberg, \& Paulus, 2009).

One of the most prominent approaches to teaching speaking a foreign language is TBLT in which students are taught another language through communication activities using tasks such as simulations. Simulations has been found to improve overall ELL speaking skills (Eliss, 2005; Hellermann, 2007; Long, 1996), reduce language anxiety for the language student (Izadpanah, 2010), and provide opportunities for ELLs to practice speaking with immediate feedback from their interaction partner (Ellis, 2003).

In this study, simulations involving adult, post-secondary ELLs and NESs were conducted both in the more traditional face-to-face environments and in a MUVE using Second Life. Simulations were conducted in the MUVE Second Life given the current advances in technology and rapid emergence of virtual worlds which are providing a great opportunity for educators to consider using these environments for collaborative student learning (Jamaludin, Chee, \& Ho, 2009). ELLs' anxiety when interacting with NESs was measured because anxiety is considered to be a variable that may significantly affect language performance (Dulay \& Burt, 1977; Krashen, 1985), and research has demonstrated that ELLs often have high levels of anxiety when interacting with NESs 
(Woodrow, 2006). Further, the literature indicates that the interactive nature of virtual environments provided by MUVE simulation activities may provide a more (or equally) comfortable space for ELLs to practice foreign language speaking (Bradley \& Lomicka, 2000; Roed, 2003). Thus, combining the positive advantages of both using MUVEs and simulations for speaking development provided solid grounds on which this study was conducted.

In sum, there is an increasing population of ELLs around the world, and there is a need to investigate additional methods to keep up with the growing demand to learn English. This study proposed to facilitate English language learning by means of reducing adult ELLs' speaking anxiety. This was investigated through having ELLs participate in oral simulations in a face-to-face classroom environment and in a MUVE (through the use of Second Life). Perceived anxiety was measured and then compared at across the two environments.

\section{Statement of the Problem}

The study investigated the effects of face-to-face and MUVE classroom environment on the perceived speaking anxiety levels of adult post-secondary English language learners when interacting with NESs. Perceived speaking anxiety was measured using a self-report questionnaire of a 10-point Likert scale, and further assessed in an exit interview.

This study extends the work of Satar and Ozdener (2008) in which the effects of synchronous $\mathrm{CMC}$ on speaking proficiency and anxiety were tested. The differences between this study and the Satar and Ozdener study are fourfold. First, in this study the CMC MUVE of Second Life was used, instead of a website specifically created for the 
study. Second, this study only used voice as a means of interaction during the simulation activities, whereas in Satar and Ozdener study both text and voice were used. Third, this study paired Native English Speakers with the ELL participants in the simulation activities unlike Satar and Ozdener in which ELLs were paired. Forth, in Satar and Ozdener, language anxiety was measured using the Foreign Language Learning Anxiety Scale developed by Horwitz et al. (1991), whereas in this study, speaking anxiety was measured using an 8-question English Language Learner Speaking Anxiety Scale (ELLSAS) adapted by the researcher from Horwitz's (1986) Foreign Language Classroom Anxiety Scale and from Woodrow's Second Language Speaking Anxiety Scale.

This study contributes to the existing research on the use of MUVEs with ELLs in several ways. First, it targeted post-secondary adult ELL students' speaking skill in virtual worlds, which could add to the insufficient research in this area (Garcia-Ruiz, Edwards, \& Aquino-Santos, 2007; Zheng et al., 2009). Second, this study addressed the issue of speaking anxiety as a result of face-to-face interactions in simulations in comparison to simulations in a MUVE. The anonymous relationship offered by the use of avatars and speaking has been investigated in the literature. However, no other studies were found that measured speaking anxiety in the MUVE of Second Life using simulations with native English speakers.

\section{Research Questions}

This research compared the effects of virtual environments on adult ELLs' speaking anxiety when performing simulation activities with native English speakers. More specifically the research questions were as follows: 
1. Is there a decrease in perceived speaking anxiety of post-secondary adult English language learners when speaking to native English speakers through simulation activities face-to-face in a classroom environment?

2. Is there a decrease in perceived speaking anxiety of post-secondary adult English language learners when speaking to native English speakers through simulation activities in a multi-user virtual environment?

3. Are there differences in decreases in the perceived speaking anxiety of postsecondary adult English language learners when speaking to native English speakers for those who experienced simulation activities in virtual environments and for those who experienced simulations face-to-face in a classroom environment?

\section{Delimitations}

This study had certain built-in exclusions. The participants in this study were limited to adults 18 years of age or above with basic skills in technology, for example operating computers and computer games. Furthermore, all participants were English language learners at least at an intermediate English level studying in a well-established language institution. Also, only the Second Life MUVE environment was used even though others exist.

\section{Chapter Summary}

The population of English Language Learners (ELLs) around the world has been increasing substantially every year. In the United States alone, Adult ELLs are the fastest growing portion of learners in adult education programs (Yang, 2005). This emphasizes the significant need to teach English to ELLs in the United States (U.S. Census Bureau, 
2007). ELLs' proficiency in English requires fluency in four language skills: reading, listening, writing, and speaking (CCSSO, 1992). Van Duzer (1997) emphasized that the success of any exchange is impacted by the speaker's skills and speech habits. Nunan (1999) states that being able to function in another language is generally described as being able to speak that language.

Numerous studies have found that for ELLs, speaking is the most anxietygenerating activity (Young, 1991; Horwitz, 2001; Pichette, 2009) and that anxiety can have a debilitating effect on the process of language learning (Woodrow, 2006). Other studies of foreign and second language classrooms have found a significant negative correlation between anxiety and language performance in general and specifically with speaking (Aida, 1994; Cheng, 1999; Horwitz, 1986; Kim, 2009; Phillips, 1992; Woodrow, 2006).

Task-Based Language Teaching (TBLT) had been shown to be an effective language learning method for oral skills (Brown, 2007; Ellis, 2003; Izadpanah, 2010), and has shown to reduce anxiety amongst ELLs (Izadpanah, 2010). TBLT is a modified CLT approach that concentrates on giving ELLs specific tasks to accomplish using the target language (Willis, 1996). A commonly used TBLT approach for teaching oral skills is simulations, in which students are assigned roles and asked to perform and complete certain tasks. The use of simulations corresponds with TBLT and the need to use and utilize purposeful language in the classroom (Crookall, 2002; Higgins \& Johns, 1984; Jones, 1986). Simulations have traditionally been conducted in a classroom setting, however more recently there have been opportunities for simulation activities to be conducted using computer technologies and CMC. 
Synchronous CMCs have also been shown to reduce speaking anxiety (Satar \& Ozdener, 2008). Multi-user virtual environments, such as Second Life, are considered to be a synchronous $\mathrm{CMC}$ tool, and have provided an enhanced learning environment (Barkand \& Kush, 2009; Peterson, 2006; Zheng et al., 2009). However, in the area of language development and speaking, research on the use of MUVEs is insufficient (Garcia-Ruiz, Edwards, \& Aquino-Santos, 2007; Zheng et al., 2009). Even though the relationship between anonymity offered by the use of avatars and speaking has been investigated in the literature, no studies were found in a review of the literature that measure speaking anxiety in the MUVE of Second Life using simulations with native English speakers. This study investigated the effects of face-to-face simulation activities held in a classroom and those conducted using Second Life, a MUVE, on adult ELLs' speaking anxiety when performing simulation activities with native English speakers in Second Life. Differences in the effects were compared. 


\section{CHAPTER II}

\section{LITERATURE REVIEW}

This chapter provides a literature review for the existing research. First, a general introduction to ELLs and the relevance of their speaking skills and language development will be discussed. Second, this chapter provides a discussion of anxiety and the effects it has on speaking a foreign language and language development. Third, a discussion of the approaches used for second-language development and reducing speaking anxiety will be presented. This is followed by a discussion of the use of technology (e.g. computers, social software, and virtual environments) in language development in relation to anxiety will be discussed.

\section{English Language Learners (ELLs)}

Generally speaking, an ELL is a learner whose first language is not English, and includes both learners who are just beginning to learn English and those who already have various levels of proficiency (NEA, 2010). ELLs in the United States differ in ethnicity, culture, language, and educational background (Bailey \& Santos, 2009). In 2007, the population of 5 year olds and older who spoke a language other than English at home reached 55.4 million, of which 34.5 million spoke Spanish or Spanish Creole and almost 2 million spoke French (U.S. Census Bureau, 2007).

In the United States alone, adult ELLs are the fastest growing portion of learners in adult education programs (Yang, 2005). The Office of Vocational and Adult Education at the U.S. Department of Education (2006) reported that between 2003-2004 (1.2 million) $45 \%$ of adults enrolled in state-administered adult programs attended English as a Second Language (ESL) classes. From 1980 to 2007 in the United States, there was a 
$140 \%$ in the number of people who spoke a language other than English at home. This staggering number reflects not only the growing number of potential English learners but emphasizes the significant need to teach English to ELLs in the United States (U.S .Census Bureau, 2007).

In order for adult ELLs in the United States and other English-speaking dominant countries to obtain social, cultural, and economic success, a certain level of fluency in speaking English is required of them (Chaney \& Burke, 1998; Wrigley et al., 2003) otherwise they face poor labor market prospects. Unfortunately, the need for language job training is greater than the current resources available (Wrigley et al., 2003), hence placing additional challenges on the limited English proficient speakers.

From an educational prospective, adult ELLs need a certain level of academic proficiency. For example, a minimal level of proficiency in English is required for international students (whose native language is not English) to apply to colleges and universities in the United States. A common examination accepted as proof of English proficiency from international students is the Test of English as a Foreign Language (TOEFL). The TOEFL evaluates the potential success of an individual to use and understand standard American English at a college level. This four-hour test consists of four sections, each measuring one of the basic language skills (i.e., reading, listening, speaking and writing) used in an academic, higher-education environments. To successfully pass the TOELF, ELLs need to have English language skills far beyond basic conversational language.

For ELLs to improve their English, they sometimes attend schools or language institutes if it is affordable to them, while others learn at home, self teach or practice the 
language with family members or friends (Panferov, 2010). In 2008, more than 57,600 international students enrolled in intensive English programs in the United States, reflecting a six percent increase over the previous year (Institute of International Education [IIE], 2009). These ELLs entered university-intensive English programs to pass English language proficiency levels required to function in an academic setting. In addition, the ELL population also consists of refugees and immigrants (Bailey \& Santos, 2009; Blumenthal \& Machado, 2006). These diverse ELLs speak several different languages, as well as differ in ethnicity, culture, and educational background.

In order for ELLs to become proficient in English, they need to be fluent in four language skills: reading, listening, writing, and speaking (CCSSO, 1992). Generally in learning a language, listening and speaking precede reading and writing (Burninger, 2000). Van Duzer (1997) emphasized that the success of any exchange is impacted by the speaker's skills and speech habits. As such, speaking, "the process of building and sharing meaning through the use of verbal and non-verbal symbols, in a variety of contexts" (Chaney, 1998, p. 13), should be an important part of each adult ELL's curriculum. Nunan (1999) stated that being able to function in another language is generally described as being able to speak that language, and ELLs themselves view speaking as the most important language skill they can acquire when learning a language (NCLRC, 2004). Unfortunately, even though speaking is key to communication (Florez, 1999), some instructors underestimate the importance of speaking in second-language pedagogy and have not given it attention beyond repetition and memorization of dialogues (Kati, 2006). Additionally, for many years oral language has not been given its importance in curriculum. Loban (1976) places the blame on the difficulty to assess oral 
language, therefore, for the reason for its exclusion from high-stakes testing system in the United States.

\section{ELLs and Learning English from Childhood through Adulthood}

Learning English may pose a challenge to ELLs of all age groups. Even though age is considered to be a major factor that determines success in learning a second or foreign language, Marinova-Todd, Marshall, and Snow (2000) stated that "age differences reflect differences in the situation of learning rather than the capacity to learn" (p. 9).

Language learners encounter a number of obstacles when it comes to secondlanguage development (MacIntyre, 2007). For ELLs in school, Allen and Franklin (2002) note that many do not have the basic skills needed to interact in the classroom, resulting in schools placing these students in lower-track learning environments. This can occur despite the fact that these students are able to engage with the academic material presented. Over time, this situation is one that can give rise to student disengagement in the classroom. Allen and Franklin further note that among all student groups, ELLs have one of the highest dropout rates. Lack of engagement in the classroom can make it difficult for ELLs to acquire the foundational tools needed for lifelong learning. Allen and Franklin also assert that these outcomes can impact the student across the lifespan and have negative implications for the education of the student in adulthood.

MacIntyre (2007) noted that learners from various experience levels face challenges in their efforts to gain English language competency. According to MacIntyre, these ELLs generally face obstacles in a number of different areas including: motivation, time constraints, and willingness to communicate. Motivation, as reported by MacIntyre 
requires the learner to develop an internal desire to learn the English language and engage with others. Time constraints exist in the classroom, as educators must balance English language learning with content and subject material (MacIntyre, 2007). Willingness to utilize the English language can be impacted by the student's motivation and the anxiety that exists with regard to language use (MacIntyre, 2007). MacIntyre argues that anxiety experienced by the language learner not only impedes the willingness to utilize the language but also may have direct implications for the cognitive processing of the student, limiting the ability of the learner to effectively utilize English and further develop language competence.

According to Allen and Franklin (2002), ELL students are often reluctant to engage in learning environments due to fear or anxiety that English speaking peers and educators will mock them because of their overall English language competence. They note that the unwillingness of ELLs to speak in the classroom can make it more difficult for these learners to engage in the experiential learning activities needed to improve language use and competence. Thus, anxiety can have significant implications for the ability of educators to improve ELL language skills and for the ELL to engage in the classroom. Allen and Franklin contend that this lack of engagement may also disenfranchise the ELL learner from the classroom and create ongoing challenges for education across the lifespan. According to Campbell and Ortiz (1991), adult university ELLs have alarming levels of language anxiety, and is estimated that debilitating levels of language anxiety are experienced by $50 \%$ of the language learners. 


\section{Anxiety: Speaking and Language Development}

Izard (1972) identifies three general classifications of anxiety: trait anxiety, state anxiety, and situation-specific anxiety. From a second language learning perspective, MacIntyre and Gardner (1991a) further explain Izard's three classifications in which they view trait anxiety as a long-term personality trait, state anxiety as an emotional state experienced at the moment, and situation specific anxiety as a reoccurring situation-based anxiety which means the level of anxiety is increased depending on the situation in which the speaker finds him or herself.

An ELL is likely to experience situation specific anxiety when speaking English when participating verbally in class, speaking in public, or taking tests (Williams \& Burden 1997). Speaking to an NES is a situation that commonly increases an ELL's anxiety level (Woodrow, 2006). Halic, Greenberg, and Paulus (2009) conducted a phenomenological study with adult non-native English-speaking international students at a southeastern research university. Eight participants were interviewed in the context of their graduate studies where they were asked about their experiences regarding the English language. The data collected were explored through interpretive analysis, and the findings showed a recurring theme of expressed higher anxiety feelings by the participants when speaking with NESs.

Woodrow (2006) conducted a study in Austria where he explored the relationship between second language anxiety and speaking performance. The participants were 275 adult advanced English language students studying Intensive English for academic purposes prior to entering a university in Australia. Their speaking anxiety was measured using the Second Language Speaking Anxiety Scale and through oral assessments. The 
findings reconfirmed research conducted by others (Aida, 1994; Cheng, 1999; Horwitz, 1986; Kim, 2009; Phillips, 1992), indicating that there was a significant negative relationship between second language speaking anxiety and oral performance. In Woodrow, correlations were computed using the Pearson correlation coefficient to assess the relationship between speaking anxiety and oral performance. The analysis indicated that second language anxiety levels were substantial predictors of oral achievement. Additionally, interviews with subjects revealed that face-to-face communication with native speakers produced the most anxiety. Anxiety resulted in two specific problems for the subjects including: retrieval interference and skill deficits (Woodrow, 2006).

More recently, Kim (2009) conducted a study with 57 Korean college students learning English to examine whether language anxiety and motivation remained stable across two courses, a reading course and a conversation course. Anxiety was measured through a survey, and the responses were analyzed using repeated-measures MANCOVA. The study indicated that levels of anxiety may vary according to instructional-context. The study also found a significant difference in levels of anxiety across the two courses, in that students reported higher levels of anxiety in the conversation course than in the reading course. Even though the differences in anxiety levels may be ascribed to the different classroom tasks and procedures, an item analysis of the anxiety measure revealed that higher anxiety in the conversation classes were related to speaking spontaneously, speaking in front of a class, and fear of negative evaluation. Subsequently, this study suggested that that speaking may carry increased anxiety. 
Given the negative affect of anxiety on language instruction for ELLs, it is imperative that instructors provide effective second language instruction that does not increase anxiety levels in learners to an aversive level. One approach that has shown to be effective with the language development of second language learners is TBLT (Brown, 2007; Ellis, 2003; Izadpanah, 2010).

\section{Approaches: Anxiety and Language Development}

The issue of language anxiety is so significant for English Language Learners that specific instructional efforts have been made to effectively address the problem (Jang, 2011). This section addresses the use of two approaches TBLT and simulations. English language teachers frequently use task-based language teaching, including simulations, for language development (Izadpanah, 2010).

\section{Task-based Language Teaching}

Efforts to reduce language anxiety have also been addressed by Izadpanah (2010) who notes the use of TBLT as a principle means to help reduce anxiety experienced by second language learners. In reviewing the specific foundations for TBLT that can reduce language anxiety for the student, Izadpanah argues that TBLT provides facilitates the design of communicative tasks that focus on the learner's actual language use. Izadpanah reports that research regarding the approach has consistently demonstrated that TBLT promotes the use of "content oriented meaningful activities" that enable the learner to engage with and utilize language as a means to promote language competency and confidence (p. 47). Izadpanah also argues that TBLT is unique because it provides a bridge between pedagogy of second language acquisition and the real world. As a result of this bridge, the learner develops a higher level of competence in engaging in real- 
world language tasks. This has implications for improving self-confidence and reducing anxiety associated with language use in the real world.

Meng and Cheng (2010) investigated college students' perceptions of TBLT. In their study, a total of 96 engineering sophomores enrolled at a university in Mainland China were surveyed. The goal was to understand which TBLT tasks were preferred and the specific ways in which this approach was perceived to improve language outcomes. The results of the investigation indicate that students preferred two-way tasks that enabled them to interact with peers, where more than $79 \%$ of the participants preferred two-way tasks. These tasks were judged to be beneficial and engaging for the students as they prompt significantly more linguistic and conversational adjustments. Additionally, more than $76 \%$ of the subjects noted that TBLT encouraged student participation, which reduced apprehension and made it easier for students to participate in English language conversations. These findings support Long's (1981) assertion that interactions enhance the development of language fluency. The findings also support the general implications that TBLT guided role-play activities are effective for the development of oral performance in English as a second or foreign language.

Oxford (2006) provided an overview of task-based language teaching, noting its theoretical application to second language learning. As noted by this author, TBLT provides a means for learners to connect past learning experiences with their current instruction on language development. This, in turn, has positive implications for constructing a structured teaching and learning format for students. In terms of anxiety issues for second language learners, Oxford argued that the structured nature of task- 
based language learning may provide a foundation for reducing students' apprehension and improving the student's engagement in language learning.

Plews and Zhao (2010) provide a more general review of task-based language teaching noting that this approach focuses on the development of tasks for communicative language teaching. "In TBLT, teachers set language-learners genuinely purposeful, problem-oriented, or outcome-driven tasks, which are thus comparable to real world activities, for the sake of encouraging meaningful communication and providing a context in which to study language" (p. 42). Plews and Zhao further note that TBLT has been successful for the education of second language learners because it provides a means for engaging the learner and creating the motivation for reviewing and evaluating language outcomes. Through this process, learners are provided with some of the basic supports that they need to engage in language use. This provides them with the ability to effectively reduce their level of anxiety and engage in communicative language (Plews \& Zhao). According to Plews and Zhao, TBLT also provides a means for making language instruction meaningful for the student. This has implications for the ability of the student to engage with and utilize the language (Plews \& Zhao).

Jiang (2010) considered the use of TBLT using a double-output hypothesis. Specifically, the author employed a combination of writing and speaking TBLT to enhance student performance on both writing and speaking tasks. Jiang conducted his research using a case study approach including students from two classrooms. The participants $(n=108)$ for the study were divided into a control group $(n=55)$ and an experimental group $(n=53)$. Both groups had equal English proficiency, did not like to communicate in English, and had low speaking and writing levels. The study took place 
over an eighteen-week period, with the control group continuing with the old teaching and managing method and the intervention group undergoing: metacognition, cognition, and social emotional strategy. Throughout the multi-activity study, the intervention group was given assignments, asked to evaluate each other's learning content, given free writing tasks and so forth. Pre- and post-written/spoken tests to assess the effectiveness of the learning approach were used. Findings suggest that after 5 months, the experimental group's grade total increased by 6.9 points out of 110 points, reflecting approximately a $6.2 \%$ increase. Data obtained in the investigation demonstrated that speech improvements through the use of TBLT could be achieved. Jiang argued that the success of the program was primarily achieved through the combined use of complementary speech and writing tasks to enhance student output.

Simulation and roleplaying. Simulations and roleplaying in the development of English language learning have also been shown to be useful in reducing language anxiety and improving English language competence (Ranalli, 2008). Where roleplaying involves assigning one or more members of a group a role and an objective that must be accomplished (Brown, 2007), simulations vary slightly in which the role-player assumes his or her identity. Ladousse (1987) maintains that while simulations are complex and lengthy, role-plays are simple and brief. The terms "simulation." "role-play", " role-play game," and "role-play simulation" have often been used interchangeably (Crookall \& Oxford, 1990. For the purpose of this paper the term "simulation" will be used hereafter. Ranalli provided a review of simulations for English language instruction noting that simulations in English instruction have been shown to promote language use in specific contexts. Ranalli asserts that this has benefits for the learner because, 
"Simulations are said to promote metacognitive strategy use and to foster strategic and communicative competence by helping learners assess the characteristics of a languageuse situation, set communicative goals, plan responses and control the execution of their plans" (p. 442). Simulations, games, and roleplaying have been used in classroom setting. However, there has been an increasing shift from classroom-based learning to technology-based learning.

\section{Technology and Language Development}

The use of technologies to support language development has existed for multiple decades. For example, the phonograph was used for the teaching of intonation (Stocker, 1921), and the radio was considered a technological resource around the world (Garfunkel, 1972). In the 1980s, technologies such as film, television, and language labs were also used for language instruction (Cunningham, 1998).

\section{Computer-Assisted Language Learning (CALL)}

Computers, in particular, can be useful in second language development as they allow for the integration of sound, voice interaction, text, video, and animation in a selfpaced interactive learning environments that could be used to enhance the classroom model of language learning significantly (Davis \& Thiede, 2000; Ehsani \& Knodt 1998). CALL is used to describe an approach that uses computers for teaching English to second language learners (Chaka, 2009). Lasagabaster and Sierra (2003) reason that numbers of students using CALL technologies are constantly increasing, and CALL has been reported to have positive correlations with students' performances (Furstenberg, 1997; Kelm 1998; Warschauer, 1997). One rationale behind the increased use of technologies to facilitate the acquisition of language is that these may be more enjoyable learning 
activities and may facilitate the acquisition of language, especially when compared to memorization of words (Marriott \& Torres, 2008). Along with enjoyment, these computer-based language activities have the capability of actively connecting words they are using to real-world scenarios (Hertel \& Millis, 2002).

\section{Social Software and CMC for Language Development}

In recent years, more serious consideration has been given to the use of computers for language instruction using social software over the Internet. Social software is defined as software that enables individuals to create and join online communities in which the users collaborate (Guth \& Petrucco, 2009). The software allows the user to interact with other users via computers, instead of interacting with a computer. Interaction using social software is referred to as $\mathrm{CMC}$, which is defined as any communicative transaction that occurs through the use of two or more networked computers (McQuail, 2005). Types of CMCs include email, instant messaging, and chat rooms (Merchant, 2001). Sites such as myspace and facebook are used to socialize with friends. Youtube, and flickr are used to express creativity. Blogs and wikis are used to share knowledge (Huffaker, 2005). Lastly, interaction through Internet-based video-conferencing allows two or more users to interact via two-way video and audio transmissions simultaneously (Plonczak, 2010).

The impact of various forms of social software on language and/or communication skills of ELLs has been encouraged in recent years (Black, 2005; Bloch, 2007; Molenda \& Pershing, 2008; Sykes et al., 2008). Moreover, research on the use of social software for language development has been conducted (Bakar, Latif \& Ya'acob (2010); Fellner \& Apple, 2006; Kovacic, Bubas, \& Zlatovic, 2007; Mak \& Coniam, 2008; Satar \& Ozdener, 2008). 
Satar and Ozdener (2008) examined the effects of synchronous CMC on the speaking proficiency and anxiety of 90 ELL participants between the ages of 16-17 in a high school in Turkey. The participants were evenly distributed into 3 groups, voice chat and text chat (experimental groups), and a control group. The participants in the experimental groups engaged in 40-45 minute-long chat sessions in dyads. The activities were assigned out of class for the experimental group for a period of four weeks with a total of eight tasks that required participants to collaborate and exchange information using a CMC website. The control group was not assigned any tasks out of their class. The researchers used the Foreign Language Learning Anxiety Scale developed by Horwitz et al. (1991) to measure anxiety and speaking tests developed by Hughes (2003) for measuring speaking proficiency. The study found that the speaking proficiency of both experimental groups increased in comparison with the control group, providing that social software may aid in language development. Findings also showed that the text chat experimental group had a greater decrease in language anxiety than the voice experimental group, where $53 \%$ of the text chat group reported that the chat sessions decreased their language anxiety and $20 \%$ of the voice chat group reported the same. These findings confirm previous reports that speaking may cause higher levels of anxiety than other language skills among ELLs.

Kovacic et al. (2007) supplemented the traditional (face-to-face) teaching with several online wiki-based e-tivities (online tasks) for two undergraduate English for specific purpose courses. At the University of Zagreb in Croatia 113 participants took part in the study and upon completion the students evaluated the e-tivities and the overall use of the wiki using a Likert-type response scale. At the end of the semester students 
evaluated their experiences with the wiki and e-tivities which were performed as part of their assignments. The participants favorably and positively evaluated the usability of wiki technology in their English for special purposes courses. The participants' responses ranged from 3.4 (average) to 3.8 (good). The study concluded that the use of a wiki for English development is a useful and innovative way of enriching the students' learning environment when compared to traditional face-to-face teaching. In addition to contributing to the development of writing skills, the study engaged the students more fully with topics of English for special purposes courses, enabled online collaborative learning, and facilitated the participants' critical thinking in the creation of the wiki pages (Kovacic et al., 2007)

Bakar, Latif and Ya'acob (2010) used blogs by ESL students to improve language learning. Blogs are defined as an Internet-based resource, which was initially used by bloggers as an online journal or web diary. In this investigation, a blog was created as part of classroom learning and ESL students were required, over the course of a semester, to contribute to the blog. The 197 participants (20-34 years old) who took part in this study were undergraduate students attending English for Social Sciences course. Following the completion of the project, the participants were surveyed about their experiences through a four-point Likert scale. The percentages were tabulated, and responses were analyzed through descriptive statistics in the form of frequency analysis. The questionnaire analysis showed that over $90 \%$ of the participants reported that they felt the blog had enhanced both their written and spoken language skills. In addition, more than $87 \%$ of the participants claimed that the blog had reduced their overall 
language anxiety. Based on these outcomes the authors advocated for the use of blogs for ESL students to enhance both academic and language learning in the classroom.

Supporting research in the use of blogs for language development was used with 21 Japanese students. Fellner and Apple (2006) conducted a study on a low proficiency and low motivation target population. The participants were Japanese university ELLs attending a seven-day (38-hour) intensive English program designed to assist the students in passing a college English proficiency exam. The study aimed to utilize students' blogs to measure writing fluency by means of calculating the number of words written over a 20-minute period. The results demonstrated that the use of blogs increased English writing proficiency by $350 \%$ from the beginning of the course. The participants averaged 35 words over a 20 -minute period with all words falling within the most frequent 1000 word level. By the end of the program the students averaged 122 words with all words falling within the most frequent 2000 word level. In addition to the number of words written, the word level vocabulary also expanded (Fellner \& Apple, 2006).

Hsu, Wang and Comac (2008) evaluated audioblogs (defined as a blog that includes audio clips) and their usefulness in strengthening English language learning. In particular, Hsu and colleagues employed the use of an audioblog in a classroom and evaluated outcomes (e.g., student and educator feedback) to assess how these tools could enhance language-learning outcomes for students. The participants were 17 international adult ELLs enrolled in an advanced English conversation course. Using a mixed methods approach, students where surveyed on the perception of blog use as a facilitator of English language learning. The majority of the participants (82.4\%) believed that the audioblogs were a good language-learning tool. After a complete semester of using 
audioblog learning $64.7 \%$ of the participants reported having stronger confidence in using English than before. These findings suggest that social software may be an efficient tool for language development.

The impact of social software has not only affected language development, but also language pedagogy in general. Bonaiuti (as cited in Guth \& Petrucco, 2009) asserts that the existence of social software can impact pedagogy in at least two ways. First, social software learning can be more informal than formal and one can easily shift from content-based to collaborative learning, therefore allowing for a more relaxed setting in which to converse and possibly acquire the language more effectively. Second, Mejias (2006) noted that when social software tools are used together, students learn how to learn by managing software tools, working cooperatively, and developing online research skills, thus allowing the learner to engage in a cooperative relaxed environment.

With more recent advancements of software and Internet technologies, virtual environments have emerged and are playing a role in education (Dalgarno, 2002; Dickey, 2005; Schwienhorst, 2002; Zhang, \& Zigurs, 2009). The next section of this chapter, will explore the uses of virtual environments and the effects they have on language development.

\section{Virtual Environments and Language Development}

Virtual Reality is defined as a class of computer-controlled multisensory communication technologies that allow more intuitive interaction with data and involve human senses in new ways (McLellan, 2004). Jacobson (1993) simply defines a virtual world as an environment that is created by a computer in which the user feels present. In MUVE sites, users can find digital three-dimensional graphical representation of physical 
environments in which they may move and interact with other users at the site (Jamison, 2008). The terms virtual world and virtual environments are interchangeably used throughout the literature, however, for consistency reasons the term MUVE will be used here after. Within three-dimensional MUVEs avatars that are three-dimensional characters on the screen are used to represent the users and can be controlled by the user to walk, talk, fly and so forth. Subsequently, users via their avatars can interact within the online environment with other users through movement, text chat, and voice chat in real time (Dickey, 2005; Henderson, Huang, Grant, \& Henderson, 2009). This means that users can interact synchronously with each other making it a potentially useful learning environment (Henderson et al., 2009).

There are numerous reasons to consider using MUVEs in education (Clarke \& Dede, 2005; Jarmon, Traphagan, Marrath \& Trivedi, 2009; Kalyuga, 2007; Prensky, 2006). For example, recent research has suggested that virtual worlds/environments are correlated with motivation (Tuzun, Soylu, Turkan, Yavuz, \& Gonca, 2009), and learner autonomy and creativity (Henderson, et al., 2009). Research in educational virtual reality reveals that 3D interactive environments provide support for constructivist-based learning activities by allowing learners to interact directly with information from a first-person perspective (Bricken \& Byrne, 1993; Dede, 1995). Winn (1993) argued that information taught in schools is often presented as third-person symbolic experiences, whereas innately, we mostly learn through first-person non-symbolic experiences. According to Winn, MUVEs can help bridge the gap between experiential learning and information representation. More recently, Ranalli (2008) in particular considers the use of the MUVE SIMS as a virtual learning tool to increase language use and comprehension. 
Ranalli reports that virtual environments that provide language simulations are rich in natural associations that facilitate cohesive meaningful use of language.

Outside of education, MUVEs have been used in varied ways from delivering exposure therapy to posttraumatic stress disorder among veterans (Rizzo, Parsons, Belinda, et al. 2011) to training instructions that allow trainees to learn assembly operations (Brough et al., 2007). Similarly, in education, MUVEs have been used for a variety of disciplines such as pre-service teacher training (Bull, Bull, \& Kajder, 2004; Bronack, Riedl, \& Tashner, 2005; Schlager, Fusco, \& Schank, 2002), science-based activities (Kafai, 2006), biology instruction (Mikropoulos, Katsikis, Nikolou, \& Tsakalis, 2003), and engaging in scientific inquiry (Clarke, Dede, Ketelhut, \& Nelson, 2006). For example, using the MUVE of River City, approximately 2000 middle-school students took part in a study aimed to investigate novel pedagogies for helping teachers infuse inquiry into a science curriculum. The data showed a 32-35\% improvement of 300 students' biological knowledge for the experimental (virtual environment) treatment group, and 17\% improvement for the control (paper based) group (Ketelhut, Nelson, Clarke, \& Dede, 2010).

Baker, Parks-Savage and Rehfuss (2009) argue that virtual environments can be used to teach students social interaction skills. Using this as a foundation for investigation, the authors examined the use of virtual environment technology for teaching social skills to elementary school children. Sixteen participants aged 7-10 were obtained from 4 different classrooms to take part in this study. Seven different areas for social development were evaluated including: problem behaviors, cooperation, assertiveness, responsibility, empathy, self-control, and academic competence. Data 
collected by the authors through the Social Skills Rating System parent form indicates that improvements in four of these areas were noted, including problem behaviors, cooperation, responsibility, and self-control. The effect size for each of four improved variables with measurable differences was generally large $(r>0.40)$. The most important observed advantage of using virtual environments to teach social interaction skills was promoting the ability of children to make decisions and to understand the consequences of their actions (Baker, Parks-Savage, \& Rehfuss, 2009).

In another study, Zheng et al. (2009) investigated the effect of the MUVE of Quest Atlantis on the ELLs attitude towards English, self-efficacy toward advanced use of English, and self-efficacy toward e-communication. In this study, 61 students in seventh grade from China were randomly selected and placed in an intervention or control group. The intervention group used "Quest Atlantis" to travel to virtual lands, talk to others through chat, and build virtual personalities and personas. The control group had the same period of time to interact with other participants face-to-face. The data from the questionnaire were analyzed using a posttest quasi-experimental design. The MUVE group (intervention) rated themselves higher in comparison to the control group. With 'attitudes towards English', the intervention group showing a mean and Standard deviation of $(3.83 \pm 0.43)$ compared to the control group with (3.34 \pm 0.84$)$. The 'Self-efficacy toward advanced use of English' showed (3.76 \pm 0.61$)$, and (3.19 \pm 0.94$)$ for the intervention and control group respectively. Finally the 'Self-efficacy toward ecommunication' showed a decrease from $(4.0 \pm 0.67)$ to $(3.43 \pm 0.94)$ from the intervention group and control group respectively. 
With respect to language learning, there is an emerging but limited body of literature discussing the potential benefits of MUVEs. For example, Von Der Emde, Schneider, and Kotter (2001) assert that virtual learning environments for language instruction provides learners with the ability to contextualize language use as part of culture and social interaction. Research suggests that through interactive activities in virtual communities, ELLs can construct their identities while engaging in multiple learning practices (Black, 2005; Lam, 2000; Yi, 2008). Further, these benefits can be achieved in the convenience of the individual's Internet connected device without the need to physically travel anywhere. The end result for ELLs can be an individualized, authentic, and autonomous language learning experience (Von Der Emde, Schneider, \& Kotter 2001).

However, empirical research on the effects of MUVEs on ELL's language development and speaking is limited (Garcia-Ruiz, Edwards, \& Aquino-Santos, 2007; Zheng et al., 2009). There is also a shortage of research that clearly demonstrates the benefits of using virtual learning environments for ELLs (Ranalli, 2008). Most of the research done on the topic of virtual environments and ELLs has revolved around perceptions, attitudes, and self-efficacy (Henderson et al., 2009; Zheng et al., 2009). However, of the few studies available, it has been found that virtual environments have provided an enhanced learning environment (Miller \& Hegelheimer, 2006; Peterson, 2006).

Miller and Hegelheimer (2006) investigated the effects of SIMS (a multi-user virtual environment) on acquisition of vocabulary in adult ELLs. For the duration of 5 weeks the participants (placed in groups of three) met once a week for 50 minutes. Each 
group individually experienced mandatory supplemental material (station 1), volunteer access to material (station 2), and no supplemental material (station 3) while completing tasks using SIMS. Mandatory supplementary material consisted of explicit vocabulary, grammatical, and cultural instruction via a computer. Results indicated that there was a statistically significant difference between group 1 and station $2(p=0.035)$. The difference between stations 1 and $3(p=0.069)$ was marginally statistically significant, whereas mean scores between station 2 and 3 where not statistically significant ( $p=$ 0.88). These data indicate that when a group of participants were exposed to the mandatory material along with tasks using SIMS, there was a significant increase in that group's vocabulary acquisition.

Peterson (2006) conducted an experimental study on 24 intermediate adult language learners at Tokyo University of Foreign Studies, which aimed to explore the nature of learner interaction management in "Active Worlds" a three-dimensional virtual environment. The study duration was 5 weeks in which the participants worked in dyads for 90-minute sessions on three task types: opinion exchange, decision-making, and opinion exchange. Through sequential analysis and discourse analysis of qualitative data, the findings showed that when the participants managed their discourse, and adopted a number of interactional and transactional strategies, an important role in facilitating interaction in online environments occurred. Thus, this suggests that the interaction in virtual environments may be useful as a tool for purposes of language development. Although this paper did not measure a language skill directly, it did however report that the use of interactional and transactional strategies in the MUVE may indirectly facilitate language development. 


\section{Simulations and MUVEs}

Simulations and other language-development activities for ELLs are typically conducted in a real-world classroom setting under the direct supervision of the language teacher. However simulations have more recently been used in MUVEs partially due to its adaptability, flexibility, and anonymity of participants' identities. Ranalli (2008) stated that students may freely make mistakes in MUVEs without the anxiety that can accompany traditional classroom instruction.

Within the scope of using simulations for reducing anxiety, Cole and Griffiths (2007) consider the use of multiplayer online role-playing games (MMORPGs) and their impact on reducing social anxiety for individuals. According to these authors, research regarding MMORPGs demonstrates that those who use this type of simulation are able to develop deep friendships with significant emotional ties. This is often accomplished when individuals are unable to establish these relationships in their daily lives. Cole and Griffiths explicate this outcome as a result of the simulated environment. According to these authors, MMORPGs reduce anxiety of the individual and allow for more authenticity and engagement in communication and social interactions.

In a pilot study designed to measure if Ever Quest 2, a virtual environment, increased ELLs' English proficiency Rankin et al. (2006) recruited five students. These high-level (beginner to advanced) participants defined by the Basic English skills Test were required to spend a minimum of four hours per week for four weeks playing Ever Quest in groups of two. The positive response in the post-game questionnaire from all 4 students (1 dropped) indicated that Ever Quest 2 improved their English vocabulary skills. The researcher decided to test each participant's acquisition of vocabulary through 
word frequency counts. All participants were found to accurately define more than $35 \%$ of the new vocabulary words after hearing the word once during the simulation. This number increased to $55 \%$ after hearing the word six or more times during the simulation. This study suggested that virtual environment may accelerate the development of vocabulary to advanced high-level ELLs.

Sha (2009) examined the use of AI-based (Artificial Intelligence based) chatterbots that enable students to engage in spoken human-avatar simulations to promote improvements in spoken English. Fifteen students from a pool of 150 volunteered to participate in this study. The participants were first and second grade ELLs attending a speaking course. The chatterbots were found to promote presentation, practice, and production as integral components for fostering spoken language in English language learners. In addition, Sha noted the interest of students in utilizing the technology with $13 \%$ feeling "amused," and 80\% feeling "interested" with no participants feeling "bored" or "nervous." Surveys of student attitudes toward chatterbots and observations of student engagement with the technology suggest that these tools provide an engaging and exciting platform for students to develop spoken English skills.

Second Life: A multi-user virtual environment. Multiple MUVEs exist, but one of the most explored is Second Life. Second life is considered to be the most established and recognized environment, and it has been researched and welcomed by educational institutes (Au, 2009; Rymaszewski et al., 2007). Second Life is software to access a virtual world via the Internet in which users (residents) create an identity with the potential to engage in social, educational, and financial activities. The residents are represented on the screen by three-dimensional characters referred to as avatars. 
Communication through Second Life is available by means of text chat, instant messaging, and live voice. The opportunity for residents to meet together combined with the ability to build virtual property means that an educational environment could be built for students to practice online virtual learning and for research on its effects. The versatility of MUVEs could be why universities, colleges, and other educational institutions have taken the initiative in exploring MUVE by building campuses and offering a variety of courses in the MUVE of Second life.

Thorne, Black, and Sykes (2009) examined the theoretical foundations of different virtual environments and online games for promoting language use and socialization for second language learners. In this review, Second Life was reviewed as an online gaming environment that could potentially improve student language use through socialization. According to Thorne and colleagues, Second Life promotes what is known as social virtuality in which students are able to interact in social environments that are similar to those that they would experience in real life (e.g., university classroom, coffee shop, park). These settings provide the student with comfort and familiarity and enable assessment of language use and communication that would be similar to what they would use in the real world. Additionally, Thorne and colleagues note that Second Life represents a task-based environment in which learners are encouraged and motivated to complete language tasks.

Dominguez-Noriega, Agudo, Ferreira and Rico (2011) considered the cultivation of language learning and practical language use in Second Life. The authors note that the virtual environment of Second Life provides language learners with the ability to explore new ways for using language. Decision-making in this environment can provide users 
with a better understanding of the correct and incorrect use of language in social situations. Because students are able to make decisions about language use on their own and are able to experiment with variations in language use, they not only benefit from interacting with language but also benefit from the ability to make mistakes and learn what works.

Second Life is being used in higher education to create virtual classrooms that bring together students from remote locations to interact with one another in a controlled immersive environment (Kelton, 2007). Second Life has also been shown to be highly effective for distance education in a post-secondary environment (Barkand \& Kush, 2009). For example, according to Henderson et al. (2009) Second Life can support competency-based training such as oral skills, vocabulary, and grammar. In addition, they see that it can also support synchronous interaction with teachers, students and others, including native speakers in rich creative ways. In a quantitative study by Henderson et al., 100 university students participated in a lesson conducted in Second Life. The study aimed to measure the students' capacity to use Mandarin in a variety of authentic contexts in the MUVE of Second Life. Pre- and post-questionnaires were matched and a paired $t$-test was used to identify significant changes. The researchers found significant improvements between the participants' pre and post self-efficacy ratings, which in turn may have constructive associations with language development.

In Sweden, Petrakou (2010) conducted an ethnographic study on seven students enrolled in an oral production course in higher education, the study aimed to explore how Second Life facilitates online education. Petrakou paired the participants with American students attending the University of Missouri in a "buddy" system in which they worked 
on language-related assignments such as interviews, pair discussions, and presentations. The participants had to undergo five, 2-hour sessions in Second Life. The data gathered through virtual voice recordings and interviews found that the MUVE of Second Life enhanced interactivity because it allowed for synchronous communication and for the student to be placed in a spatial dimension. The authors also conclude that in their study, using a virtual world was not adequate by itself, the lack of participants' technical skills diverted the experience from the language learning process to a technical informative interaction (Petrakou, 2010).

Liou (2012) conducted a study to assess how Second Life can be infused with CALL. Participants consisted of 25 college students who were provided with four language-learning and teaching related tasks that lasted for eight weeks. Task A was an orientation to Second Life and chatting in Second Life. Task B was Second Life for peer review, Task C was Second Life for English teaching, and task D was a Second Life tour. Through a 25-item questionnaire participants reported that Second Life provided them with an authentic environment for communication and interaction. Liou reports that $96 \%$ of the participants rated the ease of interaction with others as (very high). Data showed that Second Life assisted with their language learning as $64 \%$ reported that interaction in Second Life promoted their English proficiency. With regards to anxiety, 76\% reported that Second Life reduced their anxiety of English learning, and 72\% believed that Second Life provided a real-life context that they found to be helpful in learning English.

\section{Chapter Summary}

With the increasing number of ELLs and the importance of speaking English for social and professional goals, there comes a need to teach English competently to meet 
the demand. ELLs are required a certain level of oral proficiency to achieve social and economic success (Chaney \& Burke, 1998; Wrigley et al. 2003). However, speaking English for ELLs can be one of the most anxiety initiating undertakings and may hinder the process of acquiring oral skills (Allen \& Franklin, 2002; MacIntyre, 2007).

Literature indicates that there is a significant negative relationship between speaking anxiety and oral performance (Aida, 1994; Cheng, 1999; Horwitz, 1986; Kim, 2009; Philips, 1992). Research suggests that TBLT, more specifically simulations, may promote ELL speaking ability, and reduce speaking anxiety levels amongst ELLs (Aliakhbari \& Jamalvandi, 2010; Izadpanah, 2010; Jiang, 2010).

Computers have been used for decades to support English language teaching, and have allowed students to interact with material concerning English language learning. By using computers to assist in language learning researchers, teachers, and ELLs have been able to integrate voice interaction, text, and video to enhance the classroom model of language learning significantly (Davis \& Thiede, 2000; Ehsani et al., 1998).

In more recent years, with the development of the Internet, more serious consideration has been given to social software for language development. Students now have the ability to communicate with others using the computers in CMC (e.g. Twitter, Facebook, Skype, Wikis, and blogs). Researchers have examined and encouraged the use of social software to develop language skills (Baker, Latif, \& Ya'acob, 2010; Kovacic et al., 2007; Satar \& Ozdener, 2008). Their research has consistently reported positive attitudes, perceptions, and results when using social software for language development. Kovacic et al. concluded that using Wikis for English language development was a useful 
and innovative way of enriching students' learning environment when compared to faceto-face teaching.

Using computers and online MUVEs (e.g. Quest Atlantis, Second Life, and SIMS) to perform simulations have also been reported to reduce anxiety among ELLs and promote language learning (Cole \& Griffiths, 2007; Jia \& Chen, 2009; Rinalli, 2008; Sha, 2009; Thorne, Black, \& Sykes, 2009; Zheng et al., 2009). According to Cole and Griffiths, using MUVEs for simulations reduces the anxiety levels of the student and allows for more authenticity and engagement in communication. Rinalli points out that the anonymity factor freely allows ELLs to make mistakes in MUVE without the anxiety that may be a result of face-to-face interaction.

A widely used MUVE for adult English language development has been Second Life, where many institutions, libraries, and universities have opened virtual representations of their physical structures. Second Life gives students the ability to interact in social environments similar to real life ones (Thorne, Black, \& Sykes, 2009). There are several benefits from Second Life. First, students benefit from their ability to make mistakes by receiving immediate feedback. Second, Interaction through Second Life provides the learners with a better understanding of correct and incorrect use of language in social situations (Dominguez-Noriega, Agudo, Ferreira, \& Rico, 2011). Second Life also enhances interactivity among ELLs as it allows for synchronous communications (Petrakou, 2010).

Only a limited number of studies have demonstrated benefits of MUVE for language development (Ranalli, 2008). Most studies have been concerned with perceptions, attitudes, and motivation of students, but the number of studies remains 
limited on MUVEs and ELLs' language and speaking development (Garcia-Ruiz, Edwards, \& Aquino-Santos, 2007; Zheng et al., 2009). This study is designed to add to the limited MUVE research by comparing the effects of MUVE on speaking anxiety of adult ELLs. Specifically it examined the speaking anxiety levels of ELL participating in simulations in Second Life, and compared it to those of ELLs participating in the same simulations in traditional face-to-face environments. 


\section{CHAPTER III}

\section{METHOD}

This study investigated the perceived anxiety levels of adult ELLs when speaking English to Native English Speakers during simulations conducted face-to-face in the classroom and virtually in Second Life. Comparisons in perceived anxiety levels between the two conditions were made. Self-perceived anxiety was measured through the English Language Learners Speaking Anxiety Scale (ELLSAS) that was administered to the participants after each of the 10 simulation activities.

This chapter contains a description of the study's participants, setting, and materials. Additionally, the experimental design and dependent variables are identified and explained. This chapter concludes with detailed general procedures and a chapter summary.

\section{Participants}

Eleven adult post-secondary English language learners from the English Language Institute (ELI) at Florida International University (FIU) participated in this study. The 11 participants, six men and five women, were randomly assigned to two groups. Participant ages ranged from 18 to 62 with the majority of participants being in their twenties.

Participants in the control group engaged in face-to-face simulation activities with native English speakers; whereas, participants in the experimental group participated in identical simulation activities conducted in a MUVE (Second Life) with the same native English speakers. In order for individuals to take part in the study, they had to 
read, understand, and sign a consent form (Appendix A) provided to them at the beginning of the study.

Another criterion for inclusion in the study was that participants had to meet the eligibility criteria for English communication level 3 (based on a 1-6 scale with 1 being beginner and 6 being advanced). In order to be placed at level 3 (low to high intermediate proficiency) the participants had to obtain a score between (48 and 74) on the Mike Test. ELLs at levels 3 exhibit the following, (a) fluency, they may show hesitation between sentences, search for adequate words, phrases, and constructions; (b) structure, ELLs make only occasional grammatical errors and other structure problems; (c) vocabulary, ELLs must use basic appropriate vocabulary, that is verbs and nouns, needed to tell a story; and (d) pronunciation, ELLs must produce generally understandable pronunciation. An ELI language instructor conducted the assessment, which had fluency, structure, vocabulary, and pronunciation components. This assessment and placement was developed by the ELI and was referred to as "The Mike Test". This test is based on the original "John Test," a test designed to test oral fluency of adult ESL students (Center for Applied Linguistics, 1979). The Mike Test is a series of pictures of a person named "Mike" who is performing actions during a typical day. The assessment required the ELL to answer questions based on the pictures in English. The assessed student is also required to form questions directed to the test administrator (e.g. "What is the name of the man in the picture?"). Additional participant demographics can be found in the results section of this document. 


\section{Setting}

Participants in the experimental group and control group used the same classroom settings but at different times. Characteristics of the setting sites are provided below.

\section{Control Group (Face-to-Face Simulation)}

The settings for the participants in the face-to-face group simulation activities were conducted in six small (12 x 19 feet) classrooms (ZEB 263-266) in the Ziff Education Building at FIU. The rooms contained a desk, chair, air conditioning, and was well lit. Each classroom was void of other students at the times used for this research project. In each classroom there was one Apple MacBook laptop placed by the researcher facing the NES. The participants were shown where to sit and there was a sign on the door indicating, "Dissertation Research Project in Session. Please do not Disturb."

\section{Experimental Group (Multi-user Virtual Environment Simulation)}

The settings for the participants in the experimental group (simulation in multiuser virtual environment) were identical to those of the experimental group. However, the only two differences were that there was no NES in the room and the Apple Macbook laptop was facing the ELL participant.

\section{Materials}

Following are descriptions of the materials that were used in the study. This includes the various permission forms, technology, and other materials.

\section{Assessments}

The ELLSAS is an assessment that consists of eight questions designed to measure English language learners' speaking anxiety levels in the language classroom or in a MUVE (Appendix B). The scale has a 10-point Likert scale ranging from not anxious 
(1) to extremely anxious (10). The scale was composed and edited from two scales by the researcher, the Foreign Language Classroom Anxiety Scale (FLCAS) by Horwitz (1986), and the Second Language Speaking Anxiety Scale (SLSAS) by Woodrow (2010). Four content experts validated the resulting assessment at Florida International University.

\section{Hardware}

Six Apple MacBook laptop equipped with an Intel GMA X3100 integrated "graphics processor with 144 MB of DDR2 SDRAM shared with main memory," and a 13.3" widescreen TFT active-matrix "glossy" display (1280x800 native resolution). The laptops were connected to FIU's fiber-optic T3 wireless Internet connection. This connection has the capability to transmit full motion video at speeds of 44.6 mbps. The laptops had a built in microphone used for voice chat.

\section{Participant Consent Form}

A consent form (Appendix A) was given to all participants prior to the study. The consent form included pertinent information regarding the purpose, length of study, and expectations of the existing study. The form was written in English of an appropriate

level, and was free of complex terminology or words above conversation level 3 terms. In addition, researcher and university contact information were included in the form.

\section{Participant Demographic Form}

On this form, participants provided standard personal background and demographic information. This form was administered to the participants at the beginning of the study. This form (Appendix C) also acted as an inclusion/exclusion form, and allowed the researcher to identify potential candidates for the existing research. All potential participants passed the inclusion criteria and were included in the study. 


\section{Simulation Activities}

A total of 10 simulation activities were used throughout the study. The simulation activities reflected authentic situations in which ELLs engage with NESs in a conversation. Each simulation activity was printed and contained a detailed section for language, aim, procedure, ELL role card, and NES role card to guide the participants (Appendix D).

\section{Treatment Fidelity Checklist}

There were two treatment fidelity checklists for the purpose of this study, a researcher treatment fidelity checklist and a simulation treatment fidelity checklist.

Researcher treatment fidelity checklist. An outside rater with a TESOL masters degree used the researcher treatment fidelity checklist for 30\% ( 3 out of 10 ) of the simulation activities. The checklist included the specific conditions that needed to be consistent in every simulation activity (Appendix E).

Simulation treatment fidelity checklist. The simulation treatment fidelity checklist served two purposes, it was used by the NESs in every simulation activity, it was also used by an independent rater. The checklist included a number of specific conditions that need to be executed with each scenario activity in the study (Appendix F). The checklist also had specific proposed unclear sentences to be spoken to the ELL during the simulation (e.g. Have you lied drinking to them about a meal?). The reason for these potentially unclear sentences was to prompt the ELL to ask the NES for clarification. The independent rater used the checklist to verify that the NES implemented proper procedures by independently filling out another simulation treatment fidelity checklist form for approximately $30 \%$ of sessions for each participant. 


\section{Second Life Viewer Software}

Second Life viewer for Mac, which is a 3D browsing software was used to activate Second Life on Apple operating systems. The latest version (3.3.4) was used to account for consistency and to avoid any technical difficulties during the simulations.

\section{Dependent Variables}

The dependent variable in this study was the perceived anxiety as measured by the ELLSAS questionnaire (Appendix B). The ELLSAS consisted of a 10-point Likert self-report scale in which participants rated their levels of anxiety immediately after each simulation activity. The questionnaire consisted of 8 questions and options to rate each question from not anxious to very anxious. Speaking anxiety was defined as a distinct complex of self-perceptions beliefs, feelings, and behaviors related to classroom learning that surface from the uniqueness of the language learning process (Horwitz, Horwitz, \& Cope, 1986). Four experts in the field of psychology, ESL, and statistics validated the survey. Professors from the college of education revised the survey and the modified the survey based on the experts' feedback.

\section{Procedures}

The following describes the procedures of the study. The pre-study procedures are those that were completed prior to the beginning of the study including identification, consent, and training of ELLs, NESs, and research assistants. The general study procedures section describes the experimental and control conditions.

\section{Pre-study Procedures}

The following procedures were implemented prior to the beginning of the study. These procedures were used for the selection of participants, consent forms, and training. 
ELLs' identification, consent, training, and group assignment. The researcher was given access to a Level 3 class by the ELI at Florida International University for the purpose of conducting this research. The researcher addressed the 11 students in the class and briefly explained their potential involvement in this research project. The potential participants were notified that simulation activities would be conducted during the last 40 minutes of their "communication" class time period and that no additional time would be used. Those willing to take part in the study were asked to identify themselves, and were considered for inclusion in the study. All 11 students agreed to become part of the study and were given a participant general information form (name, age, sex, exclusion criteria) to obtain basic demographic data and to identify those who qualified to participate based on the inclusion and exclusion criteria (Appendix C). All participants qualified for the study and were asked to read and sign a consent form indicating their willingness to participate (Appendix A). The participants were then randomly assigned to a control or experimental group, in which the control group had five participants, and the experimental group had six participants. Five names for control group and 6 names for the experimental group were selected by drawing cards with names on them from a box without looking.

All participants' personal information adhered to IRB regulations and each participant was given a pseudonym to ensure his or her confidentiality. For example faceto-face control group participants were referred to as FF1 to FF5 (FF = face-to-face), and experimental group participants were referred to as VE1 to VE6 (VE = virtual environment). 
All participants underwent a brief tutorial on the nature of simulations. The researcher explained and defined a simulation activity, and a practice session between two pairs was conducted. Then participants from the experimental group underwent a brief 15-minute tutorial session in the College of Education computer lab, where the steps of the MUVE simulation activities were explained and where they learned how to chat and control their view in Second Life. Upon completion of the training, the researcher assessed the experimental group participants' abilities related to the basic movement and communication features of Second Life. This was done in one-to-one sessions where the participants were asked to perform the tasks identified on the Second Life Assessment Checklist (Appendix G). In the case that a participant did not succeed in basic navigation and communication controls, the participant was individually taught the necessary controls. Upon completion the participant was assessed again on his/her ability to navigate and control the avatar, as well as communicate with other avatars.

\section{Native English speakers (NESs) identification, assent, and training. Five NESs} were recruited from FIU's College of Education's Department of Teaching and Learning. The NESs were all women and were senior-year undergraduate students seeking a bachelor's degree in different fields in education with an English-speakers of Other Languages (ESOL) endorsement. The NESs were paid \$15 per hour and were informed that participating in this study would not affect their grades.

The five NES worked with both the control and experimental groups as a simulation partner, where they were randomly assigned to their ELL simulation partners and were assigned to interact twice with each ELL. When working with the control group, NES engaged with the ELL participants in face-to-face simulation activities. 
When working with the experimental group, NESs engaged with ELL participants in identical simulation activities conducted in the Second-Life MUVE setting with different ELLs.

NESs were trained and given instructions on the face-to-face and the simulation procedures. Then NESs underwent a 60-minute tutorial session in the College of Education computer lab, where they learned how to navigate their avatar, chat, perform gestures, and log off and back on to Second Life. Upon completion of the training, the researcher assessed that all NESs abilities related to the basic movement and communication features of Second Life. This was done in one-to-one sessions where the participants were asked to perform the tasks identified on the Second Life Assessment Checklist (Appendix G). Upon completion of the training, the researcher assessed that all NESs on the basic movement and communication features of Second Life by asking them to perform the tasks identified on the Second Life Assessment Checklist. All NESs acquired the necessary target skills. When an NES was unable to use basic navigation and communication controls, she would reinstructed the necessary controls again until the necessary target skills were acquired.

Research assistant's recruitment and training. One assistant was recruited to assist with the daily classroom set up, technology needs, and provide assistance when needed. The assistant has had 25 years of experience in teaching English as a second language, and was knowledgeable in working with ELLs. The researcher explained the importance of her presence during the study and requested prior notice should the research assistants need to cancel. The assistant underwent a 2-hour tutorial session in the College of Education computer lab, where she learned how to setup the classrooms and 
hardware for the activities. She was also required to assist with software-related matters, such as logging on and off Second life, chatting, and performing gestures, rebooting the laptops and connecting them to the Internet. Her presence was from required pre- and post-simulation activities for both control and experimental group activities. Upon completion of the training, the researcher assessed that the assistant knew the basic movement and communication feature of Second Life by asking her to perform the tasks identified on the Second Life Assessment Checklist and by running some troubleshooting scenarios. The assistant acquired the target skills from the initial attempt. Had the assistant failed in acquiring the skills, she would have had to be taught the necessary controls again until the skills were acquired successfully. The assistant was paid at a rate of $\$ 10$ per hour.

Simulation activities identified and prepared. The simulation activities were adapted and modified from a specialized simulation book (Maley, 1987). A total of ten simulation activities were used for the purpose of the study (Appendix D). The simulation activities were randomly assigned to correspond with each of the research sessions (10 in total). Each simulation activity sheet contained a detailed section for language, aim, procedure, ELL role card, and NES role card. Only the NESs, researcher, and assistant had access to the full role card page, while the participants had access to the ELL role card only.

Identification, preparation, and scheduling of research rooms. Classrooms, offices, and a computer lab were reserved with permission from the Department of Teaching and Learning for a period of 2 hours during each of the simulation activities 
twice a week for 2 weeks in which a total of 10 sessions were conducted. The researcher contacted the departmental secretaries to reserve the rooms.

\section{Study Procedures}

In this section, a general explanation of the study procedures is presented and further explained in detail. This includes general protocol, control group procedures, and experimental group procedures.

General protocol. For both the control and experimental group conditions, the researcher distributed the consent and general demographic forms. The nature of a roleplaying simulation was explained in general to both groups, without mentioning the environment in which they would be carrying out the simulation.

All five NESs were required to arrive 20 minutes prior to the ELLs' scheduled time in the Ziff building (ZEB 261), where they were debriefed on the simulations and any inquiries were answered. Before every simulation for 10 days, the researcher escorted all participants from the class at the ELI to the College of Education building's second floor. Once they arrived they were given a sticker marked with their pseudonym and room number for their simulation. The participants knew that the face-to-face group always went first, while the experimental group waited seated in the hallway. The reason for this was to avoid any technical difficulties that may arise when working with computers for the experimental group (e.g., software or hardware failure), which might have delayed the control group.

Within each group, all participants started the simulation activity at the same time. Outside each simulation classroom was an ELL role card taped on the door for ELLs to read. They were given 5 minutes to read and ask any clarification questions. Once they 
felt that the understood their role, they would walk in the room and start the activity. As both groups used the same room for their simulations but had different environments, each group's procedures were discussed elaborately in the latter sections. For both groups the simulation activities were carried out in dyads (ELL \& NES) with a 10-minute duration per activity. When a participant was absent, he or she was marked as absent and a make-up session was held the next day. At the end of each simulation activity, the ELL participants were required to complete the anxiety survey and submit it to the assistant. The NESs were required to submit the simulation treatment fidelity checklist to the assistant upon completion, too.

An outside rater listened to $30 \%$ of the conducted simulations and used the researcher treatment fidelity checklist (Appendix E) to check the specific conditions that needed to be consistent in every simulation activity.

\section{Control Group (Face-to-Face) Procedures}

Each NES was assigned to her room, where she waited for the ELL to walk in and begin the simulation. Once the participant entered the room he or she found an NES sitting at a desk ready to start a simulation. The ELL participants were asked to always start the conversation, as later they will be asked to report on how they felt initiating a conversation with an NES. Once the simulation ended the NES handed the ELL the ELLSAS survey and exited the room where she would go to the lab located on the first floor of the same building. Once the ELL participant has completed the survey he/she exited the room and handed the survey to the assistant. The participant was then released to go back the his/her class at the English language institute and was informed not to 
discuss the topic of the simulation with the MUVE group waiting for their turn in the hallway.

\section{Experimental Group (Second-Life) Study Procedures}

Upon entering the computer lab NESs were required to prepare for the experimental group simulations which was a different room than where the simulations took place. The NESs then logged onto Second Life, entered the virtual classroom in which the simulation was to be carried, and waited for the ELLs to begin the simulation. Once the participant entered the room he or she found a computer on a desk already logged on to Second Life with the ELL's avatar sitting at a desk in the virtual classroom and an NES sitting at the opposite side of the desk. ELL participants were asked to always start the conversation, as later they will be asked to report on how they felt initiating a conversation with an NES. Once the activity finished, the ELL opened the door and found the ELLSAS survey pinned outside the door. Once the ELL participant completed the survey he or she exited the room and handed the survey to the assistant and was released to go back his/her class at the English language institute. The NES logged off Second Life and turned the computer off. The College of Education's Office for Informational Technology was available during the online simulations to assist with any technical difficulties. No difficulties were reported.

\section{Research Design, Instrumentation, and Data Analysis}

This section describes the research design and instrumentation used for the purpose of collecting data. Also included is a description of the data analysis methods. 


\section{Research Design}

A true experimental treatment control group repeated measures design was used to compare the two conditions. The participants were randomly assigned to a control (face-to-face simulations) or experiment (Second-Life simulations) group. The design had strong internal validity, as defined by Campbell and Stanley (1963) and Newman, Newman, Brown, and McNeely (2006). This is an appropriate design because the multiple observations within groups are not independent. This strategy allows for the separation of within group variance into variance due to occasions (time) and variance due to differences in individuals. As a result, the analysis of variance will have higher statistical power (Hinkle, Wiersma, \& Jurs, 2003). The following table (Table 1) illustrates the research design in which $\mathrm{R}=$ Random selection, $\mathrm{E}=$ experimental group (virtual Environment), $\mathrm{C}=$ control group (face-to-face), $\mathrm{X}=$ treatment (simulation), and $\mathrm{O}=$ measurement (ELLSAS questionnaire).

Immediately after each intervention and upon completion of the activity, a repeated measures survey was administered to the participants. Upon completion of the

research study, each participant in each group had completed ten simulation activities and ten questionnaires, totaling in 110 surveys. 
Table 1

Research Design

\begin{tabular}{cc}
\hline Control & Experimental \\
\hline $\mathrm{R}$ & $\mathrm{R}$ \\
$\mathrm{XC1} 1$ & $\mathrm{XE1}$ \\
$\mathrm{O} 1$ & $\mathrm{O} 1$ \\
$\mathrm{XC2} 2$ & $\mathrm{XE} 2$ \\
$\mathrm{O} 1$ & $\mathrm{O} 1$ \\
$\mathrm{XC} 3$ & $\mathrm{XE3}$ \\
$\mathrm{O} 1$ & $\mathrm{O} 1$ \\
$\mathrm{XC4}$ & $\mathrm{XE4}$ \\
$\mathrm{O} 1$ & $\mathrm{O} 1$ \\
$\mathrm{XC5}$ & $\mathrm{XE5}$ \\
$\mathrm{O} 1$ & $\mathrm{O} 1$ \\
$\mathrm{XC6} 6$ & $\mathrm{XE6}$ \\
$\mathrm{O} 1$ & $\mathrm{O} 1$ \\
$\mathrm{XC7}$ & $\mathrm{XE7}$ \\
$\mathrm{O} 1$ & $\mathrm{O} 1$ \\
$\mathrm{XC} 8$ & $\mathrm{XE} 8$ \\
$\mathrm{O} 1$ & $\mathrm{O} 1$ \\
$\mathrm{XC} 9$ & $\mathrm{XE9}$ \\
$\mathrm{O} 1$ & $\mathrm{O} 1$ \\
$\mathrm{XC10}$ & $\mathrm{XE10}$ \\
$\mathrm{O} 1$ & $\mathrm{O} 1$ \\
\hline
\end{tabular}

\section{Instrumentation}

The research used a repeated measures design (Tabachnick \& Fidell, 2007). The data collection method consisted of eight closed-ended Likert scale questions and an exit survey which included four close-ended 5-point Likert scale questions and three open ended questions about the ELLs experience in general. The repeated measures ELLSAS questionnaire was designed to measure English language speaking anxiety, and was based on self-report of perceived speaking anxiety. The self-report questionnaire is a noninvasive tool to measure perceived speaking anxiety. The questionnaire was validated for content validity by three experts as recommended by Lynn (1986), and yielded a Core 
Values Index (CVI) of 1.0. Based on the calculations suggested by Davis (1992), a CVI of 0.8 or above is recommended. The questionnaire was also practiced by a sample of three participants representing level 3 ELL at the ELI. The results showed that that the questionnaire language level was within level 3 ELLs' comprehension.

\section{Data Analysis}

The data analysis for this research was conducted through the computer package SPSS OSX Apple Macintosh. A repeated measures trend analysis one-tailed test was used to analyze the data. This design was used because it allowed for the separation of within group variance into variance due to occasions (time) and variance due to differences in individuals, which might result in higher statistical power for the analysis of variance.

\section{Chapter Summary}

This study investigated the perceived anxiety levels of adult ELLs when speaking English to Native English Speakers during simulations conducted face-to-face in the classroom and virtually in Second Life. The differences between self-perceived anxiety levels were determined through the ELLSAS that was administered to the participants after each of the ten simulation activities. The dependent variable for this study was the perceived speaking anxiety as measured by the ELLSAS.

The participants for this study were postsecondary students attending English language proficiency classes (low to high intermediate level) at the ELI at Florida International University prior to entering colleges and universities. The students were randomly selected from one level 3 oral communication class at the ELI. 
A true experimental treatment control group repeated measures design was used for this study. The pre-study procedures began with identifying the random communication level 3 class and the ELL participants. This was followed by a brief explanation provided by the researcher to the students about their potential involvement in this existing study. The ELLs who were willing to take part in the study were asked identify themselves. The pool of potential participants were asked to fill in a general information form that was used to identify those who qualify to take part based on the inclusion and exclusion criteria. Then five NESs participants were also identified and recruited from the College of Education (COE) at FIU. Lastly, the research assistant was recruited from the COE FIU to assist with the study.

After all 11 participants agreed to and signed the consent form. Then they underwent a 15-minute explanation of the nature of simulations, and were instructed as to what was expected of them. However, ELLs assigned to the experimental group (MUVE) were later given a brief 10-minute explanation of the virtual environment, and were taught how to control volume and use the speak button. Upon completion of all training, ELLs were assessed on performing the target skills on Second Life. The assistant underwent a 2-hour tutorial session, where she learned how to set up the classrooms and hardware for the activities. The NESs underwent a 60-minute tutorial session in the College of Education computer lab, where they learned how to navigate their avatar, chat, perform gestures, and log off and back on to Second Life.

The study was performed successfully according to the protocol mentioned in the above sections. Finally, $100 \%$ of the surveys were collected then, the information was entered to SPSS and analyzed. The following chapter reports the findings. 


\section{CHAPTER IV}

\section{RESULTS}

This chapter provides an analysis of the data collected for the purpose of this study. The chapter begins with a review of the research questions, followed by a description of the participants, the results of the ELLSAS questionnaire, and a report on the exit survey. The chapter concludes with a summary.

The 11 participants were randomly divided into a control group ( 5 participants) to carry out simulations face-to-face or an experimental group (6 participants) to carry out the same simulations using their avatars in Second Life. The control group participants were numbered and referred to as FF1 to FF5, while the experimental group participants were also numbered but referred to as VE1-VE6. During the study, there were six absences that were made up the following day, therefore resulting in a $100 \%$ participation rate. In addition to the ELLSAS questionnaire, participants were administered a brief exit survey containing four closed-ended and three open-ended questions related to their overall experience in this study. The research questions for this study were:

1. Is there a decrease in perceived speaking anxiety of post-secondary adult English language learners when speaking to native English speakers through simulation activities face-to-face in a classroom environment?

2. Is there a decrease in perceived speaking anxiety of post-secondary adult English language learners when speaking to native English speakers through simulation activities in a multi-user virtual environment?

3. Are there differences in decreases in the perceived speaking anxiety of post- 
secondary adult English language learners when speaking to native English speakers for those who experienced simulation activities in virtual environments and for those who experienced simulations face-to-face in a classroom environment?

\section{Description of the Sample}

The age of the participants across both groups ranged from 18 to 62 years old ( $M$ $=28.10$ years; $S D=12.85$ ), with the majority of participants less than 33 years of age. In the control group the age range was 20 to 62 , and in the experimental group it was 18 to 32. The median age for the overall group of participants was 26 years, with the median age in the control group being 26, and in the experimental being 26.5 . A total of $45.4 \%$ ( $n$ $=5)$ of participants across both groups were women, and 54.6\% $(n=6)$ were men. Within the control group 3 were women and 2 were men, and within the experimental group 2 were women and 4 were men. A frequency analysis of the participants across both conditions regions of origin indicated that $18.1 \%(n=2)$ of the participants were from South East Asia, 27.3\% $(n=3)$ from the Middle East, and 54.6\% $(n=6)$ from South America. Within the control 2 were from South East Asia, and 3 were from South America, and within the experimental group 3 were from the Middle East and 3 were from South America. When all participants across both groups were asked about languages spoken at home, $45.4 \%(n=5)$ reported speaking Spanish, 27.3\% $(n=3)$ Arabic, 9.1\% $(n=1)$ Portuguese, 9.1\% $(n=1)$ Korean, and 9.1\% $(n=1)$ Thai. Within the control group one participant spoke Korean, one spoke Thai, and three spoke Spanish. Within the experimental group one spoke Portuguese, two spoke Spanish, and three 
spoke Arabic. When asked about any MUVE activities 100\% $(n=11)$ of the participants reported that they were not part of any multi-user virtual environment.

A series of $\chi^{2}$ analyses were performed to test the possibility of systematic differences in proportional representation by demographic variable between the experiment and control groups. The first analysis examined the possible group differences in years studying English. That analysis revealed there was not a significant group difference in years speaking English $\chi^{2}(5)=4.50, p=.48$. The second analysis examined the possible group differences in weeks spent in the United States. Similarly, this analysis revealed there was not a significant group difference in weeks spent in the United States $\chi^{2}(5)=4.44, p=.49$. The third analysis examined the possible group differences in sex and revealed there was not a significant group difference in $\operatorname{sex} \chi^{2}(1)=$ $0.78, p=.38$. Finally, a fourth analysis examined the possible group differences in place of origin and revealed there was not a significant group difference in place of origin $\chi^{2}(2)$ $=4.95, p=.08$. Table 1 displays a frequency table of all participant demographics examined for this study.

\section{Treatment Fidelity}

To determine whether the conditions were followed as designed, fidelity data were collected by an independent observer using a researcher treatment fidelity checklist (Appendix E), and of the NESs using a simulation treatment fidelity checklist (Appendix F) was used to determine whether the NESs covered all the points requiring completion for each of simulation activities in both conditions. An independent observer conducted the fidelity observations on $33 \%$ of the sessions ( 3 of 10 ) and simulation fidelity on $30 \%$ (33 of 110) of the sessions. The results were $100 \%$ fidelity in both. 
Table 2

Frequency Table of Demographic Variables

\begin{tabular}{|c|c|c|c|}
\hline Demographics & Variable & Frequency & Percentage \\
\hline Age & $\begin{array}{l}\text { FF1* } \\
\text { FF2 } \\
\text { FF3 } \\
\text { FF4 } \\
\text { FF5 } \\
\text { VE1 } \\
\text { VE2 } \\
\text { VE3 } \\
\text { VE4 } \\
\text { VE5 } \\
\text { VE6 }\end{array}$ & $\begin{array}{l}22 \text { yrs. } \\
32 \text { yrs. } \\
20 \text { yrs. } \\
62 \text { yrs. } \\
26 \text { yrs. } \\
30 \text { yrs. } \\
30 \text { yrs. } \\
26 \text { yrs. } \\
18 \text { yrs. } \\
27 \text { yrs. } \\
18 \text { yrs. }\end{array}$ & $\begin{array}{l}9.1 \\
9.1 \\
9.1 \\
9.1 \\
9.1 \\
9.1 \\
9.1 \\
9.1 \\
9.1 \\
9.1 \\
9.1\end{array}$ \\
\hline Sex & $\begin{array}{l}\text { Female } \\
\text { Male } \\
\text { Total }\end{array}$ & $\begin{array}{c}5 \\
6 \\
11\end{array}$ & $\begin{array}{c}45.4 \\
54.6 \\
100\end{array}$ \\
\hline Region of Origin & $\begin{array}{c}\text { South East Asia } \\
\text { Middle East } \\
\text { South America } \\
\text { Total }\end{array}$ & $\begin{array}{c}2 \\
3 \\
6 \\
11\end{array}$ & $\begin{array}{l}18.1 \\
27.3 \\
54.6 \\
100\end{array}$ \\
\hline First Language & $\begin{array}{c}\text { Arabic } \\
\text { Korean } \\
\text { Portuguese } \\
\text { Spanish } \\
\text { Thai }\end{array}$ & $\begin{array}{l}3 \\
1 \\
1 \\
5 \\
1\end{array}$ & $\begin{array}{r}27.3 \\
9.1 \\
9.1 \\
45.4 \\
9.1\end{array}$ \\
\hline $\begin{array}{l}\text { Previous MUVE } \\
\text { Activity }\end{array}$ & $\begin{array}{l}\text { Yes } \\
\text { No } \\
\text { Total }\end{array}$ & $\begin{array}{c}0 \\
11 \\
11\end{array}$ & $\begin{array}{c}00 \\
100 \\
100\end{array}$ \\
\hline
\end{tabular}

Note: $*=$ Refers to participant's reference number. Numerals in numbers column refer to how many participants met that that particular with the exception of age, which refers to the participants' ages. 


\section{Examination of Research Questions}

\section{Research Question \#1}

Is there a decrease in perceived speaking anxiety of post-secondary adult English language learners when speaking to native English speakers through simulation activities face-to-face in a classroom environment?

For the control group (face-to-face) the data gathered for research question one demonstrated a grand mean of 25.48 (see Table 3). In addition, it illustrated that the control group reported a general decrease in mean anxiety from Simulation One to Ten.

Table 3

Control Group Descriptive Statistics $(N=5)$

\begin{tabular}{lcc}
\hline Simulation \# & Mean Anxiety Level & Std. Deviation \\
\hline 1 & 33.20 & 13.58 \\
2 & 37.60 & 17.47 \\
3 & 30.20 & 19.11 \\
4 & 23.00 & 3.39 \\
5 & 30.80 & 27.63 \\
6 & 19.40 & 11.71 \\
7 & 23.00 & 13.29 \\
8 & 27.40 & 18.33 \\
9 & 15.40 & 3.21 \\
10 & 14.80 & 6.10 \\
Grand Mean & 25.48 & $\mathrm{x}$ \\
\hline
\end{tabular}


The reported mean anxiety for the group in the first lesson was $33.20(S D=13.59)$. By Simulation Ten, the reported mean anxiety was $14.83(S D=6.10)$. This represents a reported decrease in the mean anxiety from Simulation One to Ten by 18.40 points or $55.40 \%$. However, even though there was an observable descending trend in mean perceived anxiety from the first simulation through the last (i.e., an overall reduction in mean anxiety), there was some variability in the descending trend (see Figure 1). There was also variability in the standard deviations across the simulations. The results of the repeated measures ANOVA revealed after the Huynh-Feldt epsilon correction (sphericity assumption was not met), $F(2.12,8.50)=3.25, p=.004$. Thus, the evidence suggests that there was a significant decrease in anxiety levels over time from the first face-to-face simulation to the tenth and final simulation.

Figure 1:

\section{Control Group Anxiety}

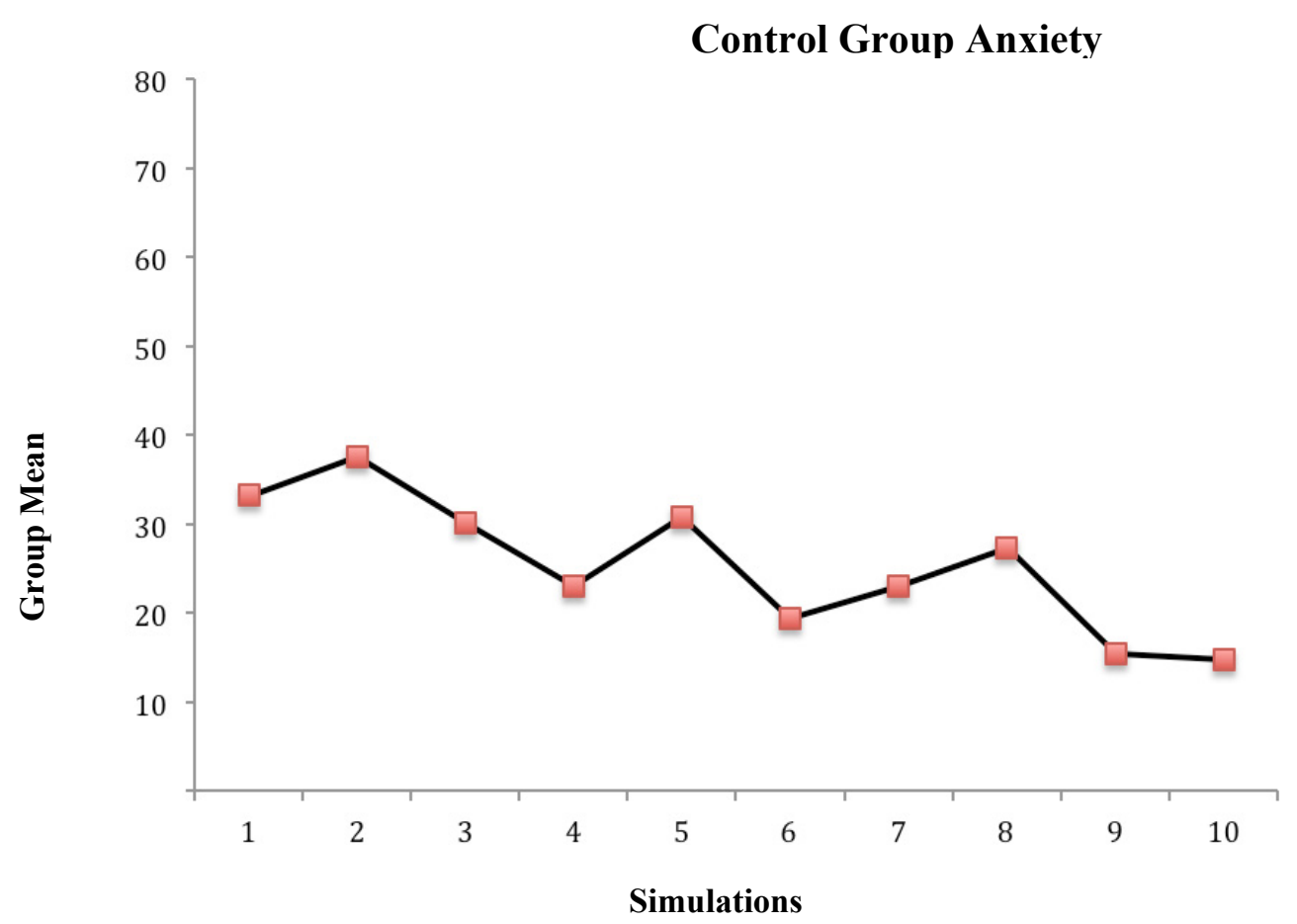




\section{Research Question \#2}

Is there a decrease in perceived speaking anxiety of post-secondary adult English language learners when speaking to native English speakers through simulation activities in a multi-user virtual environment? A multi-user virtual environment is a threedimensional virtual environment used by multiple users via avatars.

For the experiment group the data gathered for research question 2 showed a grand mean of 20.60 (see Table 4). In addition, it showed that the experimental group reported a decrease in anxiety from Simulation One to Ten.

Table 4

Experimental Group Descriptive Statistics $(N=6)$

\begin{tabular}{lcc}
\hline Simulation \# & Mean & Std. Deviation \\
\hline 1 & 27.33 & 8.80 \\
2 & 23.33 & 15.25 \\
3 & 19.50 & 11.48 \\
4 & 18.50 & 8.94 \\
5 & 22.83 & 12.61 \\
6 & 17.83 & 7.28 \\
7 & 22.83 & 9.43 \\
8 & 21.17 & 12.70 \\
9 & 18.83 & 6.52 \\
10 & 13.83 & 2.79 \\
Grand Mean & 20.60 & $\mathrm{x}$ \\
\hline
\end{tabular}


The reported mean anxiety for the experimental group in the first simulation was (27.33; $S D=8.80)$. By simulation 10 the reported mean anxiety was $13.83(S D=2.79)$ (See Figure 2). This represents a reported decrease in the mean anxiety from Simulation One to Ten by 13.50 points or $49.40 \%$. There was an observable descending trend in mean perceived anxiety from the first simulation through the last (i.e., an overall reduction in mean anxiety). As can be seen in Figure 2, there was minimal variability of performance in the mean reduction (only two simulations). In addition, there was variability in the standard deviations across the simulations. For this question, the repeated measures ANOVA results revealed after the Huynh-Feldt epsilon correction, $F(9,45)=1.83, p=$ .005 . Consequently, the evidence suggests that there was a significant decrease in anxiety levels over time from the first virtual simulation to the tenth and final simulation.

Figure 2:

\section{Experimental Group Anxiety}

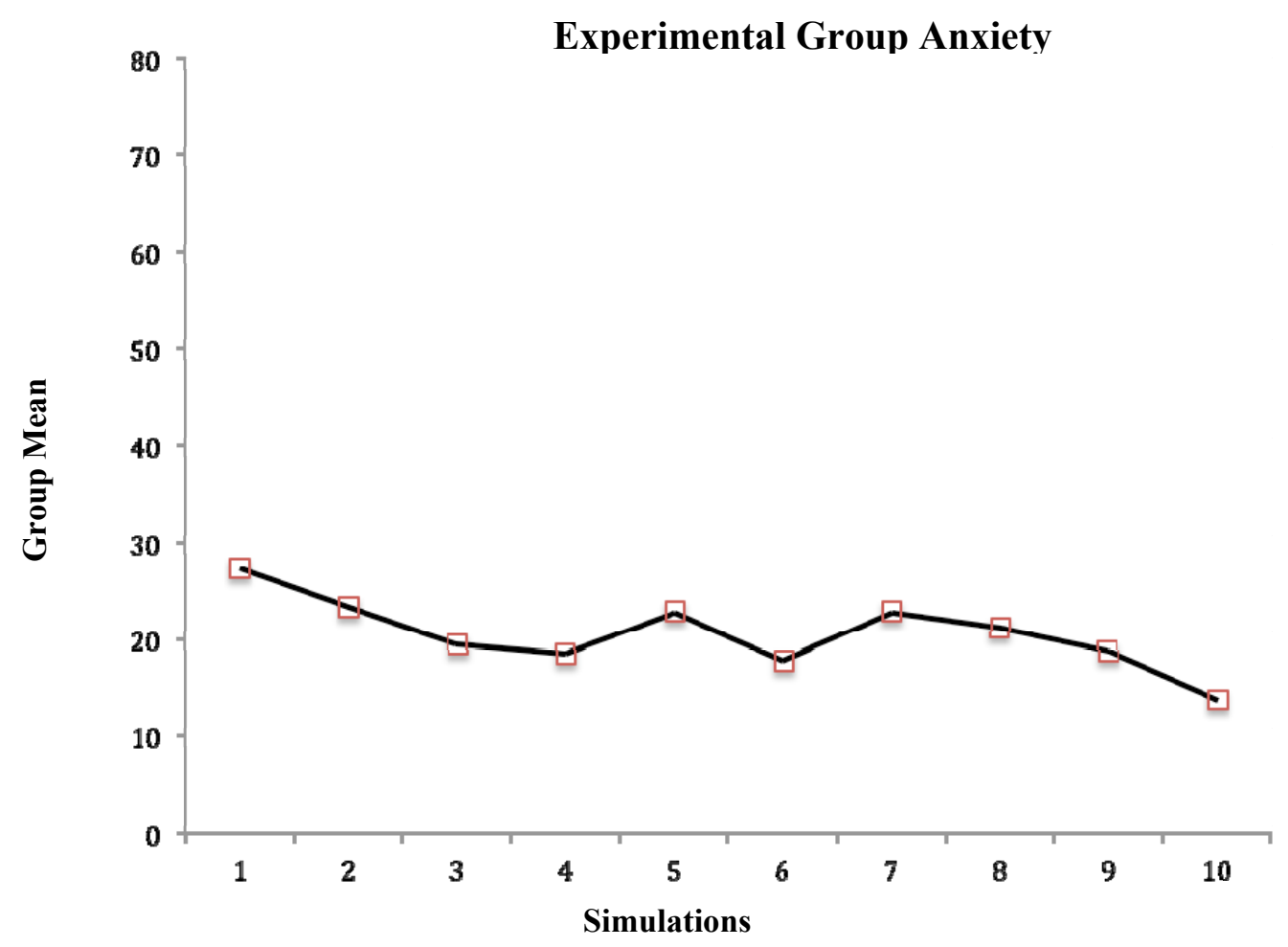




\section{Research Question \#3}

Are there differences in decreases in the perceived speaking anxiety of postsecondary adult English language learners when speaking to native English speakers for those who experienced simulation activities in virtual environments and for those who experienced simulations face-to-face in a classroom environment?

A comparison of both groups (See Table 5 and Figure 3 ) shows that the control group reported a higher grand mean in anxiety across all 10 sessions than did the experimental group (i.e., 25.48 vs. 20.60). With respect to perceived anxiety levels reported by the participants, both groups showed a descending trend line between simulations one and ten, reflecting a reduction in anxiety. While the control group had a descending trend line with variability, the experimental group had a more stable descending trend line. For this question, the repeated measures ANOVA results revealed after the Huynh-Feldt epsilon correction (sphericity assumption was not met), $F(4.07,36.6)=4.87, p=.0015)$. The effect size for differences between groups was $\eta 2=.351$. Chiefly, through testing for differences in group means, there was a significant group difference suggesting the intervention was successful. 
Table 5

General Descriptive Statistics

\begin{tabular}{|c|c|c|c|c|}
\hline Simulation \# & Group & Mean & Std. Deviation & $N$ \\
\hline \multirow[t]{2}{*}{1} & Face-to-Face & 33.20 & 13.59 & 5 \\
\hline & Virtual & 27.33 & 8.80 & 6 \\
\hline \multirow[t]{2}{*}{2} & Face-to-Face & 37.60 & 17.47 & 5 \\
\hline & Virtual & 23.33 & 15.25 & 6 \\
\hline \multirow[t]{2}{*}{3} & Face-to-Face & 30.20 & 19.11 & 5 \\
\hline & Virtual & 19.50 & 11.48 & 6 \\
\hline \multirow[t]{2}{*}{4} & Face-to-Face & 23.00 & 3.39 & 5 \\
\hline & Virtual & 18.50 & 8.94 & 6 \\
\hline \multirow[t]{2}{*}{5} & Face-to-Face & 30.80 & 27.62 & 5 \\
\hline & Virtual & 22.83 & 12.61 & 6 \\
\hline \multirow[t]{2}{*}{6} & Face-to-Face & 19.40 & 11.72 & 5 \\
\hline & Virtual & 17.83 & 7.28 & 6 \\
\hline \multirow[t]{2}{*}{7} & Face-to-Face & 23.00 & 13.28 & 5 \\
\hline & Virtual & 22.83 & 9.43 & 6 \\
\hline \multirow[t]{2}{*}{8} & Face-to-Face & 27.40 & 18.32 & 5 \\
\hline & Virtual & 21.17 & 12.70 & 6 \\
\hline \multirow[t]{2}{*}{9} & Face-to-Face & 15.40 & 3.21 & 5 \\
\hline & Virtual & 18.83 & 6.52 & 6 \\
\hline \multirow[t]{2}{*}{10} & Face-to-Face & 14.80 & 6.10 & 5 \\
\hline & Virtual & 13.83 & 2.79 & 6 \\
\hline \multirow[t]{2}{*}{ Grand Mean } & Face-to-Face & 25.48 & & 5 \\
\hline & Virtual & 20.60 & $\mathrm{x}$ & 6 \\
\hline
\end{tabular}


Figure 3:

Control and Experimental Group

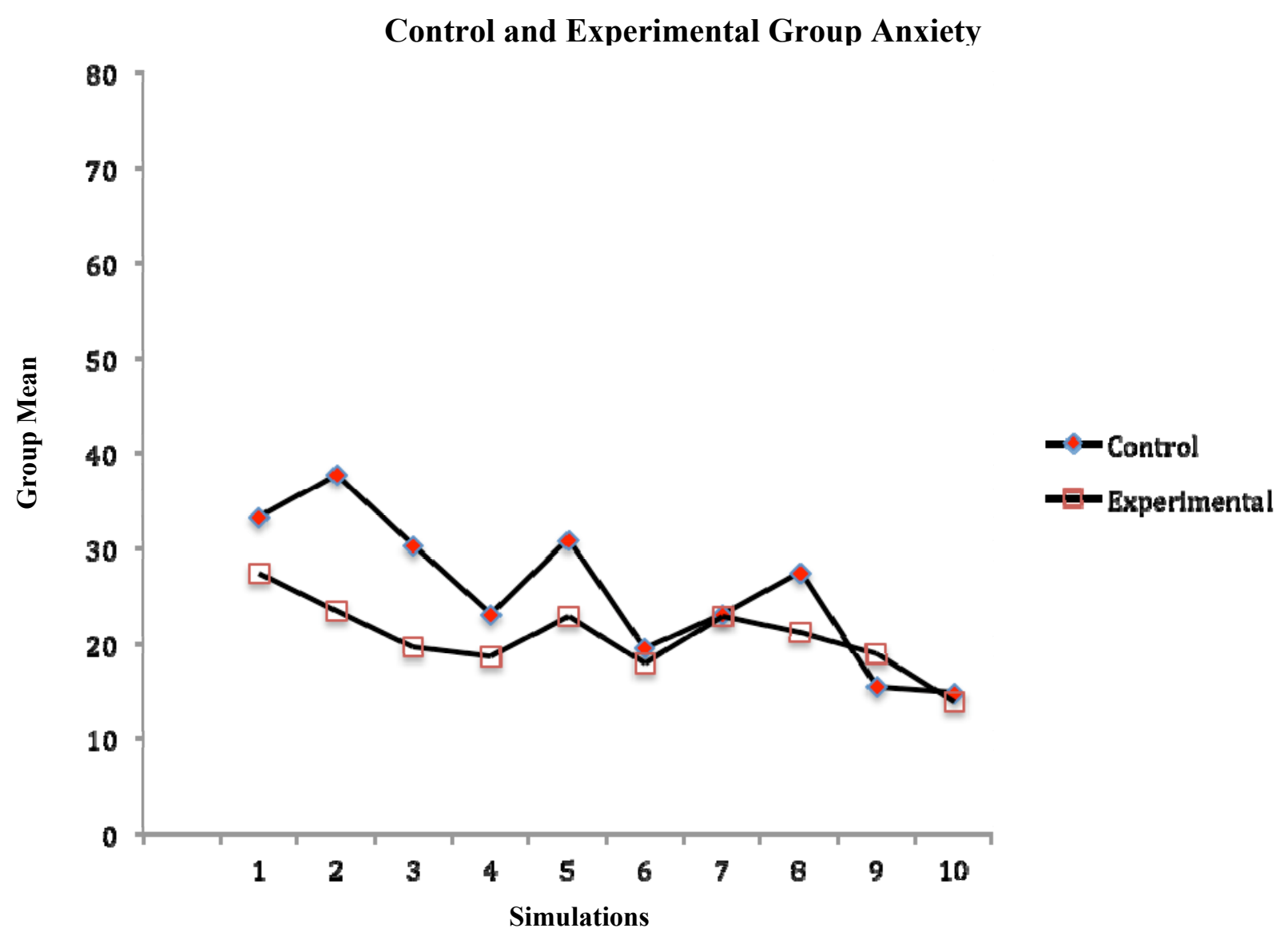

Exit Survey

The informal exit survey consisted of 7 items (Appendix H), in which participants in the control and experimental groups were verbally asked about their views on participating in simulation conversations with NESs in face-to-face (as was the case with the control group) or the MUVE Second Life (as was the case with the experimental group). The responses for the first four questions were measured by a 5-point Likert scale with 1 being "Not at all" and 5 being "Very much" related to the extent to which 
their anxiety was or was not reduced by participating in their study condition. The openended questions asked them to identify specific components of their condition that were or were not helpful and for additional information. More specifically, the quantitative questions asked how much did participating in face-to-face or Second Life conversations with an NES:

1. Reduce your anxiety to start talking with a native English speaker at the English Language Institute classroom?

2. Reduce your anxiety to start talking with a native English speaker in places other than the English Language Institute classroom?

3. Reduce your anxiety when answering questions by native English speakers at the English Language Institute?

4. Reduce your anxiety when answering questions by native English speaker outside the English Language Institute classroom?

A summary of the results of the first four (Exit Survey) Interview questions can be found in Table 6. The first two questions related initiating conversations with NESs inside and outside of the classroom setting. Question One asked how much did participating in the simulation activities reduce their anxiety to speak to an NES in their classroom. The control group had a mean score of 3.60, while the experimental group had a slightly higher mean score of 4.00 (i.e., 0.40 higher). When asked whether the simulation activities reduced their anxiety to speak to an NES outside your classroom, the control group had a mean score of 3.40 , while again the experimental group had a slightly higher mean score of 3.83(i.e., 0.43 higher). 
Table 6

Mean and Range Results of Quantitative Component of Exit Survey

\begin{tabular}{|c|c|c|}
\hline Exit Survey Questions & $\begin{array}{l}\text { Control } \\
\text { Group }\end{array}$ & $\begin{array}{c}\text { Experimental } \\
\text { Group }\end{array}$ \\
\hline $\begin{array}{l}\text { 1. How much did participating in face-to-face (or } \\
\text { MUVE) simulation reduce your anxiety to speak } \\
\text { to an NES in your classroom? }\end{array}$ & $\begin{array}{l}3.60 \\
(2-5)\end{array}$ & $\begin{array}{l}4.00 \\
(2-5)\end{array}$ \\
\hline $\begin{array}{l}\text { 2. How much did participating in face-to-face (or } \\
\text { MUVE) reduce your anxiety to speak to an NES } \\
\text { outside your classroom? }\end{array}$ & $\begin{array}{l}3.40 \\
(3-4)\end{array}$ & $\begin{array}{l}3.83 \\
(2-5)\end{array}$ \\
\hline $\begin{array}{l}\text { 3. How much did participating in face-to-face (or } \\
\text { MUVE) simulation reduce your anxiety when } \\
\text { answering questions by NES in your classroom? }\end{array}$ & $\begin{array}{l}3.60 \\
(2-4)\end{array}$ & $\begin{array}{l}3.83 \\
(2-5)\end{array}$ \\
\hline $\begin{array}{l}\text { 4. How much did participating in face-to-face (or } \\
\text { MUVE) simulation reduce your anxiety when } \\
\text { answering questions by NES outside your } \\
\text { classroom? }\end{array}$ & $\begin{array}{l}3.40 \\
(2-5)\end{array}$ & $\begin{array}{l}3.33 \\
(2-5)\end{array}$ \\
\hline
\end{tabular}

Note: The top number refers to the mean on a 5-Point Likert scale. The bottom numbers is the range of responses.

The third and fourth exit survey questions related to responding to conversations with NESs inside and outside of the classroom setting. With respect to how much did participating in the simulation activities reduced their anxiety when responding to NESs in their classroom, the control group had a mean score of 3.60, while the experimental group had a slightly higher mean score of 3.83 , which is 0.23 higher than the control group. In question four, when asked whether the simulation activities reduced their anxiety when responding to NES outside your classroom, the control group had a mean score of 3.40, while the experimental group had a comparable mean score of 3.33, which is 0.07 lower than the control group. 
In closing, with respect to the four quantitative survey questions. Both the control and experimental groups reported relatively similar means, with the experimental group having slightly higher means in the first three questions. Even though for the last question the control group reported a higher mean than the experimental group, the difference was 0.07 points.

With respect to the three open-ended questions, questions five to seven of the exit survey, participants were asked three questions (Note: Either Face-to-Face or Second Life was in the question, depending on the participant's condition). In the following section each question discussed, and the participants' feedback is provided.

\section{Question 1: What Parts of the Face-to-Face or Second Life Simulations Helped You Talk with Native English Speakers?}

According to the survey participants from the control (face-to-face group) generally gave positive feedback. Participant FF1 stated, "When I became with the NES, I felt that I was able to speak more comfortably." FF2 expressed that having the chance to speak with an NES helped her lower her anxiety when talking to other people. As for participant FF3, she reported that when the NES asked her questions and asked for clarification is when she felt face-to-face simulations helped. Participants FF4 and FF5 both agreed that the topics of the face-to-face simulations helped them speak more to the NES, for example FF4 stated, "The different topics helped me to speak more with native English speakers." and FF5 asserted the when speaking about his hobbies and his country he found it easier to speak to the NES.

Participants from the experimental (MUVE) group had similar positive responses to the control group participants. VE1, VE2, and VE3 expressed that conducting 
simulation on Second Life enabled them to practice their English and also gave them confidence and courage to speak to NESs. VE4 shared the same views about gaining courage to speak to NESs and added that she felt comfortable talking through an avatar because the NES could not see her. VE3 and VE6 gave the same feedback, they both stated, "It was ok to make mistakes" while speaking to NESs. VE 5 gave a more elaborate response to this question by stating, "It broke barriers." He also added that in Second Life facial expressions that could potentially be negative in person are absent, which helped him practice.

\section{Question 2: What Parts of the Face-to-Face or Second Life Simulations Did Not Help You Talk with Native English Speakers?}

Two participants (FF2 \& FF3) had nothing negative to report about face-to-face simulations, on the contrary they stated, "Everything helped." However, three other participants (FF1, FF4 and FF5) were in agreement that they felt the topics didn't help them speak to NESs. Participant FF4 felt that the second simulation was the most difficult and didn't help as much as other simulation with speaking to NESs.

Out of the six experimental group participants, four (VE1-VE4) gave similar feedback as the control group to this question. They all stated that there was nothing negative to report, and that everything in the MUVE simulations helped. Participant VE5 stated that in Second Life, he couldn't see the NES's facial expressions, which made the interaction more challenging. Additionally, he added that he could not make gestures to help him speak to the NES. VE6 stated, "It did not help me practice my grammar, it only helped me practice my speaking skills." 


\section{Question 3: Is There Anything Else That You Want to Tell Me About Participating in Face-to-Face or Second Life Second Life Simulations?}

Three control group participants expressed that face-to-face simulations helped them become more confident when speaking to NESs. They also stated that the simulations were good practice for their English. Participant FF2 expressed that she got nervous when the NESs spoke fast, and that it was hard for her to come up with some questions to ask the NES during simulations. FF4 simply inquired about the purpose of this study, and expressed his desire to know the findings. He stated, "Where did the students feel better, in the classroom or in Second Life?"

Four of six experimental group participants stated that the simulations were interesting and they enjoyed them, making statements such as, "It was fun and interesting.", "It was a great experience.", and "This is a good way to practice with NESs." Only one participant complained that there was too much background noise during the simulations, that is he could hear other NESs speaking to other ELLs (Note: For this study, all NESs were in the same lab at the same time communicating with their ELL via Second Life. One other participant (VE6) refrained from giving his comments.

\section{Summary}

In summary, this chapter provided a detailed analysis of the data collected for the purpose of the research questions. The 11 participants were randomly assigned into a face-to-face environment control $(N=5)$ or a MUVE experimental group $(N=6)$, where they carried out ten simulations, each group in their environment. A series of $\chi^{2}$ analysis were performed to test the possibility of systematic differences in proportional representation by demographic variable between the experiment and control groups. The 
analysis revealed there was no significant group difference in years speaking English $\chi^{2}(5)=4.50, p=.48$, in weeks spent in the United States $\chi^{2}(5)=4.44, p=.49$, in sex $\chi^{2}(1)$ $=0.78, p=.38$, or in place of origin $\chi^{2}(2)=4.95, p=.08$.

In regards to the control group, the reported grand mean anxiety score, which was the mean across all ten simulations) of 25.48. The mean score after the first simulation was $33.20(S D=13.59)$. By Simulation Ten, the reported mean anxiety score was 14.83 $(S D=6.10)$. This represents a general decrease in mean anxiety from Simulation One to Ten. However, there was an observable variability in the descending trend line in mean scores. The results of the repeated measures ANOVA revealed after the Huynh-Feldt epsilon correction (sphericity assumption was not met), $F(2.12,85)=3.25, p=.004$. Thus, the evidence suggests that there was a significant decrease in anxiety levels over time from the first face-to-face simulation to the tenth and final simulation.

Data concerning the experimental group showed that the experimental group reported a decrease in anxiety from Simulation One to Ten. The reported grand mean anxiety score, which was the mean across all ten simulations) was 20.60. The reported mean anxiety for the experimental group in the first simulation was $(27.33 ; S D=8.80)$. By Simulation Ten, the reported mean anxiety was $13.83(S D=2.79)$. This also represents a general decrease in mean anxiety from Simulation One to Ten. However, there was minimal variability in the descending trend line in mean scores (only two simulations). The repeated measures ANOVA results revealed after the Huynh-Feldt epsilon correction (sphericity assumption was not met), $F(9,45)=1.83, P=.005$. Consequently, the evidence suggests that there was a significant decrease in anxiety levels over time from the first virtual simulation to the tenth and final simulation. 
When comparing face-to-face and MUVE simulations, both groups showed a descending trend line from Simulations One to Ten, reflecting a reduction in anxiety. However, the control group reported a higher mean in anxiety across all ten sessions than did the experimental group (i.e., 25.48 vs. 20.60). The repeated measures ANOVA results revealed after the Huynh-Feldt epsilon correction (sphericity assumption was not met), $F(4.07,36.6)=4.87, p=.0015$. The effect size for differences between groups was $\eta 2=$ .351. Mainly, there was a significant group difference suggesting the intervention was successful.

In regards to the informal exit interview (Exit Survey), participants across both groups gave their feedback. In summary, some control group participants expressed that the simulations gave them more confidence, courage, and lowered their anxiety for future face-to-face interactions with NESs. Others were differed in their feedback. While some expressed that some topics didn't help with their English skills, others stated that the simulations were good practice. As for the experimental group, more positive feedback was received. Most participants voiced their satisfaction with simulations conducted on Second Life, explaining that these simulations helped them practice their English skills, lowered their anxiety, and they felt comfortable speaking through avatars because it hid the NESs possible negative expression while allowing them (participants) to make mistakes without getting embarrassed. Most experimental group participants had nothing negative to report about the MUVE simulation, except one who expressed that the absence of gestures and expressions made the interaction more challenging, and another participant that believed these simulations did not help him with his grammar skills. Overall, the feedback collected from the informal exit interview generated feedback that 
may be associated with the ELLSAS survey, the associations are made in the next chapter. 


\section{CHAPTER V}

\section{DISCUSSION}

This chapter presents a discussion of the results of this study. First presented is a brief overview of the study followed by a summary of the results and a comparison to the literature related to face-to-face and virtual language instruction simulations, particularly with respect to speaking anxiety. Next, presented are the implications for practice and limitations of the study. Finally, suggestions for future research and a summary are provided.

This study investigated the perceived anxiety of 11 adult post-secondary ELLs after participating in simulations with NESs conducted face-to-face in a classroom environment (control group) or in a multi-user virtual environment (experimental group) using the MUVE Second Life. Perceived anxiety was measured using the ELLSAS scale that was administered at the end of each of the ten simulation sessions in either condition. In total, data were collected and analyzed on a total of 110 surveys, across 10 simulations, with 11 participants (6 in the experimental group and in the control group). After all simulations were completed, an informal exit interview was administered that contained four closed-ended and three open-ended questions related to their overall experiences in this study.

\section{Summary of the Results}

The 11 participants were randomly assigned to either the control or experimental groups. An analysis revealed there was no significant group difference in years speaking English, weeks spent in the United States, sex, or in place of origin between the two groups. 
In regards to the grand mean anxiety score (mean score across all ten simulations), the control group had a mean of 25.48 , while for the experimental group it was a 20.60 , a $20 \%$ difference. Therefore, with respect to the grand mean, the experimental group reported less overall anxiety than the control group. However it should be noted that the control group reported higher anxiety at the end of the first simulation than did the experimental group (i.e., 33.20 vs. 27.333).

Overall, the results of this study showed that participating in simulations in either the face-to-face or MUVE conditions resulted in a decline of the participants' reported speaking anxiety. Further, the results show that the control group had a steeper decline as they began at a higher reported speaking anxiety level than the experimental group. The control group reported a decrease in speaking anxiety that started with a means of 33.20 and ended with 14.80 , while the experimental group reported a decrease in speaking anxiety that started with a means of 27.33 and ended with 13.83 . However, both groups showed similar anxiety levels by the last simulation activity. It was noticed that the control group showed increasing anxiety for Simulations 2, 5, and 8 . These simulations shared a topic that pertained to academics. It seemed like the mentioned simulations evoked anxiety for the control group more that the experimental group. The following makes a connection of the results to the existing literature. Also, the informal exit interview revealed that participants from both groups were satisfied with simulation activities and generally believed that they helped them practice their English speaking skills and prepared them for future interactions with NESs

The results of this study, including the similarities and differences between the groups, support and extend the existing literature. First, given that both groups reported a 
reduction in perceived anxiety from Simulation One to Ten, these findings imply that participating in simulation activities between ELLs and NESs can have an effect on the reduction in perceived speaking anxiety by ELLs. The reduction in anxiety experienced by the control group, aligns with the previous literature in that, TBLT activities such as simulations can have a positive effect on reducing anxiety amongst ELLs (Izadpanah, 2010; Meng \& Cheng, 2010; Oxford, 2006). In the exit interview, participants from the control group made statements such as, "When I became with the NES, I felt I was able to speak more comfortably." Another participant expressed that having the chance to speak with an NES helped her lower her anxiety when talking to other people. In general, control group participants gave positive feedback about face-to-face simulations with NESs.

Secondly, the similar reduction in perceived anxiety reported by the experimental group suggests that virtual environments may represent a relaxed learning environment which could initially reduce anxiety, and be advantageous for second language learners (Roed, 2003; Zheng et al., 2009; Henderson et al., 2009). Participants' feedback from the informal exit interview also supports the assertion that virtual environments may offer a reduction in anxiety for ELLs when speaking to NESs. Most of the experimental group participants believed that Second Life lowered their anxiety, gave them courage and confidence to interact with NESs.

\section{Task-Based Language Teaching Language Development and Anxiety}

As mentioned earlier in the literature review, TBLT has been shown to have an effect on reducing language anxiety (Izadpanah, 2010, Meng and Cheng, 2010, Oxford, 2006). Findings from this study support arguments by Izadpanah in that first, TBLT 
provides the design of communicative tasks that focus on the learner's actual language use. Second, TBLT promotes the use of "content oriented meaningful activities" that enable the learner to engage with and utilize language as a means to promote language competency and confidence. Last, the uniqueness of TBLT in that it provides a bridge between pedagogy of language acquisition and the real world. The use of simulation activities, which are considered to be TBLT combined with the decreased language anxiety reported by all participants, provides support for Izadpanah's assertions. In addition, this study supports findings by Meng and Cheng (2010). Their study found that students preferred two-way tasks that enabled them to interact with peers, similarly this study reports the same findings. Participants in this study across both groups reported that interacting with an NES gave them a chance to practice their English and reduce their anxiety. The difference between the two studies is that this study paired ELLs with NESs instead of peers.

This study also aligns with Oxford's (2006) overview of TBLT. Oxford notes that TBLT provides a means for learners to connect past learning experiences with their current instruction on language development. Oxford adds that TBLT constructs a structured pedagogical environment, which in turn has positive implications and may provide a foundation for reducing anxiety. This study supports Oxford's views in that simulations were constructed with structured nature allowing a foundation for improving participant engagement and reducing student anxiety. The findings also support Long's (1981) assertion that interaction generates and enhances the development of language fluency. As finding from this study suggest that most participants, especially ones from the control group reported that interactions with NESs allowed them to practice their 
English language skills. This study supports Long's assertion in that it was built entirely on ELLs interactions with NESs through simulations in two different environments.

Rinalli (2008) states that in the development of English language learning, simulations and roleplaying activities have been shown to be useful in reducing language anxiety and improving language competence. This study used ten simulation activities that represented real life academic or social situations in which participants in these simulations reported that it reduced their speaking anxiety and that it helped them practice their English language. This study adds to the literature information concerning ELLs' interaction with NESs. Most studies were conducted with ELLs communicating with other ELLs. In this study, ELLs interacted with NESs. Participants from the experimental and control groups conveyed that speaking to NESs was a positive element in practicing their English speaking skills during the simulations.

\section{Virtual Reality Environments and Anxiety}

This study conducted simulation activities in face-to-face classroom environments and in Multi-User Virtual Environments (MUVEs). In this study, participants from the experimental (MUVE) group reported lower levels of anxiety than the control (face-toface) group. These findings align with findings by Satar and Ozdener (2008) that computer-mediated communication in this case MUVEs reduce speaking anxiety. This study was partially built on Satar and Ozdener's study. In their study, 90 ELLs participants between the ages of 16-17 were divided into three groups, voice chat, text chat, and control. Participants from the voice chat group engaged in 45-minute chat sessions in dyads with other ELLs in a computer mediated communication program built specifically for their study. Satar and Ozdener found that both voice chat and text chat 
groups increased in speaking proficiency, but the voice chat group reported higher anxiety than the text chat group. Both studies share similar components in which both assessed the effects of computer-mediated communications on speaking anxiety as measured by a language anxiety scale. The differences between both studies are fourfold. First, this study used the MUVE of Second Life, whereas in the other study a specific website was built for the interactions. Second, this study only used voice communication whereas in the other voice and text were used. Third, this study paired ELLs with NESs, whereas the other study paired ELLs were paired together. Fourth, this study used the ELLSAS developed by the researcher to test for speaking anxiety, whereas the other used the Foreign Language Speaking Anxiety Scale developed by Horwitz et al. (1991). The limited research on simulation and speaking anxiety for adult ELLs seems to support findings by this study in that simulations, simulations in MUVE, and TBLT activities reduce anxiety.

Another study by Kovacic et al. (2007) supplemented traditional face-to-face teaching with online wiki-based online tasks. In their study 113 undergraduate participants took part in an English for specific purposes course. Their study found that participants favorably and positively evaluated the online tasks and learning method. The existing study shares similar features in that it used an online environment to supplement a face-to-face environment and it targeted English language learners. Differences between the two studies are that this study used post-secondary ELLs and the other used undergraduate ELLs, and this study used interaction instead of wikis (writing activities). 


\section{Discussion of Findings from Theoretical Perspectives}

From a theoretical perspective, the findings of this study align with the Affective Filter Hypothesis (Krashen, 1985) and the theoretical frameworks of the Socio-Affective Filter (Dulay \& Burt, 1977). Krashen as well as Dulay, and Burt theorized that high motivation and self-confidence combined with low anxiety produce a better-equipped language learners. Even though this study did not assess language proficiency, based on the Affective Filter Hypothesis participants from both groups should be better equipped for language learning due to their reported lower anxiety levels. Additionally, the overall lower reported anxiety levels by the experimental group are in support with assertions that virtual environments represent a more relaxed and stress-free atmosphere than traditional classroom environments which could subsequently reduce anxiety and be advantageous for second language learners (Roed, 2003; Zheng et al., 2009; Henderson, et al., 2009).

Secondly, the informal exit survey revealed participants from both groups reported that simulations helped them practice English by interacting with native English speakers, which aligns with the Interaction Theory Hypothesis (Long, 1985) and the Zone of Proximal Development (Vygotsky, 1978). Long theorized that interaction and communication between English language learners and native English speakers assist the language development of the language learner. Moreover, the participants' reports are in

agreement with Vygotsky's assertion that that learning occurs through collaboration with more capable peers.

Based on the informal exit interview, two participants believed that face-to-face simulations helped lower their anxiety and gave them more confidence to speak to native 
English speakers in the future. Participants from the experimental group $(66 \%$ or $4 / 6)$ believed that engaging in simulations in Second Life helped lower their anxiety, and gave them courage and confidence to speak to NESs.

\section{Implications for Practice}

Results from this study have important implications for conducting simulations with native English speakers in both face-to-face and in MUVEs. The current study found that simulations conducted face-to face and in a MUVE had overall positive effects on adult ELLs' reported speaking anxiety. Simulations conducted face-to-face have implications for practice in English language pedagogy. First, the results suggest that language instructors consider using simulations as part of their language classroom. Due to its flexible adaptation, it is recommended that simulations be used to extend or supplement language activities. Second, language instructors should consider pairing their ELLs with NESs in dyads, as ELL participants in this study expressed their satisfaction in the simulation activities. Third, based on the feedback given by ELL participants from the face-to-face group, language instructors should consider choosing topics that students can relate to personally, e.g. talking about their country, their interests, or their future plans.

Simulations conducted in the MUVE of Second Life have also had overall positive effects on ELLs' speaking anxiety levels. Based on the findings and feedback received in this study, language instructors are encouraged to introduce such technology to their language classrooms when available. Second Life is a software that can be downloaded for free and would fit to work with most current computers with a good internet connection. Second Life assignments can be given as homework assignments for 
those who have the technology at home. Due to the availability of many different places and Second Life users, ELLs could have many opportunities to practice their English speaking with reduced speaking anxiety levels.

Another consideration for English language instructors would be to use a MUVE for language simulations initially and to follow that up with a face-to-face simulation after the ELLs have adapted to the nature of interaction with NESs. This could be useful given the initial lower reported anxiety levels of the experimental group. Even though both groups reported a decreased speaking anxiety throughout the simulation activity, the experimental group reported a lower anxiety level than the control group on the first simulation activity. It would help the students establish an understanding of the activity and a certain level of comfort that would ease the transition to a face-to-face interaction with an NES.

An alternative recommendation would be to supplement one environment with the other. The MUVE might be considered for ELLs who exhibit higher speaking anxiety as an exercise to help them acclimate to simulations and interactions with NESs. As most experimental group participants in this study reported, the anonymity factor during the simulation allowed them for an encouraging and less threatening interaction. Supplementing both environments may decrease reported speaking anxiety for adult ELLs.

\section{Limitations of the Study}

Some limitations existed pertinent to this study. First, there was limited diversity of the participants. Participants in this study belonged to only three regions, South America, Middle East, and South East Asia. Coincidently through random assignment, all 
three Middle Eastern participants were assigned to the experimental group, and both participants from Far East Asia were placed in the control group. Also, in this study, all of the NESs were college-age women, thereby limiting the study.

An additional limitation to the study was the level of difficulty for at least two of the simulation activity topics. For example, participants from both groups stated that simulations five and seven were very challenging. The survey revealed that the participants in both groups reported an increase in their speaking anxiety levels for these two simulation activities. More consideration should have been given to relevance and difficulty of the topics selected.

The results of this study are limited based on the on small number of participants. Even though there were 110 sessions (10 sessions across 11 participants), had the group sizes been larger, confidence in the generalization of the findings would be stronger.

Finally, the most substantial limitation was the fact that no anxiety assessment was given prior to the first simulation. At the end of Simulation One, the control group reported higher anxiety than the experimental group. However, because no pre-anxiety measure was given prior to the first simulation, it is unclear whether the participants in the group started the study generally more anxious than those in the experimental group or whether the first simulation resulted in less anxiety for experimental group participants.

\section{Suggestions for Future Research}

There are several recommendations for future research, including those related to the study's participants. First, all participants belonged to three regions of origin, therefore, participants from other regions should be considered for future research. With 
respect to the sample size, a higher number of participants in future research should be considered to yield more statistical power. A larger sample size may include more diversity also. Finally, all the ELLs in this study functioned at level three (intermediate) English proficiently level. Comparing face-to-face simulations conducted with ELLs who function at lower or higher levels of English speaking would add to the limited research in this area.

Future face-to-face or MUVE simulation research (and/or research that compares the two) should investigate the most beneficial types of ELL and NES pairings. In this study, all NESs were college-age women. Future research should include men and women NESs of various ages and investigate whether some types of pairings are more effective than others.

With respect to the face-to-face and MUVE simulations, several modifications could be made to extend the research. First, additional research could include the use of other types of MUVEs and/or additional uses of components of Second Life not used in this study. For example, future research could have participants building their own avatars, explore different Second Life destinations than a site built by the researcher, engage in more social activities with other avatars, and/or explore different activities in Second Life such as quests or virtual tours. Also, additional research might investigate the effects of using a combination of face-to-face and MUVE simulations on speaking anxiety. Perhaps, combining their use will provide additional benefits. Another condition modification might be to start both groups in the face-to-face classroom environment then introducing the MUVE intervention to one group, or visa versa. 
In this study, the dependent variable was speaking anxiety. However, there are other characteristics of speaking that could be measured in future research. For example, future studies might measure the quality and/or quantity of ELL/NES interactions such as length of interactions, numbers of unique words spoken, numbers of interactions initiated, ELL latency time in responding to NES initiated conversations. Also, future research should include some pre-study English anxiety assessment. This could help determine whether both groups started with equivalent levels of English speaking anxiety, thereby adding more confidence to the results.

Future researchers should place more consideration into the difficulty or interest levels of the simulation topics, as participants from this study showed more interest in some topics than others and/or had found some more challenging than others. Alternately, researchers might consider purposely identifying and selecting some more basic and more challenging conversation topics and comparing the effects of the two condition simulations on them to see if they might be more effective with one or the other.

\section{Summary}

In this study participants were assigned to two different groups, control (face-toface) and experimental (MUVE), and were asked to interact with NESs through ten simulation activities. The results of this study demonstrated that overall the use of simulations for reducing adult ELLs speaking anxiety when speaking to NESs was successful. Findings from this study support results from other studies that shared similar aspects and variables. It supports other studies in that simulations are shown useful for language anxiety reduction (Rinalli, 2008; Oxford, 2006), and that simulations in MUVEs may provide an initial reduction in speaking anxiety for the ELLs. The findings 
also align with the theory that interaction and communication between ELLs and NESs assist in language development (Vygotsky, 1978). Even though language development was not assessed in the existing study, the positive feedback reported about the interactions by members of both groups indicates that participant might indirectly benefit for language development.

This study suggests that language instructors consider using simulations as part of teaching language, pair ELLs with NESs, and consider choosing topics that appeal to the ELLs interest for the simulations. This study also suggests supplementing one environment with the other, more specifically starting with a MUVE for ELLs exhibiting higher speaking anxiety levels.

Future researchers in this area should consider focusing on a specific origin of region, a different English speaking level, and a larger sample size. It also suggests that MUVEs be explored and utilized more as they provide assortment environments, users, and activities that can be applied to assist in language teaching. 


\section{REFERENCES}

Aida, Y. (1994) Examination of Horwitz and Cope's construct of foreign language anxiety: The case of students of Japanese. Modern Language Journal, 78(2), 155168.

Aliakbari, M., \& Jamalvandi, B. (2010). The impact of "role play" on fostering learners' speaking ability: A task-based approach. Journal of Pan-Pacific Association of Applied Linguistics, 14(1), 15-29.

Allen, R., \& Franklin, J. (2002, Fall). Acquiring English: Schools seek ways to strengthen language learning. Curriculum Update, 1-10. (ED47136)

Aoyama, K., \& Guion, S. G. (2007). Prosody in second language acquisition: An acoustic analysis on duration and F0 range. In O.-S. Bohn \& M. J. Munro (Eds.), The role of language experience in second-language speech learning: In honor of James Emil Flege (pp. 281-297). Amsterdam, The Netherlands: John Benjamins.

Au, W. (2009). Social studies, social justice: W(h)ither the social studies in high-stakes testing? Teacher Education Quarterly, 36(1), 43-58.

Bailey, K. M., \& Santos, M. G. (2009) Research on ESL in U.S. community colleges: People, programs, and potential. Ann Arbor, MI: The University of Michigan Press.

Bakar, N. A., Latif, H., \& Ya'acob, A. (2010). ESL students' feedback on the use of blogs for language learning. Southeast Asian Journal of English Language Studies, 16(1), 120-141.

Baker, J., Parks-Savage, A., \& Rehfuss, M. (2009). Teaching social skills in a virtual environment: An exploratory study. Journal for Specialists in Group Work, 34(3), 209-226.

Barkand, J., \& Kush, J. (2009). GEARS a 3D virtual learning environment and virtual social and educational world used in online secondary schools. Electronic Journal of e-Learning, 7(3), 215-224.

Batalova, J., \& McHugh, M. (2010). Number and growth of students in US schools in need of English instruction. Washington DC: Migration Policy Institute.

Beckman, M. E. (1986). Stress and non-stress accent. Dordrecht, Holland: Foris.

Black, R. W. (2005). Access and affiliation: The literacy and composition practices of English language learners in an online fanfiction community. Journal of Adolescent and Adult Literacy, 49(2), 118-128. 
Bloch, J. (2007). Abdullah's blogging: A generation 1.5 student enters the blogosphere. Language Learning \& Technology, 11(2), 128-141. Retrieved from http://lit.msu.edu/vol11 num2/pdf/bloch.pdf

Blumenthal, A., \& Machado, C. (Eds.). (2006). Perspectives on community college ESL, Vol. 2. Alexandria, VA: TESOL.

Bradley, T., \& Lomicka, L. (2000). A case study of learner interaction in a technologyenhanced language learning environment. Journal of Educational Computing, 11(3), 247-368.

Bricken, M., \& Byrne, C. M. (1993). Summer students in virtual reality: A pilot study on educational applications of virtual reality technology (Report). Seattle, WA: University of Washington, Human Interface Technology Laboratory.

Bronack, S., Riedl, R., \& Tashner, J. (2005, September). Innovation in learning assumptions about teaching in a virtual world. Paper presented at the International College Teaching Methods and Styles Conference, Reno, NV.

Brough, J., Schwartz, M., Gupta, S., Anand, D., Kavetsky, R., \& Pettersen, R. (2007). Towards the development of a virtual environment-based training system for mechanical assembly operations. Virtual Reality, 11, 189-206.

Brown, H. D. (2007). Teaching by principles: An interactive approach to language pedagogy. Englewood Cliffs, NJ: Prentice Hall Regents.

Bull, G., Bull, G., \& Kajder, S. (2004). Tapped in. Learning \& Leading with Technology, 31(5), 34-37.

Burninger, V. W. (2000). Development of language by hand and its connections with language by ear, mouth, and eye. Topics in Language Disorders, 20(4), 65-84.

Campbell, C. M., \& Ortiz, J. (1991). Helping students overcome foreign language anxiety: A foreign language anxiety workshop. In E. K. Horwitz \& D. J. Young (Eds.), Language anxiety: From theory and research to classroom implications (pp. 141-150). Englewood Cliffs, NJ: Prentice Hall.

Campbell, D., \& Stanley, J. (1963). Experimental and quasi-experimental designs for research. Chicago, IL: Rand McNally.

Center for Applied Linguistics. (1979). English language testing. Retrieved from http://rcd.ncela.gwu.edu/bibliographies/BE010658 
Celce-Murcia, M. (1991). Teaching English as a second or foreign language (3rd ed.). Boston, MA: Heinle \& Heinle.

Chaka, C. (2009). Portable handheld language learning: from CALL, MALL to PALL. In R. de Cássia Veiga Marriott \& P. Lupion Torres (Eds.), Handbook of research on e-learning methodologies for language acquisition (pp. 539-553). Hershey, NY: Information Science Reference.

Chaney, A. L., \& Burke, T. L. (1998). Teaching oral communication in grades K-8. Boston, MA: Allyn \& Bacon.

Cheng, Y. S., Horwitz, E. K., \& Schallert, D. L. (1999). Language anxiety: Differentiating writing and speaking components. Language Learning, 49(3), 417-446.

Chesterfield, R. A., \& Chesterfield, K. B. (1985). Natural order in children's use of second language learning strategies. Applied Linguistics 6(1), 45-59.

Clarke, J., \& Dede, C. (2005, April). Making learning meaningful: An exploratory study of using multi-user environments (MUVEs) in middle school science. A paper presented at the annual meeting of the American Educational Research Association, Montreal. Retrieved from http://muve.gse.harvard.edu /rivercityproject/documents/aera_2005_clarke_dede.pdf

Clarke, J., Dede, C., Ketelhut, D. J., \& Nelson, B. (2006). A design-based research strategy to promote scalability for educational innovations. Educational Technology, 46(3), 27-36.

Cole, H., \& Griffiths, M.D. (2007). Social interactions in massively multiplayer online role-playing gamers. CyberPsychology \& Behavior, 10(4), 575-583.

Council of Chief State School Officers. (1992). Recommendations for improving the assessment and monitoring of students with limited English proficiency (Report). Washington, DC: Author.

Crookall, D. (Ed.). (2002). Editorial: Simulation in language learning. Simulation \& Gaming, 33, 273-274.

Crookall, D., \& Oxford, R. L. (1990) Linking language learning and simulation/gaming. In D. Crookall \& R. L. Oxford (Eds.), Simulation, gaming, and language learning (pp. 3-24). New York: Newbury House.

Crystal, D. (2003). English as a global language. Cambridge, England: Cambridge University Press. 
Cunningham, D. (1998). 25 years of technology in language teaching: A personal experience. Babel: Journal of the Australian Federation of Modern Language Teachers' Associations, 33(1), 4-7, 35.

Dalgarno, B. (2002). The potential of 3D virtual learning environments: A constructivist analysis. Electronic Journal of Instructional Science and Technology, 5(2), 1-19. Retrieved from http://www.ascilite.org.au/ajet/e-jist/docs/Vol5_No2/DalgarnoFinal.pdf

Davis, B., \& Thiede, R. (2000). Writing into changes: Style shifting in asynchronous discourse. In M. Warschauer \& R. Kern, R. (Eds.), Network-based language teaching: Concepts and practice. New York, NY: Cambridge University Press.

Davis, L. L. (1992). Instrument review: Getting the most from a panel of experts. Applied Nursing Research, 5, 194-197.

Dede, C. (1995). The evolution of constructivist learning environments: Immersion in distributed, virtual worlds. Educational Technology, 35(5), 46-52.

Dickey, M. D. (2005). Three-dimensional virtual worlds and distance learning: Two case studies of active worlds as a medium for distance education. British Journal of Educational Technology, 36(3), 439-451.

Dominguez-Noriega, S., Agudo, J. E., Ferreira, P., \& Rico, M. (2011). Language learning resources and developments in the Second Life metaverse. International Journal of Technology Enhanced Learning, 3(5), 496-509.

Dulay, H., \& Burt, M. (1977). Viewpoints on English as a second language. New York, NY: Regents.

Ehsani, F., \& Knodt, E. (1998). Speech technology in computer-aided language learning: Strengths and limitations of a new CALL paradigm. Language, Learning \& Technology, 2(1) 45-60.

Ellis, R. (2003). Task-based language learning and teaching. Oxford, England: Oxford University Press.

Fellner, T., \& Apple, M. (2006). Developing writing fluency and lexical complexity with blogs. The JALT CALL Journal, 2(1), 15-26.

Florez, M. C. (1999). Improving adult English language learners' speaking skills. Washington, DC: Clearinghouse for ESL Literacy Education. (ERIC Document Reproduction Service No. EDO-LE-99-01) 
Furstenberg, G. (1997). Teaching with technology: What is at stake? ADFL Bulletin, 28(3), 21-5.

Garcia-Ruiz, M. A., Edwards, A., \& Aquino-Santos, R. (2007). An online collaborative virtual reality environment for promoting listening comprehension. Retrieved from http://fel.uqroo.mx/adminfile/files/memorias/Articulos_Mem_FONAEL _III/Garcia_Ruiz_Miguel_Angel_et_al.pdf

Gardner, R. C., \& MacIntyre, P. D. (1993). A student's contribution to second language acquisition. Part II: Affective variables. Language Teaching, 26(1), 1-11.

Garfunkel, A. (1972). Teaching languages via radio: A review of resources. The Modern Language Journal. 56, 158-162.

Garrett, N. (2009). Computer-assisted language learning trends and issues revisited: Integrating innovation. The Modern Language Journal, 93, 719-740.

Genesee, F., Lindholm-Leary, K., Saunders, W., \& Christian, D. (2006). Educating English language learners: A synthesis of research evidence. New York, NY: Cambridge University Press.

Goldschmidt, D., MacDonald, I., \& O'Rourke, J. (2011). An interdisciplinary approach to injecting computer science into the K-12 classroom. Journal of Computing, 26(6), 78-85.

Guth, S., \& Petrucco, C. (2009). Social software and language acquisition. In R. de Cássia Veiga Marriott \& P. Lupion Torres (Eds.), Handbook of research on elearning methodologies for language acquisition (pp. 424-442). Hershey, NY: Information Science Reference.

Halic, O., Greenberg, K., \& Paulus, T. (2009). Language and academic identity: A study of the experiences of non-native English speaking international students. International Education, 38(2), 73-93.

Hellermann, J. (2007). The development of practices for action in classroom dyadic interaction. The Modern Language Journal, 93(1), 83-96.

Henderson, M., Huang, H., Grant, S., \& Henderson, L. (2009). Language acquisition in second life: Improving self-efficacy beliefs. Proceedings of the 26th Annual ASCILITE International Conference, 2009. Auckland, New Zealand: ASCILITE.

Hertel, J. P. \& Millis, B. J. (2002). Using simulations to promote learning in higher education. New York, NY: Stylus. 
Higgins, J., \& Johns, T. (1984). Computers in language learning. London, England: Addison Wesley.

Hinkle, D. E., Wiersma, W., \& Jurs, S. G. (2003) Applied statistics for the behavioral sciences. Boston, MA: Houghton Mifflin.

Horwitz, E. K. (1986). Preliminary evidence for the reliability and validity of a foreign language anxiety scale. TESOL Quarterly, 20(3) 559-562.

Horwitz, E. K. (2001). Language anxiety and achievement. Annual Review of Applied Linguistics, 21, 112-126.

Horwitz, E. K., Horwitz, M. B., \& Cope, J. A. (1986). Foreign language classroom anxiety. Modern Language Journal, 70(2), 125-132.

Hsu, H. Y., Wang, S. K., \& Comac, L. (2008). Using audioblogs to assist English language learning: An investigation into student perception. Computer Assisted Language Learning , 21, 181-198.

Huffaker, D. (2005). The educated blogger: Using weblogs to promote literacy in the classroom. AACE Journal, 13(2), 91-98.

Hughes, A. (2003). Testing for language teachers. Cambridge, England: Cambridge University Press.

Institute of International Education. (2009). Open doors data; Intensive English programs. Retrieved from http://www.iie.org/en/Research-andPublications/Open-Doors/Data/Intensive-English-Programs

Izadpanah, S. (2010). A study on task-based language teaching: From theory to practice. US-China Foreign Language, 8(3), 47-56.

Izard, C. (1972). Anxiety: Variable combination of interacting fundamental emotions. In C. D. Spielberger (Ed.), Anxiety: Current trends in theory and research (pp. 51106). New York, NY: Academic Press.

Jacobson, I. (1993). Welcome to the virtual world. In R. Swadley (Ed.), On the cutting edge of technology (pp. 69-79). Carmel, IN: Sams.

Jamaludin, A., Chee, Y. S., \& Ho, C. M. L. (2009). Fostering argumentative knowledge construction through enactive role-play in Second Life. Computers and Education, 53(2), 317-329. 
Jamison, J. B. (2008). Educators in a strange land: The experience of traditional educators when immersed into the virtual environment of second life (Doctoral dissertation). Retrieved from ProQuest. (AAT3307549)

Jang, S. (2011). Corrective feedback and language anxiety in L2 processing and achievement. English Teaching, 66(2), 73-99.

Jarmon, L., Traphagan, T., Mayrath, M., \& Trivedi, A. (2009). Virtual world teaching, experiential learning, and assessment: An interdisciplinary communication course in Second Life. Computers \& Education, 53(1), 169-182.

Jia, J., \& Chen, W. (2009) The further development of CSIEC project driven by application and evaluation in English education. British Journal of Educational Technology, 40(5), 901-918.

Jiang, Y. (2010). A feasibility study applying "double-output hypothesis" into task-based teaching approach in second language acquisition. Journal of Language Teaching \& Research, 1(4), 397-400.

Jones, C. (1986). It's not so much the program, more what you do with it: The importance of methodology in CALL. System 14(2), 171-178.

Kafai, Y. B. (2006). Playing and making games for learning: Instructionist and constructionist perspectives for game studies. Games and Culture, 1(1), 36-40.

Kalyuga, S. (2007). Enhancing instructional efficiency of interactive e-learning environments: A cognitive load perspective. Educational Psychology Review, 19(3), 387-399.

Kelm, O. (1998). The use of electronic mail in foreign language classes. In J. Swaffar, S. Romano, P. Markley, \& K. Arens (Eds.), Language learning online: Theory and practice in the ESL and L2 computer classroom (pp. 141-153). Austin, TX: Labyrinth.

Kelton, A. J. (2007). Second Life: Reaching in the virtual world of real-world learning (Research Bulletin, Issue 17). EDUCAUSE Center for Applied Research. Retrieved from https://net.educause.edu/ir/library/pdf/ERB0717.pdf

Ketelhut, D. J., Nelson, B., Clarke, J., \& Dede, C. (2010). A multi-user virtual environment for building and assessing higher order inquiry skills in science. British Journal of Educational Technology, 41(1), 56-68.

Kim, S. Y. (2009). Questioning the stability of foreign language classroom anxiety and motivation across different classroom contexts. Foreign Language Annals, 42(1), $138-157$. 
Kovacic, A., Bubas, G., \& Zlatovic, M. (2007). Evaluation of activities with a wiki system in teaching English as a second language. Retrieved from http://www.leonardo-lets.net/ict/common/download/AndrejaKovacic.pdf

Krashen, S. D. (1985). The input hypothesis: Issues and implications. New York, NY: Longman.

Lam, W. S. E. (2000). L2 literacy and the design of the self: A case study of a teenager writing on the internet. TESOL Quarterly, 34(3), 457-481.

Lantolf, J., (2000). Second language learning as a mediated process. Language Teaching, $33(2), 79-96$.

Ladousse, G. P. (1987). Role-play. Oxford, England: Oxford University Press.

Lasagabaster, D., \& Sierra, J. (2003). Students' evaluation of CALL software programs. Educational Media International, 40(3), 293-304.

Leaver, B., \& Kaplan, M. (2004). Task-based instruction in U.S. government Slavic language programs. In B. L. Leaver \& J. R. Willis (Eds.), Task-based instruction in foreign language education (pp. 47-66). Washington, DC: Georgetown University Press.

Liou, H. C. (2012). The roles of Second Life in a college computer-assisted language learning (CALL) course in Taiwan, ROC. Computer Assisted Language Learning, 25(4), 365-382.

Loban, W. (1976). Language development: Kindergarten through grade twelve (Research Report No. 18). Urbana, IL: National Council of Teachers of English.

Long, M. H. (1981). Input, interaction, and second-language acquisition. Annals of the New York Academy of Sciences: Native Language and Foreign Language Acquisition, 379, 259-278.

Long, M. H. (1985). Input and second language acquisition theory. In S. M. Gass \& C. G. Madden (Eds.), Input in second language acquisition (pp. 377-393). Rowley, MA: Newbury House.

Long, M. H. (1996). The role of the linguistic environment in second language acquisition. In W. Ritchie \& T. Bhatia (Eds.), Handbook of second language acquisition (pp. 413-468). San Diego, CA: Academic Press.

Lynn, M. R. (1986). Determination and quantification of content validity. Nursing Research, 35, 382-385. 
MacIntyre, P. D. (2007). Willingness to communicate in the second language: Understanding the decision to speak as a volitional process. The Modern Language Journal, 91(4), 564-576.

MacIntyre, P. D., \& Gardner, R. C. (1991). Methods and results in the study of anxiety and language learning: A review of the literature. Language Learning, 41(1) 85117.

Mak, B., \& Coniam, D. (2008). Using wikis to enhance and develop writing skills among secondary school students in Hong Kong. System, 36(3), 437-455.

Maley, A. (Ed.). (1987). Role play. New York, NY: Oxford University.

Marinova-Todd, S. H., Marshall, B., \& Snow, C. E. (2000). Three misconceptions about age and L2 learning. TESOL Quarterly, 34(1), 9-34.

Marriott, R. D. C., \& Torres, P. L. (2008). Handbook on research on e-learning methodologies for language acquisition. New York, NY: Idea Group.

McLellan, H. (2004). Virtual realities. In D. H. Jonassen (Ed.), Handbook of research on educational communications and technology (2nd ed., pp. 461-497). Hillsdale, NJ: Lawrence Erlbaum.

McQuail, D. (2005). McQuail's mass communication theory (5th ed.). London, England: Sage.

Mejias, U. (2006). Teaching social software with social software. Innovate, Journal of Online Education 2(5). Retrieved from http://www.innovateonline.info/pdf/vol2 _issue5/Teaching_Social_Software_with_Social_Software.pdf

Meng, Y., \& Cheng, B. (2010). College students' perceptions on the issue of task-based language teaching in Mainland China. Journal of Language Teaching and Research, 1(4), 434-442.

Merchant, G. (2001). Teenagers in cyberspace: An investigation of language use and language change in Internet chatrooms. Journal of Research in Reading, 24(3), 293-306.

Mikropoulos, T. A., Katsikis, A., Nikolou, E., \& Tsakalis, P. (2003). Virtual environments in biology teaching. Journal of Biological Education, 37(4), 176181. 
Miller, M., \& Hegelheimer, V. (2006). The SIMs meet ESL: Incorporating authentic computer simulation games into the language classroom. Interactive Technology \& Smart Education, 3(4), 311-328.

Molenda, M., \& Pershing, J. A. (2008). Improving performance. In A. Januszewski \& M. Molenda (Eds.), Educational technology: A definition with commentary (pp. 4980). New York, NY: Lawrence Erlbaum Associates.

Munoz, C. (2006). Age and the rate of foreign language learning. Clevedon, England: Multilingual Matters.

National Capital Language Resource Center. (2004). Teaching speaking. Retrieved from http://www.nclrc.org/essentials/speaking/spindex.htm

National Education Association. (2010). Meeting the needs of English language students. Retrieved from http://www.nea.org/home/29914.htm

Newman, I., Newman, C., Brown, R., \& McNeely, S. (2006). Conceptual statistics for beginners (3rd ed.). Lanham, MD: University Press of America.

Noels, K., Pelletier, L., Clement, R., \& Vallerand, R. (2003). Why are you learning a second language? Motivational orientation and self-determination theory. Language Learning, 1(52), 33-63.

Nunan, D. (1999). Second language teaching \& learning. Boston, MA: Heinle \& Heinle.

Oxford, R. (2006). Task-based language teaching and learning: An overview. The Asian EFL Journal Quarterly, 8(3), Article 5.

Panferov, S. (2010). Increasing ELL parental involvement in our schools: Learning from parents. Theory into Practice, 49(2). 106-112.

Peterson, M. (2006). Learner interaction management in an avatar and chat-based virtual world. Computer Assisted Language Learning 19(1), 79-103.

Petrakou, A. (2010). Interacting through avatars: Virtual worlds as a context for online education. Computers \& Education, 54(4), 1020-1027.

Phillips, E. (1992). The effects of language anxiety on student test oral performance and attitudes. The Modern Language Journal, 76(1), 14-26.

Pichette, F. (2009). Second language anxiety and distance language learning. Foreign Language Annals, 42(1), 77-93.

Plews, J. L., \& Zhao, K. (2010). Tinkering with tasks knows no bounds: ESL teachers' adaptations of task-based language-teaching. TESL Canada Journal, 28(1), 41-59. 
Plonczak, I. (2010). Videoconferencing in math and science preservice elementary teachers' field placements. Journal of Science Teacher Education, 14(2), 241254.

Prensky, M. (2006). Don't bother me mom, I'm learning. St. Paul, MN: Paragon House.

Pullen, M. J., \& Nah, M. H. (Eds.). (1999). A multi-user virtual environment with extensible user-friendly web-based interfaces. Proceedings from Western Simulation Multiconference '99. New York, NY: Association for Computing Machinery.

Ranalli, J. (2008). Learning English with the SIMS: Exploiting authentic computer simulation. Computer Assisted Language Learning, 21(5), 441-445.

Rankin, Y., Gold, R., \& Gooch, B. (2006). 3D role-playing games as language learning tools. Conference Proceedings of EuroGraphics 2006 Educator's Program, Vol. 25. New York, NY: Association for Computing Machinery.

Rizzo, A., Parson, T., Lange, B., Kenny, P., Buckwalter, J., Rothbaum, B., Difede, J., Frazier, J., Newman, B., Williams, J., \& Reger, G. (2011). Virtual reality goes to war: A brief review of the future of military behavioral healthcare. Journal of Clinical Psychology in Medical Settings, 18(2), 176-187.

Roed, J. (2003). Language learner behavior in a virtual environment. Computer Assisted Language Learning, 16, 155-172.

Rymaszewski, M., Au, W. J., Wallace, M., Winters, C., Ondrejka, C., \& Cunningham, B. B. (2007). Second Life: The official guide. Indianapolis, IN: Wiley.

Satar, H. M., \& Ozdener, N. (2008). The effects of synchronous CMC on speaking proficiency and anxiety: Text versus voice chat. The Modern Language Journal, 92(4) 595-613.

Schlager, M. S., Fusco, J., \& Schank, P. (2002). Evolution of an online education community of practice In K. A. Renninger \& W. Shumar (Eds.), Building virtual communities: Learning and change in cyberspace (pp. 129-158). Cambridge, England: Cambridge University Press.

Schwienhorst, K. (2002). Native-speaker/non-native-speaker discourse in the MOO: Topic negotiation and initiation in a synchronous text-based environment. Computer Assisted Language Learning, 17(1), 35-50.

Sha, G. (2009). AI-based chatterbots and spoken English teaching: A critical analysis. Computer Assisted Language Learning, 22(3), 269-281. 
Spada, N. (2007). Communicative language teaching: Current status and future prospects. In J. Cummins \& C. Davison (Eds.), International handbook of English language teaching (pp. 271-288). New York, NY: Springer.

Spiro, R. J., Feltovich, P. J., Jacobson, M. J., \& Coulson, R. L. (1991). Cognitive flexibility, constructivism and hypertext: Random access instruction for advanced knowledge acquisition in ill-structured domains. Educational Technology, 31(5), 24-33.

Stocker, C. (1921). French speech-tunes and the phonograph. The Modern Language Journal, 5, 267-270.

Sykes, J. M., Oskoz, A., \& Thorne, S. L. (2008). Web 2.0, synthetic immersive environments, and mobile resources for language education. Calico Journal, 25(3), 528-546.

Tabachnick, B. L, \& Fidell, L. S. (2007). Using multivariate statistics (5th ed.). Boston, MA: Pearson Education.

Thomas, M., \& Reinders, H. (Eds.) (2010). Taskbased language learning and teaching with technology. New York: Continuum.

Thorne, S. L., Black, R. W. \& Sykes, J. M. (2009). Second language use, socialization, and learning in internet interest communities and online gaming. The Modern Language Journal, 93(S1), 802-821.

Tuzun, H., Soylu, Y., Turkan, K., Yavuz, I., \& Gonca, K. (2009). The effects of computer games on primary school students' achievement and motivation in geography learning. Computers and Education, 52, 68-77.

U.S. Census Bureau. (2007). Languages spoken at home: 1980, 1990, 2000 and 2007. Retrieved from http://www.census.gov/hhes/socdemo/language/data/acs/appendix.html

U.S. Census Bureau. (2009). American community survey data. Retrieved from http://www.census.gov/newsroom/releases/archives/american_community_survey _acs/cb10-cn78.html

U.S. Department of Education, Office of Vocational and Adult Education. (2006). Adult Education and Family Literacy Act: Program year 2003-2004 (Report to Congress on State Performance). Retrieved from http://www2.ed.gov/about/reports/annual/ovae/2004aefla.pdf 
Van Duzer, C. (1997). Improving ESL learners' skills: At the workplace and beyond. Washington, DC: Project In Adult Immigrant Education and National Center For ESL Literacy Education.

Von Der Emde, S., Schneider, J., \& Kotter, M. (2001). Technically speaking: Transforming language learning through virtual learning environments (MOOs). Modern Language Journal, 85(2), 210-225.

Vygotsky, L. S. (1978). Mind in society: The development of higher psychological processes. Cambridge, MA: Harvard University Press.

Warschauer, M. (1997). Computer-mediated collaborative learning: Theory and practice. The Modern Language Journal, 81(4), 470-481.

Williams, M., \& Burden, R. L. (1997). Psychology for language teachers: A social constructivist approach. Cambridge, England: Cambridge University Press.

Willis, J. (1996). A framework for task-based learning. Harlow, England: Longman.

Winn, W. D. (1993). A conceptual basis for educational applications of virtual reality (Technical Report No. TR-93-9). Seattle, WA: Human Interface Technology Laboratory, University of Washington.

Woodrow, L. (2006). Anxiety and speaking English as a second language. RELC, 37(3), 308-328.

Wrigley, H. S., Richer, E., Martinson, K., Kubo, H., \& Strawn, J. (2003). The language of opportunity: Expanding employment prospects for adults with limited English skills (Workforce Development Series, Brief 2). Washington, DC: Center for Law and Social Policy.

Wrigley, H. S., Chen, J., White, S., \& Soroui, J. (2009). Assessing the literacy skills of adult immigrants and adult English language learners. New Directions for Adult and Continuing Education, 121, 5-24. doi:10.1002-ace.321

Yang, Y. (2005). Teaching adult ESL learners. Internet TESL Journal, 11(3). Retrieved from http://itesl.org/Techniques/Yang-AdultLearners.html

Yi, Y. (2008). Relay writing in an adolescent online community. Journal of Adolescent \& Adult Literacy, 51(8), 670-680.

Young, D. J. (1991). Creating a low-anxiety classroom environment: What does language anxiety research suggest? The Modern Language Journal, 75(4), 426-439. 
Zhang, C., \& Zigurs, I. (2008). Learning in virtual worlds: Understanding its impact on social and cognitive processes in learning (Paper 6). MWAIS 2008 Proceedings.

Retrieved from aisel.aisnet.org/cgi/viewcontent.cgi?article=1003\&content $=$ mwais 2008

Zheng, D., Young, M. F., Brewer, R. A., \& Wagner, M. (2009). Attitude and self-efficacy change: English language learning in virtual worlds. CALICO Journal, 27(1), 205-231. 
APPENDICES

APPENDIX A

PARTICIPANT CONSENT FORM 


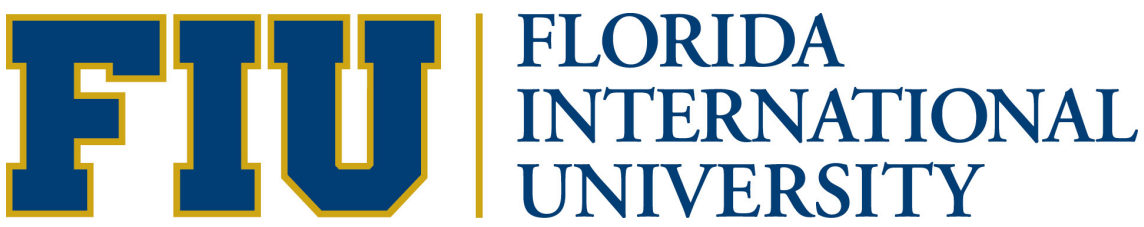

CONSENT TO PARTICIPATE IN A RESEARCH STUDY

Title: THE EFFECTS OF MULTI-USER VIRTUAL ENVIRONMENTS ON THE PERCEIVED SPEAKING ANXIETY OF ADULT POST-SECONDARY ENGLISH LANGUAGE LEARNERS

My name is Abdulaziz Abal and I am a student at Florida International University (FIU). You and some of your classmates are being asked to participate in a research study. This research study will focus on interaction through speaking English in two different environments. Being part of this study will give you a chance to practice speaking English with others.

To become a participant in this study you are required to sign this paper. If you do take part, you will meet with me twice every week for the whole communication class period (90 minutes). We will meet in the Education building at FIU next to the ELI.

1. You will carry out simulation activities with other ELI language learners (20 minutes)

2. You might be asked to work in front of a computer for no more than an hour.

3. Your voice will be recorded for 3 of the sessions for analysis.

4. You will be asked to fill in a questionnaire after each interaction.

There are no fees for being part of this study. Being part of this study will not hurt you in any way, if you feel tired you may ask for a break. Taking part in this study will not help or hurt your grade; you may ask to stop taking part in this study at any time. Your name and identification will not be revealed in any part of this study, letters and numbers will be used instead. Your personal information will be kept confidential and will not be shared with anyone else.

If you have any questions or concerns, you may contact me at anytime at (786) 925-6700. You may also contact my committee chair at FIU, Dr. Patricia Barbetta at (305) 348-2552. If you feel that you are not treated fairly in this study, you may contact the FIU office of Research Integrity by phone at (305) 348-2494 or by email at ori@fiu.edu.

If you would like to be part of this study, sign below. You will get a copy of this form.

$\overline{\text { Sign Here }}$

Investigator: Abdulaziz Abal

\section{Date}

\section{Date}


APPENDIX B

ENGLISH LANGUAGE LEARNER SPEAKING ANXIETY SCALE 


\section{ENGLISH LEARNER'S SPEAKING ANXIETY SCALE}

Please choose the best answer that represents how you feel during the activity.

1. In general while speaking during the activity I felt ...

No anxiety

High anxiety

2. When I made a mistake while speaking I felt ...

No anxiety High anxiety

3. When the lab assistant was giving me instructions I felt ...

No anxiety High anxiety

4. When my partner didn't understand me I felt ...

No anxiety High anxiety

5. When I didn't understand my partner I felt ...

No anxiety. High anxiety

6. When I started the conversation with my partner I felt ... No anxiety High anxiety

7. When my partner asked me a question I felt ... No anxiety. High anxiety

8. When I asked my partner a question I felt ...

No anxiety. High anxiety 
APPENDIX C

PARTICIPANT DEMOGRAPHIC FORM 
NAME:

AGE:

SEX: $\square$ MALE $\square$ FEMALE

NUMBER OF YEARS STUDYING ENGLISH:

FIRST LANGUAGE:

LANGUAGE SPOKEN AT HOME:

DO YOU PLAY ONLINE GAMES: $\square$ NO $\square$ YES

IF YES, NAME OF GAME:

ARE YOU AN ACTIVE MEMBER OF SECOND LIFE? $\square$ NO $\square$ YES

WERE YOU BORN IN THE USA? $\square$ NO $\square$ YES

HOW LONG HAVE YOU BEEN IN THE USA? 
APPENDIX D

SIMULATION ACTIVITIES 
SIMULATION ACTIVITY \# 1

\begin{tabular}{|c|c|}
\hline Title & Guess the famous person \\
\hline Time & 10 minutes $(\max )$ \\
\hline Aim & $\begin{array}{l}\text { To familiarize students with the idea of simulation in an activity } \\
\text { in which there is a strong game element. }\end{array}$ \\
\hline Language & Asking questions \\
\hline Procedure & $\begin{array}{l}\text { One participant (NES) will assume the role of a famous person } \\
\text { (pre-assigned). The other participant (ELL) may ask a series of } \\
\text { different questions that may only be answered with short } \\
\text { answers, sometimes the person will say a sentence or two. The } \\
\text { questions should be geared towards figuring out who the famous } \\
\text { person is. No guessing, you only get one shot at the end of the } \\
\text { activity. }\end{array}$ \\
\hline $\begin{array}{l}\text { Specific } \\
\text { Conditions }\end{array}$ & $\begin{array}{l}\text { Speak minimal sentences to fulfill the requirements on the NES } \\
\text { simulation fidelity checklist. }\end{array}$ \\
\hline NES role card & $\begin{array}{l}\text { You are Lady Gaga, but the other person doesn't know. He/she } \\
\text { will ask you many questions to find out who you are, you may } \\
\text { not lie and you may only answer with "yes, no, or maybe so", } \\
\text { you may only answer in sentences when appropriate, follow the } \\
\text { Specific Condition list for appropriate situations. }\end{array}$ \\
\hline ELL role card & $\begin{array}{l}\text { You are talking to a famous person and need to find out who } \\
\text { he/she is. You can ask any questions you want, the person can } \\
\text { only answer with "yes, no, or maybe so", if you are lucky, the } \\
\text { famous person will say a sentence or two. You can only guess } \\
\text { who the famous person is only once at the end of the activity. }\end{array}$ \\
\hline
\end{tabular}


SIMULATION ACTIVITY \#2

\begin{tabular}{|c|c|}
\hline Title & Complaining \\
\hline Time & 10 minutes $(\max )$ \\
\hline Aim & To develop students' responses in simple situations. \\
\hline Language & Complaining, listing facts, and expressing frustration. \\
\hline Procedure & $\begin{array}{l}\text { The student (ELL) is required to complain to the instructor } \\
\text { (NES) that he/she has been placed in a group where other } \\
\text { students are not doing their part. The student (ELL) is concerned } \\
\text { for his/her grade. The Instructor (NES) doesn't have enough } \\
\text { room for the student in other groups. }\end{array}$ \\
\hline $\begin{array}{l}\text { Specific } \\
\text { Conditions }\end{array}$ & $\begin{array}{l}\text { Refer to the requirements on the NES simulation requirement } \\
\text { checklist. }\end{array}$ \\
\hline NES role card & $\begin{array}{l}\text { You are an instructor in a university. You are listening to a } \\
\text { complaint from one of your students who is having difficulties } \\
\text { with some of his/her group members. You apologize, but explain } \\
\text { that there is no room in any other group for the moment. }\end{array}$ \\
\hline ELL role card & $\begin{array}{l}\text { You are a student working on a group project for your class and } \\
\text { some people in the group are not doing as much work as you. } \\
\text { You are meeting with your instructor to explain how you feel } \\
\text { about the other group members. The group members are not } \\
\text { doing their part of the project, they are not answering your } \\
\text { emails or phone calls, and they are coming late to class } \\
\text { meetings. You are worried about how it will affect your grade. }\end{array}$ \\
\hline
\end{tabular}


SIMULATION ACTIVITY \#3

\begin{tabular}{|c|c|}
\hline Title & Roommate \\
\hline Time & 10 minutes $(\max )$ \\
\hline Aim & $\begin{array}{l}\text { To encourage students to improvise freely in any situation. Ask } \\
\text { and answer questions. }\end{array}$ \\
\hline Language & Interview skills. \\
\hline Procedure & $\begin{array}{l}\text { The ELL is meeting a potential roommate to share his/her } \\
\text { apartment with. They have decided to meet (location X). The } \\
\text { ELL will ask the NES a series of questions to ensure that he/she } \\
\text { would be a good roommate. }\end{array}$ \\
\hline $\begin{array}{l}\text { Specific } \\
\text { Conditions }\end{array}$ & $\begin{array}{l}\text { Speak minimal sentences to fulfill the requirements on the NES } \\
\text { simulation fidelity checklist. }\end{array}$ \\
\hline NES role card & $\begin{array}{l}\text { You are meeting with someone who posted an ad looking for a } \\
\text { roommate. You have never had a roommate before but because } \\
\text { you're short on cash this semester you will have to share an } \\
\text { apartment. }\end{array}$ \\
\hline ELL role card & $\begin{array}{l}\text { You are looking for a person to become your roommate in an } \\
\text { apartment that you are renting, you asked your other roommate } \\
\text { to leave because she wasn't following the rules (she was } \\
\text { bringing many friends over, having parties, and causing you } \\
\text { distractions). You are meeting with someone who is looking for } \\
\text { a roommate too. Meet with him/her, have a conversation and ask } \\
\text { questions that would ensure that this time you make the right } \\
\text { choice in a roommate. }\end{array}$ \\
\hline
\end{tabular}


SIMULATION ACTIVITY \#4

\begin{tabular}{|c|c|}
\hline Title & The man from Mars \\
\hline Time & 10 minutes $(\max )$ \\
\hline Aim & $\begin{array}{l}\text { To encourage students to try deeper linguistic responses than the } \\
\text { ones they are usually content with. }\end{array}$ \\
\hline Language & $\begin{array}{l}\text { Functions: describing, explaining. } \\
\text { Vocabulary: various machinery. }\end{array}$ \\
\hline Procedure & $\begin{array}{l}\text { The person (ELL) is with someone (NES) who just arrived to the } \\
\text { planet Earth. He or she understands English, but knows } \\
\text { absolutely nothing about the technologies we have in } 2012 \text {. The } \\
\text { person (ELL) has to explain what a television. }\end{array}$ \\
\hline $\begin{array}{l}\text { Specific } \\
\text { Conditions }\end{array}$ & \\
\hline NES role card & $\begin{array}{l}\text { You are a person who just arrived to the planet Earth. The } \\
\text { person you just met is explaining to you what a television is. } \\
\text { You need to go back to your planet and explain what the gadget } \\
\text { is. }\end{array}$ \\
\hline ELL role card & $\begin{array}{l}\text { You are with someone who just arrived on planet Earth. He or } \\
\text { she understands your language, but knows absolutely nothing } \\
\text { about devices in } 2012 \text {. He or she asks you what a television is. } \\
\text { Try to explain what the device is. }\end{array}$ \\
\hline
\end{tabular}


SIMULATION ACTIVITY \#5

\begin{tabular}{|c|c|}
\hline Title & Job Interview \\
\hline Time & 10 minutes (max) \\
\hline Aim & $\begin{array}{l}\text { To familiarize and prepare students for the process of } \\
\text { overcoming challenges when applying for a job. }\end{array}$ \\
\hline Language & $\begin{array}{l}\text { Conversational English Language skills, dictation skills and } \\
\text { explore job hunting/interview vocabulary }\end{array}$ \\
\hline Procedure & $\begin{array}{l}\text { One participant (NES) will assume the role of an employer } \\
\text { seeking to hire employees for a position in a leading company. } \\
\text { The other participant (ELL) will assume the role of an applicant } \\
\text { searching for a job. The employer will meet the applicant and } \\
\text { ask him/her a series of job interview questions (see specific } \\
\text { conditions below). }\end{array}$ \\
\hline $\begin{array}{l}\text { Specific } \\
\text { Conditions }\end{array}$ & $\begin{array}{l}\text { The employer (NES) will ask the following questions to the } \\
\text { applicant during the interview: }\end{array}$ \\
\hline NES role card & $\begin{array}{l}\text { You are a recruiting executive and you will be interviewing a } \\
\text { potential employee. Carry out the interview by introducing } \\
\text { yourself and asking the applicant for his/her name. Then refer to } \\
\text { the questions below (specific conditions). }\end{array}$ \\
\hline ELL role card & $\begin{array}{l}\text { You are seeking a job in a leading company. You find out your } \\
\text { favorite company is looking for employees. You make an } \\
\text { appointment for a job interview. Answer the interview questions } \\
\text { at your best ability to get the job. }\end{array}$ \\
\hline
\end{tabular}


SIMULATION ACTIVITY \#6

\begin{tabular}{|c|c|}
\hline Title & My Country \\
\hline Time & 10 minutes (max) \\
\hline Aim & $\begin{array}{l}\text { Conveying information to an audience. Practicing public } \\
\text { speaking skills. }\end{array}$ \\
\hline Language & Listing facts. Varied. \\
\hline Procedure & $\begin{array}{l}\text { The ELL student is required to give a presentation to his/her } \\
\text { class about his country in } 10 \text { minutes ( } 7 \text { minutes presentation }+3 \\
\text { minutes Q\&A). The audience will be students from the class. }\end{array}$ \\
\hline $\begin{array}{l}\text { Specific } \\
\text { Conditions }\end{array}$ & $\begin{array}{l}\text { 1. In your country do people work hard? why? } \\
\text { 2. A) How small is the fluffy hair cuttery? } \\
\text { B) How far is your country from here? } \\
\text { 3. What is the traffic like in your country? } \\
\text { 4. When do you have the chance to practice English? } \\
\text { 5. A) Do you think that the coffee will eat my papi? } \\
\text { B) Do you think if I went there I would be happy? }\end{array}$ \\
\hline NES role card & $\begin{array}{l}\text { You have made a new friend, and they're explaining a little bit } \\
\text { about their country. Make sure you ask your new friend the } \\
\text { questions below (specific conditions). }\end{array}$ \\
\hline ELL role card & $\begin{array}{l}\text { You have made a new friend and you're explaining a little about } \\
\text { your country. Tell your friend things like where your country is, } \\
\text { what the weather is like, how people live over there, what you } \\
\text { normally do in a day. At the end allow some time for your friend } \\
\text { to ask you questions. }\end{array}$ \\
\hline
\end{tabular}


SIMULATION ACTIVITY \#7

\begin{tabular}{|c|c|}
\hline Title & Applying to a university \\
\hline Time & 10 minutes $(\max )$ \\
\hline Aim & $\begin{array}{l}\text { To prepare students for the process of overcoming challenges } \\
\text { when applying to a university. }\end{array}$ \\
\hline Language & Arguing a point, suggesting alternatives. \\
\hline Procedure & $\begin{array}{l}\text { The ELL is applying to a university that has the needed major. } \\
\text { Unfortunately the ELLs language proficiency does not meet that } \\
\text { of the required level for acceptance. The ELL sets up a meeting } \\
\text { with the admissions department, and tries to negotiate an } \\
\text { acceptance. }\end{array}$ \\
\hline $\begin{array}{l}\text { Specific } \\
\text { Conditions }\end{array}$ & $\begin{array}{l}\text { Speak minimal sentences to fulfill the requirements on the NES } \\
\text { simulation fidelity checklist. }\end{array}$ \\
\hline NES role card & $\begin{array}{l}\text { You are the head of the admissions office at the university. You } \\
\text { have an appointment with an international student who is } \\
\text { applying for undergraduate school. However, his/her TOEFL } \\
\text { score (480) is lower than the required (500) score. At first } \\
\text { decline his request but leave room for negotiation. }\end{array}$ \\
\hline ELL role card & $\begin{array}{l}\text { You are applying for undergraduate school, this is the only } \\
\text { university that has your desired major. Your English level is not } \\
\text { enough for you to get acceptance, but you know someone who is } \\
\text { the same level as you who got an acceptance from the university. } \\
\text { You have to get accepted into this university; otherwise your } \\
\text { scholarship from your country will get cancelled. }\end{array}$ \\
\hline
\end{tabular}


SIMULATION ACTIVITY \#8

\begin{tabular}{|c|c|}
\hline Title & Override? \\
\hline Time & 10 minutes (max) \\
\hline Aim & $\begin{array}{l}\text { To familiarize students with the idea negotiation. Building a } \\
\text { point and making exceptions. }\end{array}$ \\
\hline Language & Asking, suggesting, generating alternatives, appealing. \\
\hline Procedure & $\begin{array}{l}\text { The ELL wants to register a class that is desperately needed for } \\
\text { him/her to graduate on time next year, however the class is full. } \\
\text { In order to get an override the student will need to appeal to the } \\
\text { professor of that class. The appointment with the professor has } \\
\text { been set, it starts in half an hour. The student must get the } \\
\text { override. }\end{array}$ \\
\hline $\begin{array}{l}\text { Specific } \\
\text { Conditions }\end{array}$ & $\begin{array}{l}\text { Speak minimal sentences to fulfill the requirements on the NES } \\
\text { simulation fidelity checklist. }\end{array}$ \\
\hline NES role card & $\begin{array}{l}\text { You are a professor of a class that has reached full capacity. You } \\
\text { have an appointment with a student who would like to get an } \\
\text { override. However the department tries to avoid granting } \\
\text { overrides when possible due to past experiences with } \\
\text { administration. Only in extreme cases will they allow it. At first } \\
\text { decline the student's request but leave room for negotiation. At } \\
\text { the end tell the student that you will speak to the department and } \\
\text { try very hard to grant the override. }\end{array}$ \\
\hline ELL role card & $\begin{array}{l}\text { You need to register for the class that is full, if you want to } \\
\text { graduate on time next semester. Because the class is full, you } \\
\text { will need to ask the professor for an override, make you explain } \\
\text { to him/her the importance of you registering for this class. You } \\
\text { have to get registered! }\end{array}$ \\
\hline
\end{tabular}


SIMULATION ACTIVITY \# 9

\begin{tabular}{|c|c|}
\hline Title & Booking for a Vacation \\
\hline Time & 10 minutes $(\max )$ \\
\hline Aim & $\begin{array}{l}\text { To familiarize students with the idea of booking a complete } \\
\text { vacation from a travel agency. }\end{array}$ \\
\hline Language & Booking a complete vacation. \\
\hline Procedure & $\begin{array}{l}\text { One participant (NES) will assume the role of a travel agent. } \\
\text { The other participant (ELL) walks in to plan a vacation and } \\
\text { make a reservation. The questions should be geared towards } \\
\text { figuring out what the dream vacation is for the customer. }\end{array}$ \\
\hline $\begin{array}{l}\text { Specific } \\
\text { Conditions }\end{array}$ & $\begin{array}{l}\text { Speak minimal sentences to fulfill the requirements on the NES } \\
\text { simulation fidelity checklist. }\end{array}$ \\
\hline NES role card & $\begin{array}{l}\text { You are a travel agent working, and a potential customer walks } \\
\text { in and wants help in planning a vacation. Help the person by } \\
\text { asking them what they're interested in and what their ideal } \\
\text { vacation is. }\end{array}$ \\
\hline ELL role card & $\begin{array}{l}\text { You would like to plan a dream vacation and make the } \\
\text { reservation. So you walk into a travel agency, you heard that it's } \\
\text { the best travel agency around. Speak to the travel agent in the } \\
\text { travel agency and have him/her help you decide on a destination } \\
\text { and on making the reservation. }\end{array}$ \\
\hline
\end{tabular}


SIMULATION ACTIVITY \# 10

\begin{tabular}{|c|c|}
\hline Title & What's your Hobby/ Free time \\
\hline Time & 10 minutes $(\max )$ \\
\hline Aim & $\begin{array}{l}\text { To familiarize students with the idea of simulation in an activity } \\
\text { in which there is a strong game element. }\end{array}$ \\
\hline Language & Small talk/Speaking about your interests. \\
\hline Procedure & $\begin{array}{l}\text { One participant (NES) will assume the role of a person sitting in } \\
\text { a coffee shop. The other participant (ELL) is sitting next to the } \\
\text { (NES), and they start making small talk about the ELLs interests } \\
\text { or hobby. The (NES) may ask a series of different questions } \\
\text { asking for examples and elaborations. The (ELL) will explain, } \\
\text { give examples, and clarify his/her interest or hobby. }\end{array}$ \\
\hline $\begin{array}{c}\text { Specific } \\
\text { Conditions }\end{array}$ & $\begin{array}{l}\text { Speak minimal sentences to fulfill the requirements on the NES } \\
\text { simulation fidelity checklist. }\end{array}$ \\
\hline NES role card & $\begin{array}{l}\text { You are Sitting in a coffee shop next to a stranger, he or she says } \\
\text { hi and you start making small talk. You have a great interest and } \\
\text { thirst for learning, so you decide to ask him/her about their } \\
\text { interests or hobby. Learn as much as possible about that hobby. } \\
\text { Ask questions but most importantly allow the person to explain } \\
\text { and elaborate. }\end{array}$ \\
\hline ELL role card & $\begin{array}{l}\text { You are sitting in a coffee shop next to a stranger, he starts } \\
\text { talking to you and asking you about your hobbies or interests. } \\
\text { He/she is very friendly so you decide to talk to her about your } \\
\text { interests or hobbies. Make sure you explain, give examples, and } \\
\text { clarify your interests. }\end{array}$ \\
\hline
\end{tabular}


APPENDIX E

RESEARCHER TREATMENT FIDELITY FORM 


\section{PROCEDURES TREATMENT FIDELITY FORM}

Participant Identification Number:

Name of Observer Filling Out This Form:

Date of Session:

Time: (am-pm)

Group being observed: (Check One)

Virtual Environment

Real world (face-to-face)

Participants being observed: (Check One)

Participants (ELLs)

Native English Speakers (NES)

Date Of Completion Of This Form:

Time:

Simulation \#:

Simulation Topic:

Directions: Check off whether the researcher performs the following tasks.

\begin{tabular}{|c|c|c|c|}
\hline \multirow{2}{*}{ Description of Procedure } & \multicolumn{3}{|c|}{ Implemented } \\
\hline & $\mathrm{N} / \mathrm{A}$ & Yes & No \\
\hline $\begin{array}{l}\text { 1. The researcher read the simulation activity to the participants/NESs, and } \\
\text { provided instructions. }\end{array}$ & & & \\
\hline $\begin{array}{l}\text { 2. The researcher asked the participants/NESs if they understood or if they } \\
\text { had any questions about the activity. }\end{array}$ & & & \\
\hline $\begin{array}{l}\text { 3. The researcher was available to provide any necessary assistance to the } \\
\text { participants/NESs }\end{array}$ & & & \\
\hline $\begin{array}{l}\text { 4. Assistants were available to provide any necessary assistance to the } \\
\text { participants/NESs. }\end{array}$ & & & \\
\hline 5. $\quad$ Researcher administered the questionnaire. & & & \\
\hline 6. Researcher collected completed questionnaire. & & & \\
\hline $\begin{array}{l}\text { 7. Researcher reminded the participants about the next meeting date and } \\
\text { time. }\end{array}$ & & & \\
\hline
\end{tabular}

\section{Additional Comments:}




\section{APPENDIX F}

SIMULATION TREATMENT FIDELITY CHECKLIST 


\section{Simulation Treatment Fidelity Checklist}

Directions: The following requirements should occur in every role-playing activity. Please check the box whenever the requirement is met.

\begin{tabular}{|c|l|l|l|}
\hline $\mathbf{1}$ & The ELL starts the conversation always. & $\square$ & \\
\hline $\mathbf{2}$ & Pretend that you didn't understand the ELL ( twice) & $\square$ & $\square$ \\
\hline $\mathbf{3}$ & $\begin{array}{l}\text { Say an ambiguous or unclear sentence that requires the ELL } \\
\text { to ask for clarification ( } \text { twice) }\end{array}$ & $\square$ & $\square$ \\
\hline $\mathbf{4}$ & Correct a language mistake that the ELL Makes (twice) & $\square$ & $\square$ \\
\hline $\mathbf{5}$ & Ask the ELL 2 questions throughout the activity. & $\square$ & $\square$ \\
\hline $\mathbf{6}$ & ELL should ask the NES at least 2 questions. & $\square$ & $\square$ \\
\hline
\end{tabular}


APPENDIX G

SECOND LIFE ASSESSMENT CHECKLIST 


\section{SECOND LIFE ASSESSMENT CHECKLIST}

Directions: After a 60-minute tutorial session on using Second Life, the participants should be able to perform the following actions. Please check the action that the participant is able to perform.

\begin{tabular}{|c|l|c|}
\hline $\mathbf{1}$ & Able to navigate the avatar in any direction. & $\square$ \\
\hline $\mathbf{2}$ & Able to turn on/off chat function. & $\square$ \\
\hline $\mathbf{3}$ & Able to turn volume up/down. & $\square$ \\
\hline $\mathbf{4}$ & Able to sit down and stand up. & $\square$ \\
\hline
\end{tabular}


APPENDIX H

EXIT SURVEY 


\section{Exit survey questions - Virtual Environment Group}

\section{On a scale from 1-5 $(1=$ not at all $-5=$ Very much $)$ please choose the answer that shows how you feel.}

How much did participating in simulation conversations in Second Life,

1. Reduce your anxiety to start talking with a native English speaker at the ELI classroom?

$\begin{array}{ccccc}1 & 2 & 3 & 4 & 5 \\ \text { Not at all } & & & & \text { Very much }\end{array}$

2. Reduce your anxiety to start talking with a native English speaker in places other the ELI classroom?
1
2
3
4
5
Not at all
Very much

3. Reduce your anxiety when answering questions by native English Speakers at the ELI classroom?

$\begin{array}{ccccc}1 & 2 & 3 & 4 & 5 \\ \text { Not at all } & & & & \text { Very much }\end{array}$

4. Reduce your anxiety when answering questions by native English Speakers outside the ELI classroom?

$\begin{array}{ccccc}1 & 2 & 3 & 4 & 5 \\ \text { Not at all } & & & & \text { Very much }\end{array}$

5. What parts of the Second Life simulations helped you talk with native English speakers?

6. What parts of the Second Life simulations did not help you talk with native English speakers?

7. Is there anything else that you want to tell me about participating in Second Life simulations? 


\section{Exit survey questions - Face-to-Face Group}

\section{On a scale from 1-5 (1=not at all $-5=$ Very much) please choose the answer that best shows how you feel.}

How much did participating in face-to-face simulation conversations,

1. Reduce your anxiety to start talking with a native English speaker at the ELI classroom?

$\begin{array}{ccccc}1 & 2 & 3 & 4 & 5 \\ \text { Not at all } & & & & \text { Very much }\end{array}$

2. Reduce your anxiety to start talking with a native English speaker in places other the ELI classroom?
1
2
3
4
5
Not at all
Very much

3. Reduce your anxiety when answering questions by native English Speakers at the ELI classroom?
1
2
3
4
5
Not at all
Very much

4. Reduce your anxiety when answering questions by native English Speakers outside the ELI classroom?

$\begin{array}{ccccc}1 & 2 & 3 & 4 & 5 \\ \text { Not at all } & & & & \text { Very much }\end{array}$

5. What parts of the face-to-face simulations helped you talk with native English speakers?

6. What parts of the face-to-face simulations did not help you talk with native English speakers?

7. Is there anything else that you want to tell me about participating in Face-to-Face simulations?

(Open-ended answer) 
VITA

ABDULAZIZ ABAL

1994-1998

B.A., English Language and Literature

Kuwait University

Shuwiakh, Kuwait

2002-2003

M.A., Linguistics and TESOL

University of Surrey

Guildford, United Kingdom

2004-2005

Intensive English Instructor

American University of Kuwait

Salmiya, Kuwait

2007-2012

Teaching Assistant

Florida International University

Miami, Florida

2009-2012

Doctoral Candidate

Florida International University

Miami, Florida

$2010-2012$

Graduate Students Representative

University Technology Fee Committee

Florida International university

PRESENTATIONS

2006

Miami-Dade TESOL and Bilingual Association

Symposium

Miami, Florida

2010

College of Education and Graduate Student Network

Research Conference, 9th Annual

Florida International University

Miami, Florida

2010

Southeast Regional TESOL Conference

Miami, Florida 